\title{
Combustion of ultrafine coal/water mixtures and their application in gas turbines: Final report
}

Toqan, M.A.; Srinivasachar, S.; Staudt, J.; Varela, F.; Beer, J.M.

Oct 1987

Massachusetts Inst. of Tech., Cambridge (USA)

Reproduced and Distributed by:

U.S. DEPARTMENT OF ENERGY

Office of Scientific and Technical Information P.O. Box 62

Oak Ridge, TN 37831 


\section{DISCLAIMER}

This report was prepared as an account of work sponsored by an agency of the United States Government. Neither the United States Government nor any agency Thereof, nor any of their employees, makes any warranty, express or implied, or assumes any legal liability or responsibility for the accuracy, completeness, or usefulness of any information, apparatus, product, or process disclosed, or represents that its use would not infringe privately owned rights. Reference herein to any specific commercial product, process, or service by trade name, trademark, manufacturer, or otherwise does not necessarily constitute or imply its endorsement, recommendation, or favoring by the United States Government or any agency thereof. The views and opinions of authors expressed herein do not necessarily state or reflect those of the United States Government or any agency thereof. 


\section{DISCLAIMER}

Portions of this document may be illegible in electronic image products. Images are produced from the best available original document. 


\section{DISCLAIMER}

This report was prepared as an account of work sponsored by an agency of the United States Government. Neither the United States Government nor any agency thereof, nor any of their employees, makes any warranty, express or implied, or assumes any legal liability or responsibility for the accuracy, completeness, or usefulness of any information, apparatus, product, or process disclosed, or represents that its use would not infringe privately owned rights. Reference herein to any specific commercial product, process, or service by trade name, trademark, manufacturer, or otherwise does not necessarily constitute or imply its endorsement, recommendation, or favoring by the United States Government or any agency thereof. The views and opinions of authors expressed herein do not necessarily state or reflect those of the United States Government or any agency thereof.

This report has been reproduced directly from the best available copy.

Availabie from the National Technical Information Service, U. S. Department of Commerce, Springfield, Virginia 22161.

\section{Price: Printed Copy A08}

Microfiche A01

Codes are used for pricing all publications. The code is determined by the number of pages in the publication. Information pertaining to the pricing codes can be found in the current issues of the following publications, which are generally available in most libraries: Energy Research Abstracts (ERA); Government Reports Announcements and Index (GRA and I); Scientific and Technical Abstract Reports (STAR); and publication NTIS-PR-360 available from NTIS at the above address. 


\title{
Energy
}

\section{Combustion of Ultrafine Coal/Water Mixtures and Their Application in Gas Turbines}

\author{
Final Report
}

\author{
M.A. Toqan \\ S. Srinivasachar \\ J. Staudt \\ F. Varela \\ J.M. Beér
}

October 1987

Work Performed Under Contract No.: DE-AC21:84MC21287

For

U.S. Department of Energy

Office of Fossil Energy

Morgantown Energy Technology Center

Morgantown, West Virginia

By

Massachusetts Institute of Technology

Energy Laboratory and Department of Chemical Engineering Cambridge, . Massachusetts 


\title{
Combustion of Ultrafine Coal/Water Mixtures and Their Application in Gas Turbines
}

\author{
Final Report
}

\author{
M.A. Toqan
}

S. Srinivasachar

\author{
J. Staudt \\ F. Varela \\ J.M. Beér
}

Work Performed Under Contract No.: DE-AC21-84MC21287

\author{
For \\ U.S. Department of Energy \\ Offire. of Fossil Energy \\ Morgantown Energy Technology Center \\ P.O. Box 880 \\ Morgantown, West Virginia 26507-0880 \\ Ry \\ Massachusetts Institute of Technology \\ Energy Laboratory and Department of Chemical Engineering \\ Cambridge, Massachusetts 02139
}




\section{ACKNOWLEDGEMENTS}

This work has been carried out with the participation of staff at MIT Energy Laboratory. Staff personnel who have contributed include Don Bash, William Mason, and Mark James. Preparation of this report has been the responsibility of Ms. Bonnie Caputo.

The contribution of the project officer, Ms. Janna Thames to this program is gratefully acknowledged. 
Section 1

RESEARCH PROBLEM AND APPROACH

Introduction

$1-1$

Research Objectives

$1-4$

Research Plan

Section 2

EXPERIMENTAL CONDITIONS AND MEASUREMENTS

Section 3

EXPERIMENTAL APPARATUS AND PROCEDURE

Combustion Research Facility

Instrumentation and Measuring Equipment

Section 4

RESULTS OF COLD FLOW STUDY

4-1

Introduction

Experimental Input and Operating Conditions

4-1

Results

4-1

4-2

\section{Section 5}

FLAME STUDIES

Scoping Experiments

Results

$5-1$

Flame Structure

$5-1$

Section 6

REDUCTION OF ${ }^{N O} \mathrm{X}$

Introduction

$6-1$

Experimental

$6-3$

Results

$6-3$

Discussion

$6-3$ 


\section{Table of Contents (Continued)}

Section 7

Page

MECHANISM OF COAL WATER FUEL DROPLET-PARTICLE COMBUSTION

Theory of Coal Water Fuel Dropiet Combustion $7-1$

Solution Technique

$7-7$

Modeling Results and Discussion

$7-8$

Section 8

RADIATION STUDY

$8-1$

Introduction

$8-1$

Modeling of Furnace Performance

$8-2$

Gas Emissivity

$8 \div 3$

Comparison of Model Predictions and Experimental Results

$8-6$

Ultrafine and Fine grind CWF Flames

$8-6$

Natural Gae Flame

$8-6$

Sensitivity Analysis

$8-12$

Parameters Affecting Radiation Characteristics of

Coal Water Fuel Flow

Soot Concentration

$8-15$

Soot Absorption Coefficient

$8-19$

Fuel Thermal Input

$8-17$

Excess Air

$8-19$

Surface Emissivity

Temperature of Water Cooled Surfaces

$8-19$

F1 ame Spread Angle

$8-26$

$8 \cdot 26$

Partial Pressure of Carbon Dioxide Net Water Vapor

$8-28$

Degree of Fuel Oxidation

$8-28$

Section 9

HEAT EXCHANGE IN GAS TURBINE COMBUSTORS $\quad 9-1$

Introduction $\quad 9-1$

Pressure $9-2$

Combustion Dimensions $\quad 9-4$

Excess Air . $9-9$

Thermal Input $\quad 9-14$

Section 10

CONCLUSIONS

Effects of Burner Input Parameters on Fuel/air Rate of Mixing $10-1$

CWF Flames investigation

$10-2$

$\mathrm{NO}_{x}$ Emission

$10-3$

Radiative Heat Flux Distribution

$10-4$

REFERENCES 
Table of Contents (Continued)

Page

APPENDICES

Appendix A - Results of Cold Flow Study

Appendix B - Results of Flame Study

A-1

B-1 
2.1 Input Conditions for Run 1 in Cold Flow Study 2-3

2.2 Input Conditions for Run 2 in Cold Flow Study $2-4$

2.3 Input Conditions for Runs $318 \mathrm{~A}$ and $\mathrm{B} \quad 2-5$

2.4 Specifications of Coal Water Fuels 2-6

2.5 Input Conditions for the Staged CWF Flame Study 2-7

2.6 Coal Analysis for Runs 1,2 and $3 \quad 2-7$

8.1 Input Conditions for the Numerical Calculations $\quad 8-14$

8.2 Heat Extracted as a Function of Refractory Emissivity 8-25

9.1 Input Conditions of Gas Turbine Combustor Numerical Simulation 9-3 


\section{List of Figures}

Figure

Page

3.1 Furnace assembly and air staging system $3-2$

3.2 Schematic of suction pyrometer for temperature measurements 3-4

3.3 Gas sampling probe, with detail of probe tip 3-6

3.4 Schematic of gas sampling and analysis system $3-6$

3.5 Multidirectional impact tube (5-hole pitot) 3-8

3.6 Impaction tube velocity probe 3-10

3.7 Hollow ellipsoidal radiation probe, with detail of probe tip 3-11

3.8 Narrow angle total radiation pyrometer $3-13$

3.9 Water quench sampling probe $3-15$

3.10 Detail of the water quench sampling probe tip $3-15$

4.1 The effect of swirl number on CO concentration on the
jet axis

4.2. The effect of atomizing air flowrate upon axial 4-4 velocities on the jet axis in a cold flow experiment corresponding to the conditions of a $1 \mathrm{MW}$ flame.

4.3 The effect of atomizing air flowrate upon axial 4-5 velocities on the jet axis in a cold flow experiment corresponding to the conditions of a 0.7 MW flame condition

4.4. The effect of water injection upon axial velocities 4-6

on the jet axis in a cold flow experiment corresponding to the conditions of a $0.7 \mathrm{MW}$ flame

4.5 The effect of water injection upon the decay of co 4-8 on the jet axis in a cold flow experiment corresponding to the conditions of a $0.7 \mathrm{MW}$ flame.

5.1 Schematic of the combustion research facility burner assembly 5-2

5.2 Gas temperature profile on furnace axis in flames $318 \mathrm{~A} \& \mathrm{~B} \quad 5-3$ 


\section{List of Figures}

\section{Figure}

5.3 Axial velocity profile on furnace axis in flames $318 \mathrm{~A} \& \mathrm{~B}$

5.4 Concentration profile of solids on furnace axis in Flames $318 \mathrm{~A} \& \mathrm{~B}$

5.5 Concentration profile of $\mathrm{CO}$ on furnace axis in

5.6 Concentration profile of $\mathrm{O}_{2}$ on furnace axis in Flames 318A \& B.

5.7 Concentration profile of $\mathrm{CO}_{2}$ on furnace axis in Flames $318 \mathrm{~A} \& \mathrm{~B}$

5.8 Concentration profiles of $\mathrm{NO}_{x}$ on furnace axj.s in Flames $318 \mathrm{~A} \& \mathrm{~B}$

5.9 Schematic of the flow field of a highly swirling coal water slurry flame

5.10 Radial profiles of $\mathrm{O}_{2}$ at an axial distance of 0.35 meters from the burner in Flames 318A \& B.

5.11 Radial profiles of solids concentration at an axial distance of 0.35 meters from the burner in Flames $318 \mathrm{~A} \& \mathrm{~B}$

5.12 Carbon conversion efficiency of 75-90 $\mu \mathrm{m}$ particle sizip sut in Flameo $318 \mathrm{~A} \& \mathrm{~B}$

5.13 Sem photographs of char and ash particles collected at a distance of $3.62 \mathrm{~m}$ from the Nozzle in flames $318 a \& b$.

(a) Particles smallei than $38 \mu \mathrm{m}$ in flame $318 \mathrm{a}$.

(b) Particles smaller than $150 \mu \mathrm{m}$ in flame 318a.

(c) Particles smaller than $38 \mu \mathrm{m}$ in flame $318 \mathrm{~b}$.

5.14 Slze discribution of particles collected at a distance of $0.27 \mathrm{~m}$ frum the Nozzle in flanes $318 \mathrm{a} \& \mathrm{~b}$.

5.15 Mass fraction of different sized particles collected at a distance of $3.6 \mathrm{~m}$ from the Burner in flames $318 \mathrm{a} \& \mathrm{~b}$.

6.1 Mechanistic pathways of nitrogen oxides formation in 
6.2 Schematic of the staged combustion configuration

6.3 (a) The effect of water content of the CWF on $\mathrm{O}_{2}$

(b) The effect of water content of the CWF on gas

$6-5$ temperatures

6.4 (a) The effect of water content of the CWF on $\mathrm{NO}_{x}$

(b) The effect of water content of the CWF on volatile

fraction in in-flame particulate samples.

(c) Normalized nitrogen to combustibles ratio

6.5 (a) The effect of secondary air position on $\mathrm{NO}_{x}$ concentration

(b) The effect of secondary air position on volatile fraction of in-flame solids samples

(c) normalized nitrogen to combustibles ratio

6.6 Volume particle diameter as a function of axial distance in CWF flame samples

6.7 Particle size distribution at different axial distances from the burner in Run \#1

7.1 Schematic of the Combustion of a CWF droplet according to the two-zone model.

$\overline{7.2}$ Predicted behavior tor water eváporacion and volatile generation from a $53 \mu \mathrm{m}$ drop

7.3 Carbon burnout curves for Flame 318B

8.1 Zoning system of the MIT-CRF for use in the monte carlo zone method program

8.2 Radiative flux profiles in run 318 a (ultrafinegrind CWF)

8.3 Radiative flux profiles in run $318 \mathrm{~b}$ ( $\mathrm{fine}$ grind CWF)

8.4 Axial temperature profiles in run 318a (ultrafine grind CWF)

8.5 Axial temperature profiles in run $318 \mathrm{~b}$ (ultrafine grind CWF) 


\section{List of Figures}

Figure

Page

8.6 Comparison of predicted incident radiative flux

$8-11$ using the zone method with the measured radiative flux from a natural gas flame

8.7 Effect of soot concentration on heat extraction

8.8 Effect of soot absorption coefficient on heat

8.9 Effect of fuel thermal input on heat extraction

8.10 Effect of air flow rate on heat extraction

8.11 Effect of refractiory emissivity on heat extraction

8.12 Effect of culd surface emissivity on heat extraction

8.13 Effect of water cooled surface temperature on heat

9.1 The effect of the functional variation of soot concentration with pressure upon the incident ratiative heat flux in a gas turbine combustor

9.2 The effect of functional variation of soot with pressure upun gas temperalure in a gas turbine combuotor

9.3 Effect of pressure on radiative flux 9.7

9.4 Effect of pressure on gas temperature $9-8$

9.5 Effect of combustor dimensions on radiative flux 9-10

9.6 Effect of combustor dimensions on gae tcmperature $9-11$

9.7 Effect of excess air upon incident radiative flux $\quad 9-12$

9.8 Effect of excess air on gas temperature in $\rightarrow \quad 9-13$ gas turbine combustor 


\section{Executive Summary}

\section{Background}

The feasibility of using coal-water fuels (CWF) in gas turbine combustors has been demonstrated in recent pilot plant experiments. The demands of burning coal-water fuels with high flame stability, complete combustion, low $\mathrm{NO}_{\mathrm{x}}$ emission and a resulting fly ash particle size that will not erode turbine blades represent a significant challenge to combustion scientists and engineers. The satisfactory solution of these problems requires that the variation of the structure of CWF flames, i.e. the fields of flow, temperature and chemical species concentration in the flame, with operating conditions is known. Detailed in-flame measurements are difficult at elevated pressures and it has been proposed to carry out such experiments at atmospheric pressure and interpret the data by means of models for gas turbine combustor conditions.

Results are reported of an experimental-theoretical investigation in the $1.2 \times 1.2 \times 4.0 \mathrm{~m}$ flame tunnel of the MIT Combustion Research Facility focused on the detailed experimental characterization of CWF flames. The experiments were combined with mathematical modeling of the processes of pyrolysis and oxidation of CWF particles in the flame and the radiative heat flux distribution in the combustion chamber.

The research was carried out in five sequential tasks:

\section{Task 1. Cold Flow Studies}

The Combustion Research Facility (CRF) was used for determination of the velocity fields in the vicinity of the burner under varying swirl conditions and with varying mass flowrates of atomization air.

Carbon monoxide was injected as a tracer through the fuel gun and/or with the combustion air; gas sampling permitted the determination of the 
conditions appropriate for maximum convection of recirculated gas into the region which would normally contain the fuel spray.

Task 2. Studies of Conventional Fine-Grind CWF

The CRF was used for determination of:

- flow and temperature field by in-flame velocity and gas temperature measurements ;

- gaseous and solid species concentration distributions by flame sampling, and samples analyses;

- radiative heat flux distributinn alnng the flame by measirement. of the incident radiative flux at the wall.

The CRF was run under conditions selected on the basis of results from Task 1, and based on previous experience with CWF combustion. The fuel used was a conventional fine-grind CWF fuel supplied by ARC Inc., $958<44 \mu \mathrm{m}$, and the thermal input was $\sim 1.5 \mathrm{MW}$.

High speed movies of the flame front were obtained, to provide inoight 1neo the ignition mechanisms and to verify that the flame stability was adequate. Results of the above expeximents were compared with those obtained during an extensive ongoing experimental investigation of flames burning CWF fuels formulated from coal ground to two degrees of fineness; standard grind with $858<74 \mu \mathrm{m}$ and 'micronized' with $958<44 \mu \mathrm{m}$.

The testing under Task 2 was instrumented in choosing all experimental settings for Task 3, and provided a baseline for comparison with results of Task 3.

Task 3. Combustion Studies with U1trafine CWF Fuel

The optimal experimental conditions established under Task 2 were used to generate an ultrafine CWF flame. The results obtained were compared with those of the fine grind CWF flame (Task 2), and with the theoretical 
predictions generated under Task 5. The comparisons with Task 2 measurements included assessments of any differences in flame stability, carbon burnout, radiative behavior, and fly ash particle size distribution. Task 4. Reduction of NO $x$ Emission by Staged Combustion

Experiments in which the furnace chamber was divided into a fuel-rich stage (a fuel equivalence ratio $(\phi)$ of 1.3 ), followed by a stage maintained under lean conditions $(\phi-0.90)$ were carried out. This configuration was shown in another CWF testing program to result in low emissions of $\mathrm{NO}_{\mathrm{x}}$ (reduction from an unstaged value of $650 \mathrm{ppm}$ to a value less tan $200 \mathrm{ppm}$. in staged CWF flames). Residence time in the first rich stage relative to the second lean stage was varied.

The measurements which were made included gas temperatures, axial velocities, solids concentrations, carbon conversion, efficiency, gas composition, $\left(\mathrm{CO}, \mathrm{CO}_{2}, \mathrm{O}_{2}, \mathrm{NO}_{\mathrm{x}}, \mathrm{SO}_{2}\right)$, fly ash concentration and size distribution.

Task 5. Data Interpretation - Ignition and Radiation Aspects

A. Ignition. Modeling of a coal water fuel droplet combustion was used to aid in the interpretation of data obtained in Tasks 2 and 3 , and to provide predictions of flame front locations for comparison with experiment.

B. Radiation. An existing computer program, based on a Monte Carlo technique, was used for comparison of measured radiative heat transfer characteristics with predictions based on measured temperature/species concentration distributions. Calculations of radiative heat transfer in gas turbine combustors were also made utilizing both the experimental data obtained in the atmospheric pressure coal water fuel combustor and the computer zone model. 


\section{Results and Conclusions}

\section{Ignition and Flame Stability}

- Results of the combustion studies show that the combination of swirling burner air flow and a refractory-lined divergent quarl at the burner (Figure S.1) strengthens the toroidal vortex flow of hot combustion products in the central region of the flame with the consequent improvement of flame stability.

- Analysis of the data obtained in the cold flow experiments and the combustion tests indirate that for a solid cune CWF spray, the favorable position of the spray lies nn the inside of the high sheai flow region, close to the flame axis. Decelerating the CWF droplets near the burner within the internal recirculation zone, (Figure S.2) enhances the early ignition of the coal water fuel droplets and the improvement of flame stability.

\section{Carbon Burnout}

- The prime variable that determines carbon hurnout in the flame is the drop-cizc distribution of the CWF spray. Since the fine grind CWF spray was finer then the-ultra-fine CWF, carbon burnout in the first case was better.

- One method of achieving better atomization quality is the addition of small amounts of water to the coal water fuel. Diluting the fuel with water by -28 relaxes the requirements of high atomizing air/fuel ratio for sustaining very good carbon burnout. The addition of these small amounts of water would not constitute a significant penalty in terms of cycle efficiency. 

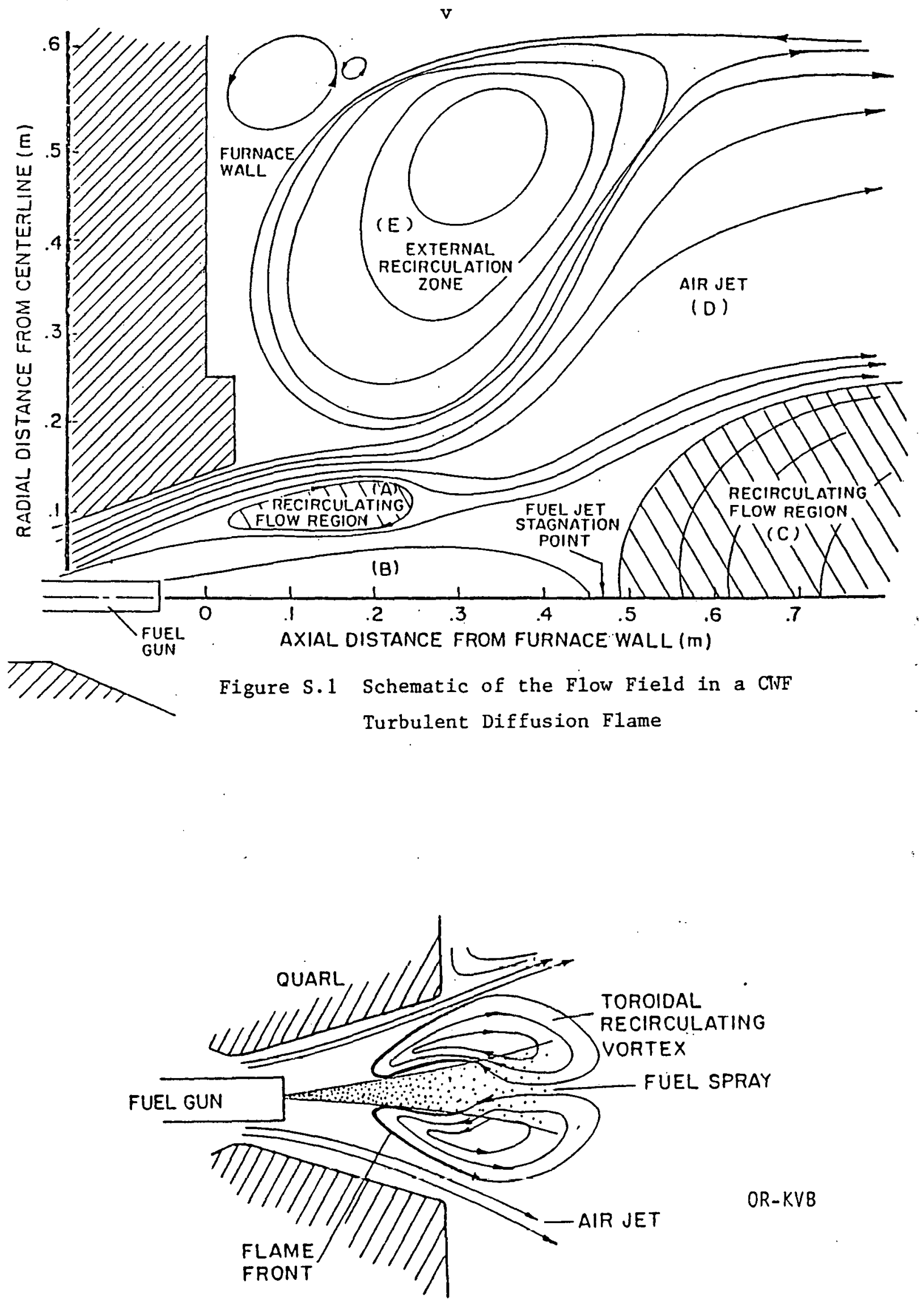

Figure S.2 Schematic showing the interaction of the CWF spray with recirculating combustion products 


\section{F1y ash}

- Fly ash particle size distribution becomes finer when the coal ash content is reduced by coal beneficiation. The reduction in the mean ash particle size is the result of the removal of high density large ash inclusions during the process of coal cleaning.

o with decreasing mineral matter content of the coal the distance between ash centers in the char agglomerate increases resulting in a lower probability of ash agglomeration

$\underline{\mathrm{NO}} \mathrm{emission}$

- Results of experimental studies on fine grind GWF flames ohow that $\mathrm{NO}_{x}$ emission can be effectively controlled by staged air injection into the flame. The $\mathrm{NO}_{x}$ emission was reduced form about $900 \mathrm{ppm}$ in single stage flames to $270 \mathrm{ppm}\left(38 \mathrm{O}_{2}\right)$ in a rich-lean combustion system.

- The fuel-rich stage residence time necessary for the conversion of FBN to $\mathrm{N}_{2}$ is determined by the nitrogen evolution time during coal pyrolysis. In a staged cumbustion configuration, when the atomization quality is high, full advantage can be taken of fine coal particle sizes in the CWF for increasing the volumotrio heat release rate in the flame without increased $\mathrm{NO}_{\mathrm{x}}$ emission.

- Fine atomization is a necessary prerequisite not only for complete combuscion in a restricted combustion space but also for increased rate of volatile nitrogen in the fuel-rich stage. 
Numerical Modelling

\section{Carbon burnout mode1}

- Carbon conversion efficiency values predicted by a mechanistic model for CWF droplet dry-out, coal devolatilization and char burnout were in good agreement with experimentally measured values.

\section{Radiation model}

- A radiative heat transfer model was successfully used to predict gas temperatures and radiative heat flux distributions measured in a fine grind and an ultrafine coal water fuel flames. The value and shapes of the predicted profiles were close to those measured experimentally.

- Experimental data on atmospheric pressure coal water fuel flames obtained in the MIT Combustion Research Facility, and a zone model of radiative heat flux distribution were used to make approximate calculations of radiative heat transfer in a gas turbine combustor. The major conclusions of these calculations were:

- The incident flux of radiation increases with total pressure; the increase is significant between atmospheric pressure and $7.0 \mathrm{~atm}$ but levels off above this pressure level.

- The net radiative heat flux to the combustor wall is insensitive to the variation of thermal input to the combustor hence the fractional radiative heat flux to the total heat extracted by the walls is inversely proportional to the heat input.

- The radiative heat flux incident on a wall element is generaily enhanced by increasing soot concentration. The enhancement is significant at low soot concentrations but reaches saturation conditione for soot concentrations in excess of $100 \mathrm{mg} / \mathrm{m}^{3}$. 
- It is noteworthy that the above calculations were made for a refractory lined combustor (as in the case of the METC experiments). The conclusions concerning the net radiative flux to the wall would be significantly affected by the reduction in the wall temperature e.g. for bare metal gas turbine combustor walls. 


\section{Section 1}

\section{Research Problem and Approach}

\section{Introduction - Background}

The task of developing a coal-burning gas turbine has challenged the ingenuity of engineers ever since the Second World War. The fuel considered for use was pulverized coal (p.c.) and the problems - most of them persisting to the present day - were to ensure good flame stability over a wide range of turn-down, to attain high combustion intensity as demanded by the limited combustion space in the combustor, to prevent slagging in the combustor, and to avoid erosion, corrosion and deposition due to coal ash in the gas turbine. Today's environmental constraints on emissions from coalburning plant impose further demands on the combustion process.

Reports on early studies of stationary gas turbines burning coal in open cycle (combustion products entered the turbine after a high temperature cyclone separator) showed the feasibility of burning finely ground P.C. (95\% $<74 \mu \mathrm{m})$ at a pressure of $100 \mathrm{psi}$ by attainment of 918 burn-out and very high volumetric heat release rate $\left(-3.0 \times 10^{6} \mathrm{Btu} / \mathrm{ft}^{3}-\mathrm{hr}\right)^{1}$. For locomotive gas turbine applications, researchers aimed at reduced heat release rates ${ }^{2}$ in order to reduce slagging of the combustor walls. Despite the promising progress in this early research no satisfactory solution was found to the problem of high temperature gas-solids separation and hence to turbine blade erosion/corrosion and fly ash deposition. Also it was not recognized in the early studies that the nature of the fly ash entering the turbine will depend upon the details of the combustion process that produces the molten or sintered fly ash particles.

Because of the difficulties of the open cycle operation of the coal burning gas turbine, attempts were made to circumvent the problems of 
turbine blade wear and deposition by the use of half-open ${ }^{3}$ and closed cycles ${ }^{4}$. However, the materials problems of the high temperature air heaters in these cycles presented difficulties of comparable magnitude to those encountered in open cycle operation. It had been expected that conditions for high temperature air heaters would be more favorable in pressurized fluidized bed combustion $(\mathrm{PFBC})^{5}$ but research and development experience indicates that erosion and corrosion risks to air heater tubes persist in fluidized bed combustors despite the more spatially uniform heat eránsfer rates and reduced exit air temperature $\left(1600^{\circ} \mathrm{F}\right)$.

As indicated in the introduction, interest has recently been growing in the use of Coal-Water Fuel (CWF) in gas turbine combustors. This fuel which was originally intended primarily for replacement of oil in utility boilers, found further applications in PFBC and in open cycle gas turbine systems. Coal-water mixtures or slurries lend themselves especially well for gas turbine applications, because the requirements for ultrafine grinding are eongruent with those for coal beneficiation. The combination of fine grinding and coal beneficiation permits' a low ash content, fine partiele size fuel to be produced which can be transported and stored conveniently and directly injected into the combustor in the form of a spray, similar to the injection of liquid fuel. This makes the fuel feed system more reliable. It is also advantageous in that, unlike in boller operation, the presence of water in the CWF does not involve a penalty in terms of thermal efficiency in the gas turbine. This then permits mixtures with higher water content (up to 508 instead of 308 as in boiler applications) to be used, as a consequence of which the fuel viscosity w1ll be greatly reduced and a finer spray results. A CWF produced from beneficiated coal with top size coal particles of $10 \mu \mathrm{m}$ and water content of 35 to $50 \%$ in the mixture seems 
to satisfy the requirements for acceptable ignition and burn-out in a gas turbine combustor.

The Pilot plant test programs for burning CWF in gas turbine combustors executed to date have demonstrated the feasibility of burning CWF fuel in gas turbine combustors at elevated pressures and have illustrated at least qualitatively the nature of the problems that have to be faced in the course of the industrial development of this process. The high pressure operation of these tests brings them close to actual gas turbine operating conditions. However, because of the elevated pressure there are difficulties in obtaining the detailed in-flame measurements necessary for a better understanding of the processes of flame stabilization, fuel burn-out pollutant formation and emissions and the transformation of mineral matter in the combustor.

It has been proposed that this type of detailed flame structure study, using ultrafine coal-water mixtures, be carried out in the MIT Combustion Research Facility.

THE RELATIONSHIP BETWEEN DETAILS OF THE COMBUSTION PROCESS AND DESIGN PARAMETERS OF THE COMBUSTOR

The novelty of the application raises a large number of design problems, all of which have to be ultimately answered before the prototype CWF turbine and combustor can be designed. Such questions include:

- how is the flame stability and the position of the flame front affected by the atomization characteristics and the flow and mixing pattern close to the burner?

- how does the coal particle size influence the atomized spray size distribution?

- will coal particles agglomerate as the slurry droplets vaporize upon their injection into the flame?

- will the fly ash particle sizes be proportional to the size of these agglomerates, or do the ash particles fragment in the flame and 
produce a fly ash as small in size as that from a micronized pulverized coal flame?

- how does the solids particle size distribution affect the flame emissivity and hence the radiation from the flame to bounding surfaces?

The processes requiring closer examination are:

- ignition of the CWF particles;

- devolatilization of the coal particles;

- combustion of the residual char;

- control of fuel nitrogen conversion into $\mathrm{NO}_{\mathrm{K}}$ or $\mathrm{N}_{2}$;

- transformation of mineral matter in the flame and the fly ash particle size distribution.

As the combustion process has to be completed within the confines of limited space in the gas turbine combustor, residence time considerations are important. Therefore, results of the CRF measurements on combustion of ultrafine CWF ought to be interpreted in terms of residence time requirements at typical combustor pressures. Characteristic times for the various stages of the combustion process have to be assessed as an aid to the initial design of a CWF combustor.

\section{RESEARCH OBJECTIVES}

The main research objective was to determine relationships between combustion characteristics of CWF flames such as

ignition delay

- carbon conversion efficiency

- NU $\mathrm{x}$ formation and emission

- radiation heat transfer from the flame and

- fly ash particle size distribution on the one hand, and operating variables such as

- fuel type ("ultrafine" and "fine grind" CWF) 
- atomizing air/fuel ratio

- combustor air swirl degree

- combustion air staging, on the other

It was envisaged to obtain this information from cold flow studies of the region close to the burner, detailed in-flame measurements in turbulent jet CWF flames and mathematical modeling of the combustion of CWF and the radiative heat transfer from the flame to the walls of the combustion chamber.

\section{RESEARCH PLAN}

The research plan was organized into five tasks:

Task 1. Cold flow studies of the flow field near the burner

Task 2. Combustion experiments for the study of ignition and burn-out of CWF and the radiation heat flux incident upon the wall of the combustion chamber.

Because of the high cost of ultrafine CWF, the experiments in Tasks 2 and 4 were performed using a "fine grind" fuel

Task 3. Selected combustion experiments using ultrafine CWF for the purpose of determining fuel type effects upon combustion characteristics as Hetermined in the Task 2 investigations.

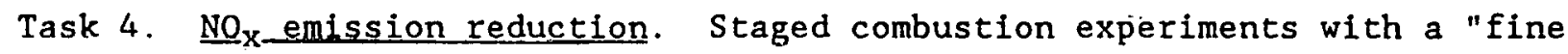
grind" CWF.

Task 5. Data interpretation - Mathematical Modeling. Two mathematical models are presented and discussed:

a) Drying - devolatilization and combustion of CWF droplets in the flame.

b) radiative heat transfer from the flame to the walls of the combustor chamber fór atmospherie and clcvatcd preseures. 


\section{Section 2}

\section{Experimental Conditions and Measurements}

\section{Task 1. Cold flow aerodynamic study - input conditions}

The variables chosen for the cold flow studies were:

- swirl number $(S=0-2.24)$

- atomizing air/fuel ratio

- combustion air flowrate (32 1b/ min - 49 lb/min)

The input variables and their respective levels are 1isted in Table 2.1 and 2.2

In-jet measurements were made of the spatial distributions of time average values of gas temperature, tracer concentrations (CO) and velocities using suction pyrometers, water-cooled gas probes and a five hole pitot tubes respectively. Still photographs of the interaction of the water jet with the surrounding combustion air were also taken.

Tasks 2 and 3 . Combustion studies

Flame Structure study (single stage configurations)

A detailed characterization study of two flames was carried out.

The two fuels used in these experiments were:

- ultra-fine coal water fuel (top particles size $38 \mu \mathrm{m}$ )

- fine-grind coal water fuel $(978<75 \mu \mathrm{m})$

The detailed input conditions of these experiments are listed in Table 2.3. A detailed analysis of the two fuels used is provided in Table 2.4 .

Probe measurements were made to obtain spatial distributions of gas velocities and temperatures, "hemispherical" radiative flux, and "narrow angle" radiation from the flames. Gas and solids sampling was used to determine the chemical species concentration distributions in the flames. 
High speed cine films (4000 frames per second) of the ignition region were also taken in this study.

Task 4 Staged Combustion Study (NO $x$ reduction)

Three flames using a fine grind coal water fuel supplied by Atlantic Research Corp. were investigated.

In these experiments the combustion chamber was divided into two stages, the first of which was fuel-rich while the second was fuel-lean. Figure 2.1 shows the configurations used in this study. The input conditions chosen for these flames are listed in Table 2.5. The fuel burned in the investigation had a mean particle size of $13 \mu \mathrm{m}$. Its proximate and elemental analysis is listed in Table 2.6.

Measurements of gas temperature, axial velocity, gaseous $\left(\mathrm{CO}, \mathrm{CO}_{2}, \mathrm{O}_{2}\right.$, $\mathrm{NO}_{\mathrm{x}}$ and $\mathrm{SO}_{2}$ ) species and solids concentration were made along the axis of the flame. The nitrogen content of flame samples and extent of carbon burnout were determined by using elemental and thermogravimetric analyzers respectively. 
Table 2.1

Input Conditions for Run 1 in Cold Flow Study

$\begin{array}{lll} & (\mathrm{a}) & (\mathrm{b}) \\ \text { Combustion air flow rate (1b/min) } & 49.7 & 49.7 \\ \text { Swirl number of combustion air } & 2.8 & 2.8 \\ \text { Temperature of combustion at inlet (K) } & 500 & 500 \\ \text { Velocity of combustion air (m/sec) } & 23 & 23 \\ \text { Quarl full angle } & 33^{\circ} & 33^{\circ} \\ \text { Atomizing air flowrate (1h//nin) } & . .9 & 20.8 \\ \text { Temperature of atomizing air (K) } & 295 & 295 \\ \text { Water flow rate (lb/min) } & 0.0 & 6.5 \\ \text { Co flowrate (lb/min) } & 68 & 68\end{array}$


Table 2.2

Input Conditions for Run 2 in Cold Flow Study

$\begin{array}{lllll} & \text { (a) } & \text { (b) } & \text { (c) } & \text { (d) } \\ \text { Combustion air flow rate (lb/min) } & 32 & 32 & 32 & 32 \\ \text { Swirl number of combustion air } & 2.24 & 2.24 & 2.24 & 2.24 \\ \begin{array}{l}\text { Temperature of combustion air } \\ \text { at inlet (K) }\end{array} & 500 & 500 & 500 & 500 \\ \text { Velocity of combustion air } & 23 & 23 & 23 & 23 \\ \text { Quarl full angle } & 33 & 33 & 33 & 33 \\ \text { Atomizing air flowrate (lb/min) } & -3.4 & -0.8 & 0.9 & 0.9 \\ \text { Temperature of atomizing air (K) } & 295 & 295 & 295 & 295 \\ \text { Water flow rate (lb/min) } & 0.0 & 4.7 & 0.0 & 4.7 \\ \text { Co flowrate (lb/min) } & 0.0043 & 0.0056 & 0.0056 & -0.0075 \\ \text { *In experiments: } & & & \end{array}$


Table 2.3

Input Conditions in Runs $318 \mathrm{~A}$ and $\mathrm{B}$

Run 318 (A)

Fue1 Type

Thermal input

Fuel flow rate

(1b/min)

Coal content

Swirl number

Gun position

from quarl inlet

Nozzle

Combustion air

flow rate $(1 \mathrm{~b} / \mathrm{min}$

Combustion air

Temperature (K)

Atomizing air

flow rate

$\mathrm{O}_{2}$ at exit

o (on dry basis)

(1b/min)
Ultrafine CWF (AMAX)

$-1.64 \mathrm{MW}$

11.20

548

1.22

0.029

$\mathrm{OR}-\mathrm{KVB}$

80

$594-609$

$-2$

2.87
Run 318(B)

Fine Grind CWF (Atlantic Research)

$-1.59 \mathrm{MW}$

11.40

548

1.22

0.029

$\mathrm{OR}-\mathrm{KVB}$

79

$580-592$

$-2$

2.96 
Table 2.4

Specifications of Coal Water Fuels

Characteristics of the CWF Fuels ARC CWF

AMAX CWF

Coal Type:

Splash Dam

Fine Grind

Ultrafine grind

Coal Particle Size

Size $(\mu \mathrm{m})$
600
75

30

9.9

4.6
\& Passing

100

96.9

80

50

30

Coal particle top size

Coal content in CWF

600

38

548

548

Characteristics of the Parent Coals

Moisture

1.07

(wt $\&$ as received)

Proximate Analysis:

(wt 8 , dry)

Ash

5.56

1.31

Volatile

30.77

Fixed Carbon

63.67

35.89

Heating Value:

14718

62.80

(Btu/1b, dry)

U1timate Analysis:

Carbon

82.91

(wt \&, dry)

Hydrogen

5.06

1. 50

Nitrogen

0.11

Chlorine

0.61

15400

Sulfur

5.56

Oxygen (diff.)

4.25

86.03

5.54

1.67

1.77

1.31

4.99

Ash Composition

wto

$\mathrm{SiO}_{2}$

$\mathrm{Al}_{2} \mathrm{O}_{3}$

34.8

$\mathrm{Fe}_{2} \mathrm{O}_{3}$

$\mathrm{CaO}$

-

22.7

23.7

- $\mathrm{MgO}$

3.89

$\mathrm{Na}_{2} \mathrm{O}$

0.808

$\mathrm{K}_{2} \mathrm{O}$

4.19

1.75

$\mathrm{TiO}_{2}$

1.14

$\mathrm{MnO}_{2}$

0.12

$\mathrm{P}_{2} \mathrm{O}_{5}$

0.209

$\mathrm{V}$

0.053

$\mathrm{Pb}$

0.365

Ash Fusion Temperatures, ${ }^{\circ} F$ (Red)

Reducing, initial deformation 
Table 2.5

Input Conditions for the Staged CWF Flame Study Run No. 1 Run No. 2 Run No. 3

\begin{tabular}{|c|c|c|c|}
\hline Fuel Thermal Input (MW) & -1 & -1 & -1 \\
\hline Coal Water Ratio & $-54 / 46$ & $-51 / 49$ & $-54 / 46$ \\
\hline Fuel Temperature (K) & 293 & 293 & 293 \\
\hline Coal Fineness & Fine Grind & Fine Grind & Fine Grind \\
\hline Combustion Temperature (K) & 503 & 503 & 503 \\
\hline Swirl Number & 1.22 & $1: 22$ & 1.22 \\
\hline $\begin{array}{l}\text { Fuel equivalence ratio } \\
\text { in first state }\end{array}$ & -1.13 & -1.13 & -1.13 \\
\hline $\begin{array}{l}\text { Secondary air injector } \\
\text { position from burner } \\
(X / D)\end{array}$ & -11.9 & -15.6 & -8.6 \\
\hline $\begin{array}{l}\mathrm{O}_{2} \text { concentration } \\
\text { at exit ( } 8)\end{array}$ & 2.8 & 3.0 & 2.9 \\
\hline $\begin{array}{l}\mathrm{NO}_{x} \text { concentration at } \\
\text { exit (ppm) }\end{array}$ & 300 & 270 & 485 \\
\hline
\end{tabular}

Table 2.6

Coal Analysis for Runs 1,2 and 3

Proximate Analysis (wto dry)

Ash

4.34

Volatile 8

31.71

Fixed Carbuin \&

63.95

Elemental Analysis of the Coal

C
H
N
S
O (diff)
Ash

79.04

4.74

1.66

1.12

9.1

4.34 


\section{Section 3}

\section{Experimental Apparatus and Procedure}

\section{Combustion Research Facility}

The Combustion Research Facility (CRF), shown schematically in Figure (3.1), was designed to facilitate detailed experimental investigations of industrial-type turbulent diffusion flames; it consists of a $1.2 \mathrm{~m} \times 1.2 \mathrm{~m}$ cross-section $10 \mathrm{~m}$ long combustion tunnel equipped with a single burner having a $3 \mathrm{MW}$ thermal input, multi fuel firing capability. During the experiments the combustion tunnel is normally comprised of 15 of $0.30 \mathrm{~m}$ wide, refractory-lined water-cooled sections.

The burner is equipped with a moveable block variable swirl generator. The combustion air enters in the form of an annular jet, the annulus being formed around the $60 \mathrm{~mm}$ diameter coal water fuel gun. In the present study the combustion air passed through a 55-60 full angle refractory divergent nozzle. The combustion air introduced was heated approximately up to $260^{\circ} \mathrm{C}$. Measurement and Analysis

During the course of the flame studies the following measurements were made :

- gas temperature using a suction pyrometer

- gas composition of major stable species $\left(\mathrm{O}_{2}, \mathrm{CO}, \mathrm{CO}_{2}, \mathrm{SO}_{2}\right.$ and $\left.\mathrm{NO}_{\mathrm{X}}\right)$ using a water cooled gas sampling probe.

- axial velocity using an impact tube probe

- total radiative heat flux and flame emissivity

- particulate samples using a water-quenched probe

- ash samples using a steam-cooled probe

- carbon burnout of particulate samples using a thermogravometric analyzer 


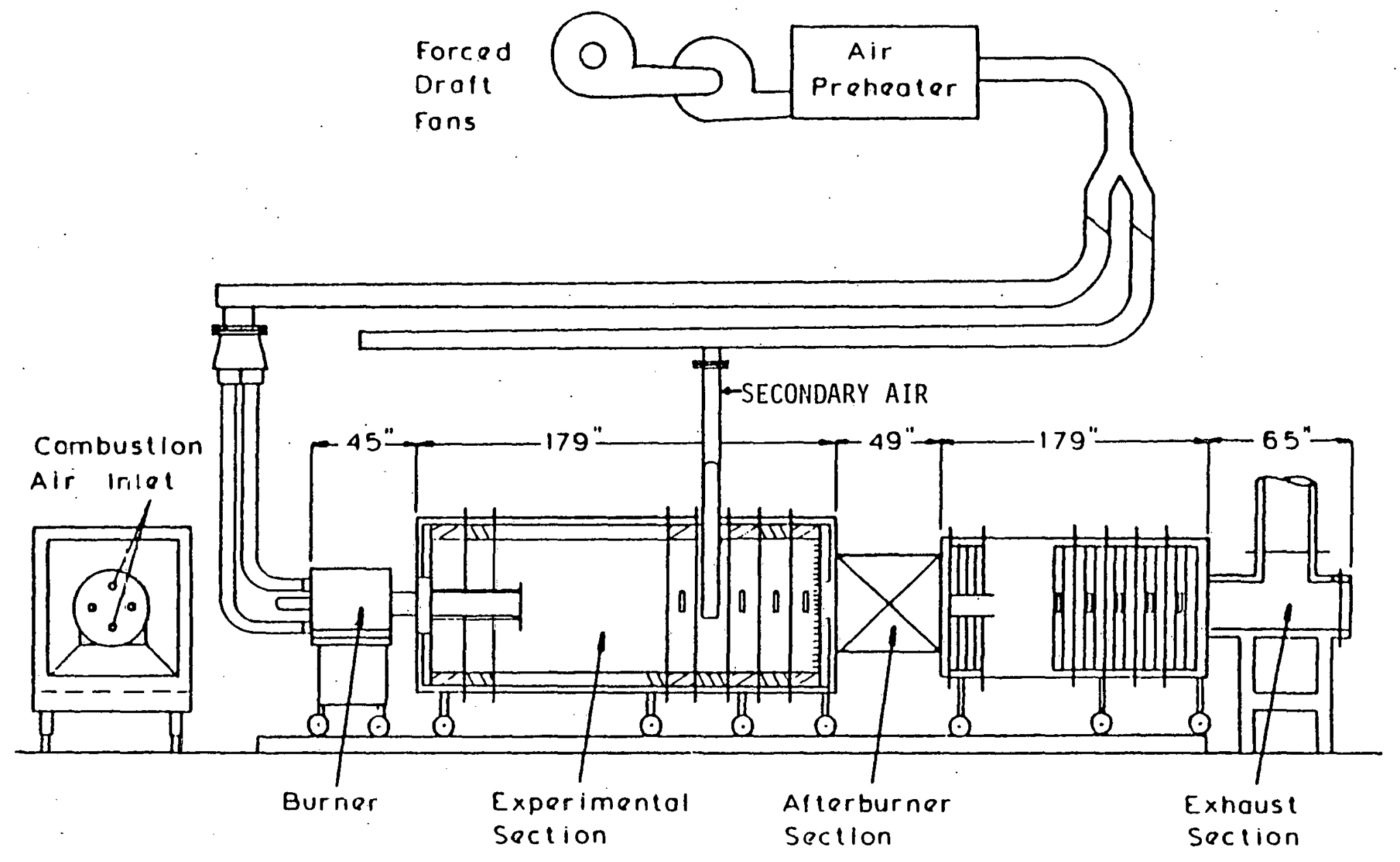

Figure 3.1 FURNACE ASSEMBLY AND AIR STAGING SYSTEM. 
- high speed cine films of the flame (4000 fr/sec).

Detailed description of the probes and instruments used are reported next.

\section{Instrumentation and measuring equipment}

\section{THE SUCTION PYROMETER}

The drawing of the standard suction pyrometer used at the MIT-CRF and at IJmuiden is given in Figure 3.2. The purpose of the suction pyrometer is to measure as accurately as possible the combustion gas temperature at a particular position in the flame. The surtion pyrometor oonolotg of a platinum-platinum/108 rhodium thermocouple protected by a fiused alumina sheath, placed in a series (usually two) of concentric refractory. Once the probe is positioned in the flame, the combustion gases are drawn over the thermocouple and through the refractory shields by a powerful vacuum pump. The system of refractory tubes and the thermocouple are mounted onto a hollow, water-cooled shaft through which the combustion gas vacuum line and the thermocouple wire are passed. The thermocouple is connected to a potentiometer in the control room which gives a temperature read-out corresponding to the voltage differential across the thermocouple junction

The principles behind the suction pyrometer design are discussed by Chedaille and Braud ${ }^{6}$ (1972) in detail. Basically, the design is ained towards minimizing errors in temperature readings due to radiation interactions between the thermocouple and its surroundings (this is the purpose of the refractory shields), and to insufficient convective heat transfer from the sample gases to the thermocouple (which is the reason for implementing a rapid rate of gas suction over the thermocouple). 

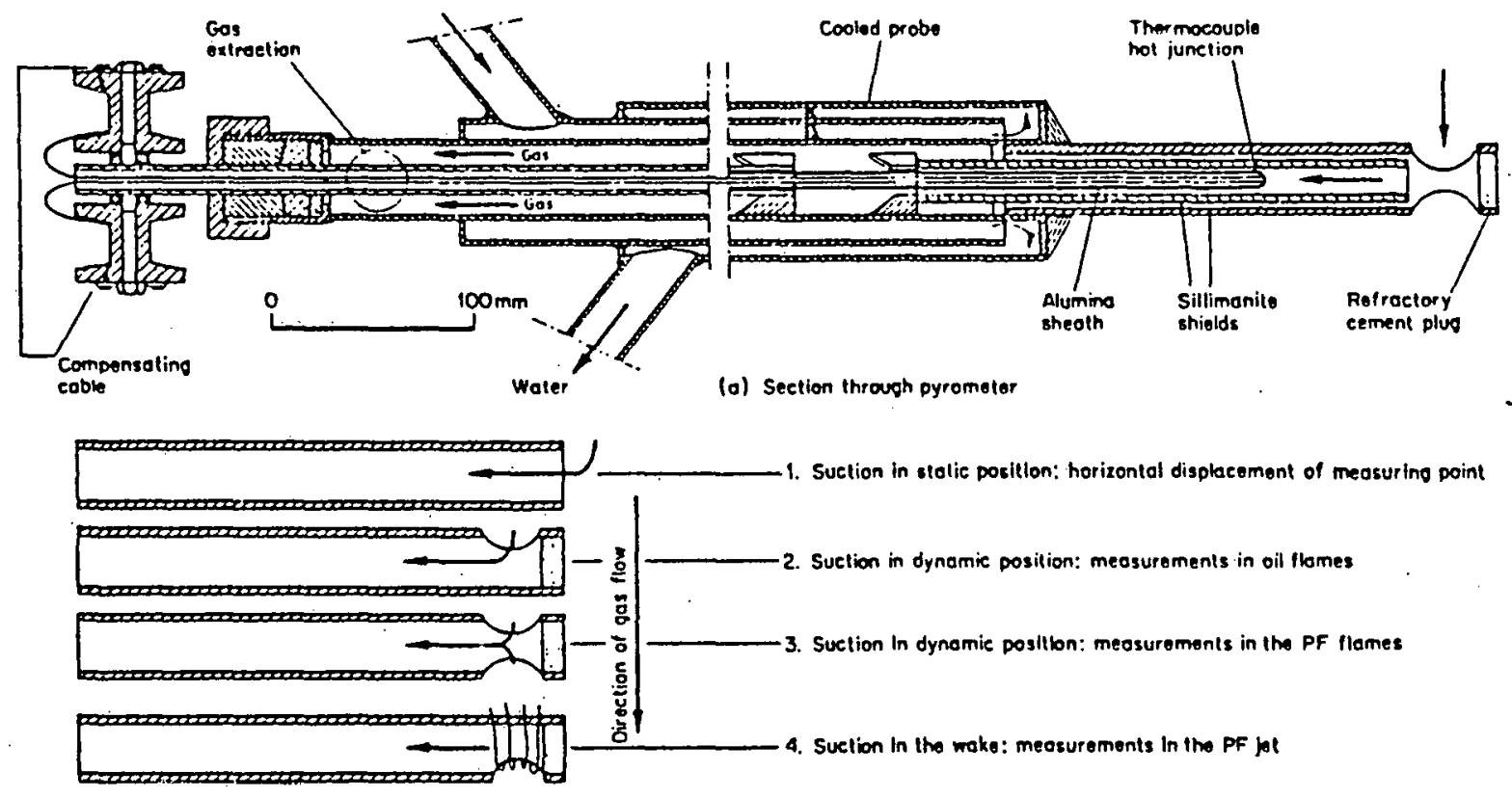

(b) External shield

Figure 3.2 Schematic of Suction Pyrometer for Temperature Measurements 


\section{THE GAS SAMPLING PROBE}

A drawing of the gas sampling probe and a schematic of the entire gas sampling and analysis system are given in Figures 3.3 and 3.4 , respectively. In simplest terms, the gas sampling probe consists of a water-cooled tube to which is applied vacuum for the purpose of drawing in combustion gases for analysis of the concentrations of their constituents. The combustion gases move under vacuum through the probe and a sample transport line to a set of continuous on-line gas analyzers (for $\mathrm{NO}_{\mathrm{x}}, \mathrm{CO}, \mathrm{CO}_{2}$, and $\mathrm{O}_{2}$ ), as shown in Figure 3.4 .

One of the primary functions performed by the probe 1.5 to cool the sample combustion gases with sufficient rapidity that the constituents in the gas are preserved in their original concentration. Combustion reactions are extremely rapid; Chedaille and Braud estimate that the gases must be cooled by the probe at least $300^{\circ} \mathrm{C}$ within $3 \mathrm{msec}$ to obviate the effects of continuing reaction kinetics once the gas sample is drawn in.

It is also desirable that the probe disturb as little as possible the flow field of the jet flame. The gas sampling probe is inserced with the intake facing the direction of overall combustion gas flow, and preferably the sample is drawn into the probe at a rate equal to that of the combustion gas velocity so as not to distort the flow streamlines (isokinetic sampling).

The probe 1tself is constructed to stainless steel. The probe is cooled by means of high pressure (150-220 psig) cooling water, and is mounted into a heavier, hollow, water-cooled shaft through which the tip water-cooled lines and gas sample line are passed (see Figure 3.3). 


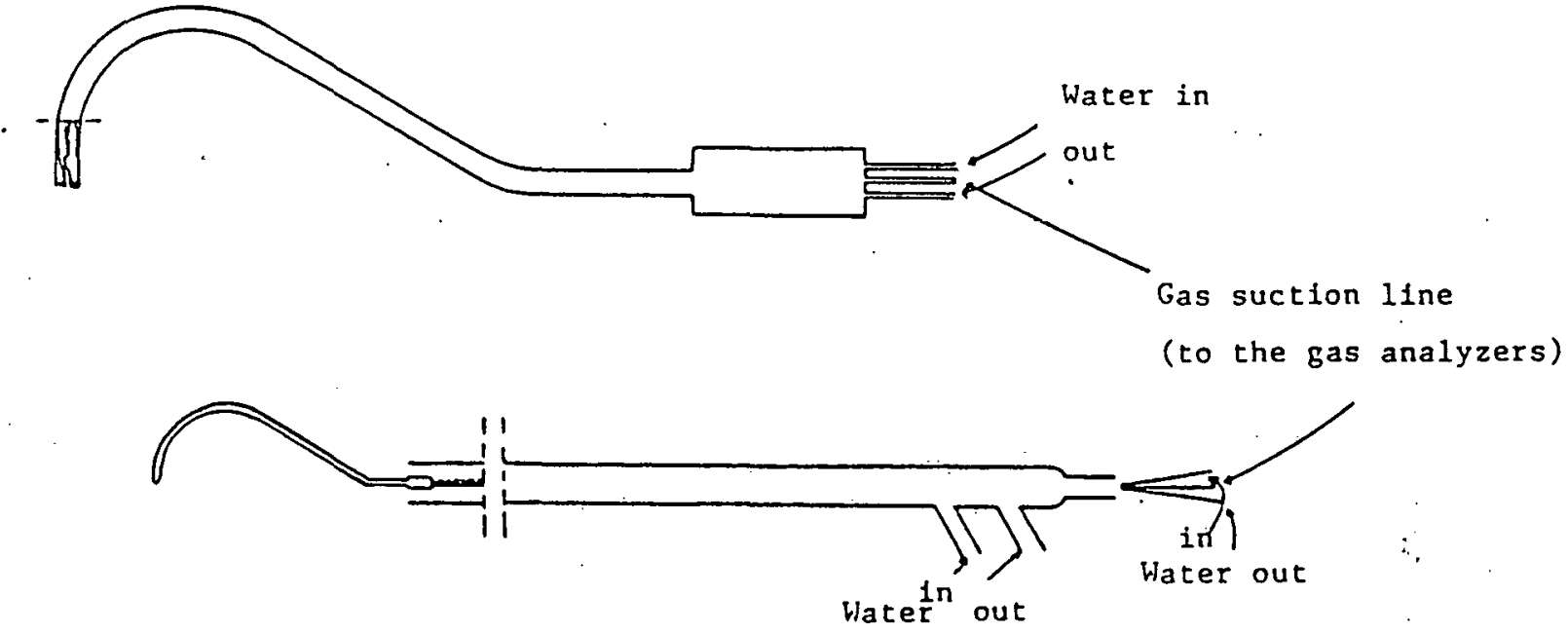

Figure 3.3 Gas Sampling Probe, with Detail of Probe Tip...

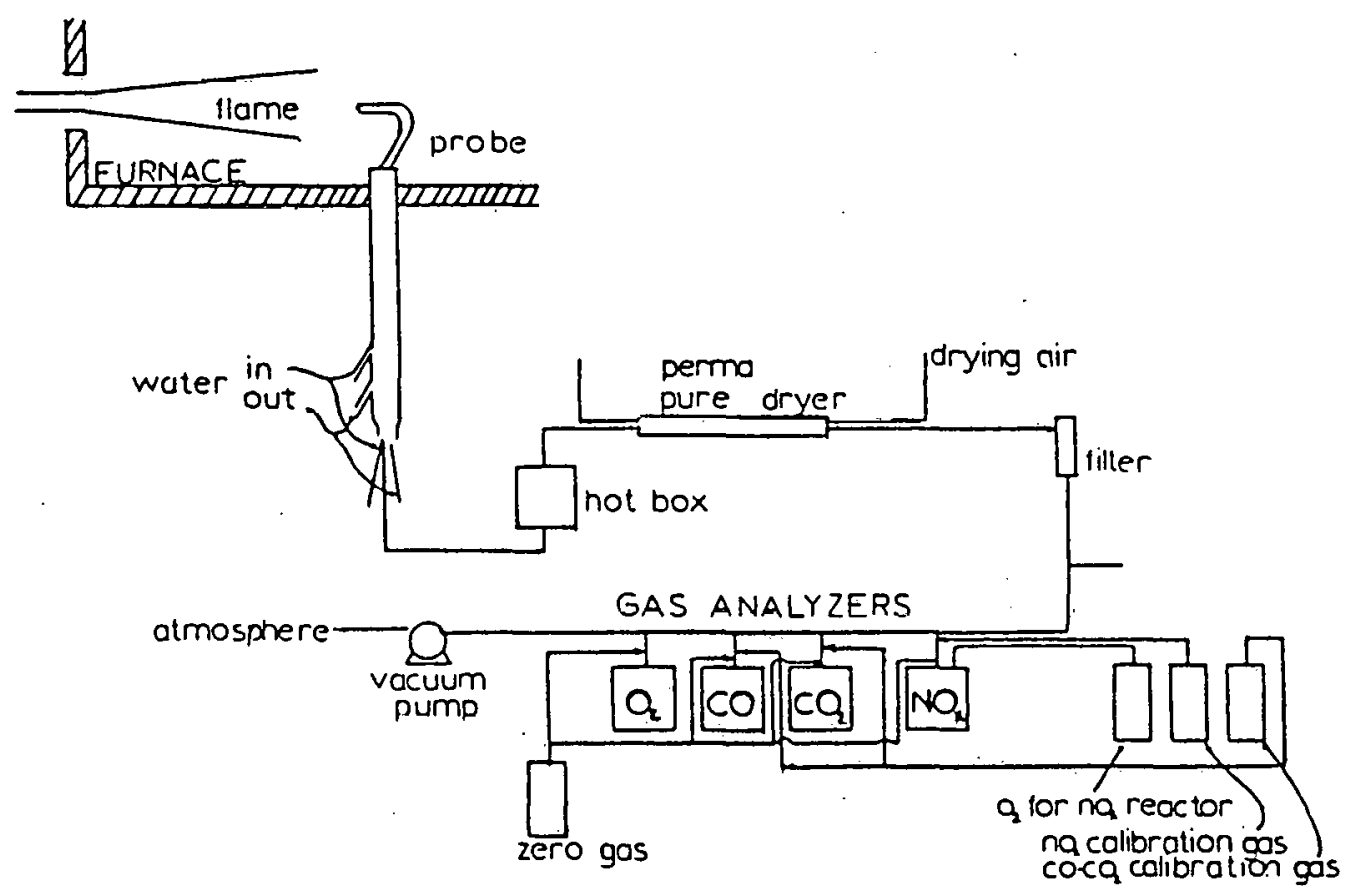

Figure 3.4 Schematic of Gas Sampling and Analysis System 


\section{THE FIVE-HOLE PITOT PROBE}

A drawing of the five-hole pitot probe is given in Figure 3.5. This probe is used for flow systems in which the direction of the gas velocity at the point of measurement is not known (e.g. highly swirling flames with recirculating flow). The five-hole pitot allows the determination of both magnitude and direction of the velocity. The velocity vector may be characterized by a scalar magnitude and two angles or by its three components in a reference system associated with the probe and/or experimental facility.

The probe head has five holes (pressure taps) drilled into it, one through the center and four others at an angle of $45^{\circ}$ with the axis of the head. As in the case of the pitot-static probe, the velocity determination is based upon the Bernoulli equation. Three independent pressure differential measurements are made across the five pressure taps; these allow the determination of velocity direction as woll as magnitudo. Extensive calibration is required in which the ratios of the pressure differentials as a function of the probe head angle with respect to a set of fixed axes is established, in a flow of known velocity magnitude and direction. This calibration work has been carried out by the International Flame Research Foundation and is presented in the book published by Chedaille and Braud (1972), along with the relevant equations for calculation of the velocity magnitude and direction. The probe tip is constructed of stainless steel, and cooled by high pressure water. As in the case of the pitot-static probe, the tip is mounted into a hollow, watercooled shaft, through which the cooling water and pressure tap lines are passed. 


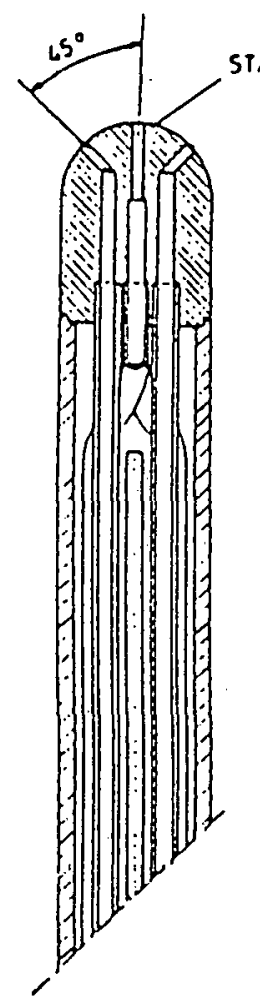

STAINLESS STEEL. .

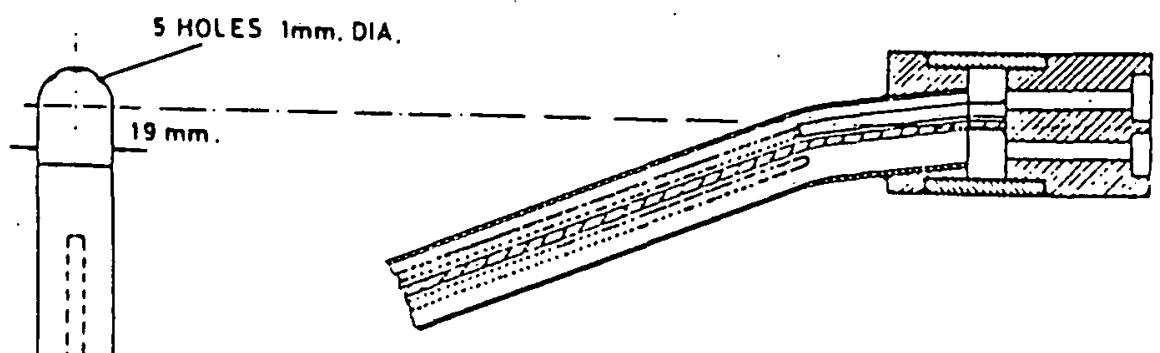

Figure 3.5 Multidirectional Impact Tube (5-Hole Pitot) 


\section{IMPACTION TUBE VELOCITY PROBE}

A drawing of the impaction velocity probe is shown in Figure 3.6. The probe consists simply of two open ended stainless-steel tubes which have been welded together in the manner shown in the figure. At the probe tip the tubes have been cut back to form a full angle of $\sim 60^{\circ}$.

A device similar to this was used by the Central Testing Laboratory of the Beifing Electric Power Bureau for the measurement of flowrates of dustladen air. The probe, designated in Figure 3.6, is described in the handbook prepared by the Thermal Power Engineering Research Institute ${ }^{7}$. The probe was calibrated by comparison of its differential pressure with the axial component of the gas velocity indicated by a five hole Pitot probe in a natural gas flame. The factor correcting the velocity calculated using the Pitot/static equation is 0.7 ; this factor was independent of gas velocity in the range 5 to $8 \mathrm{~m} / \mathrm{s}$. The uncertainty in the gas velocity is estimated to be $\pm 5 \mathrm{~m} / \mathrm{s}$. This uncertainty arises from the inability of the probe to discriminate the axial from other velocity components, and the difficulty of obtaining accurate time-averaged gas velocity using impact methods in region of high turbulence intensity. One advantage of the probe is that due to it symmetry it does not need to be rotated to measure negative velocities, Another advantage is that the orifices are large and the tip is hot so the probe is not quickly clogged when making measurements in the fuel spray. The probe is withdrawn into the water-cooled support to protect it between measurements.

THE HOLLOW ELLIPSOIDAL RADIATION PROBE

A drawing of the ellipsoldal radiometer is given in Figure 3.7. This instrument is used for measuring the radiative flux passing through an element of a plane surface. The probe has a hemispherical field of view; 


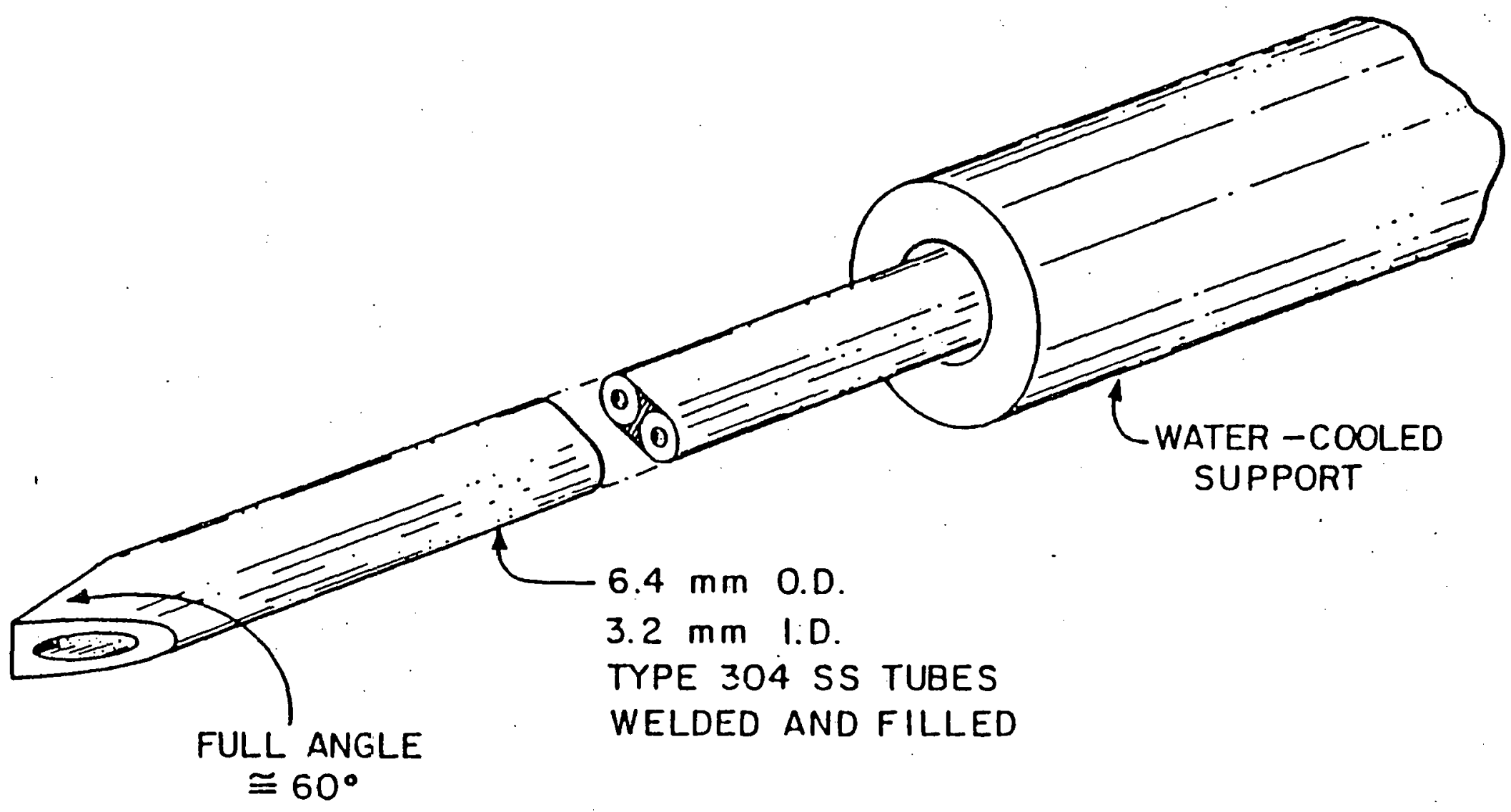



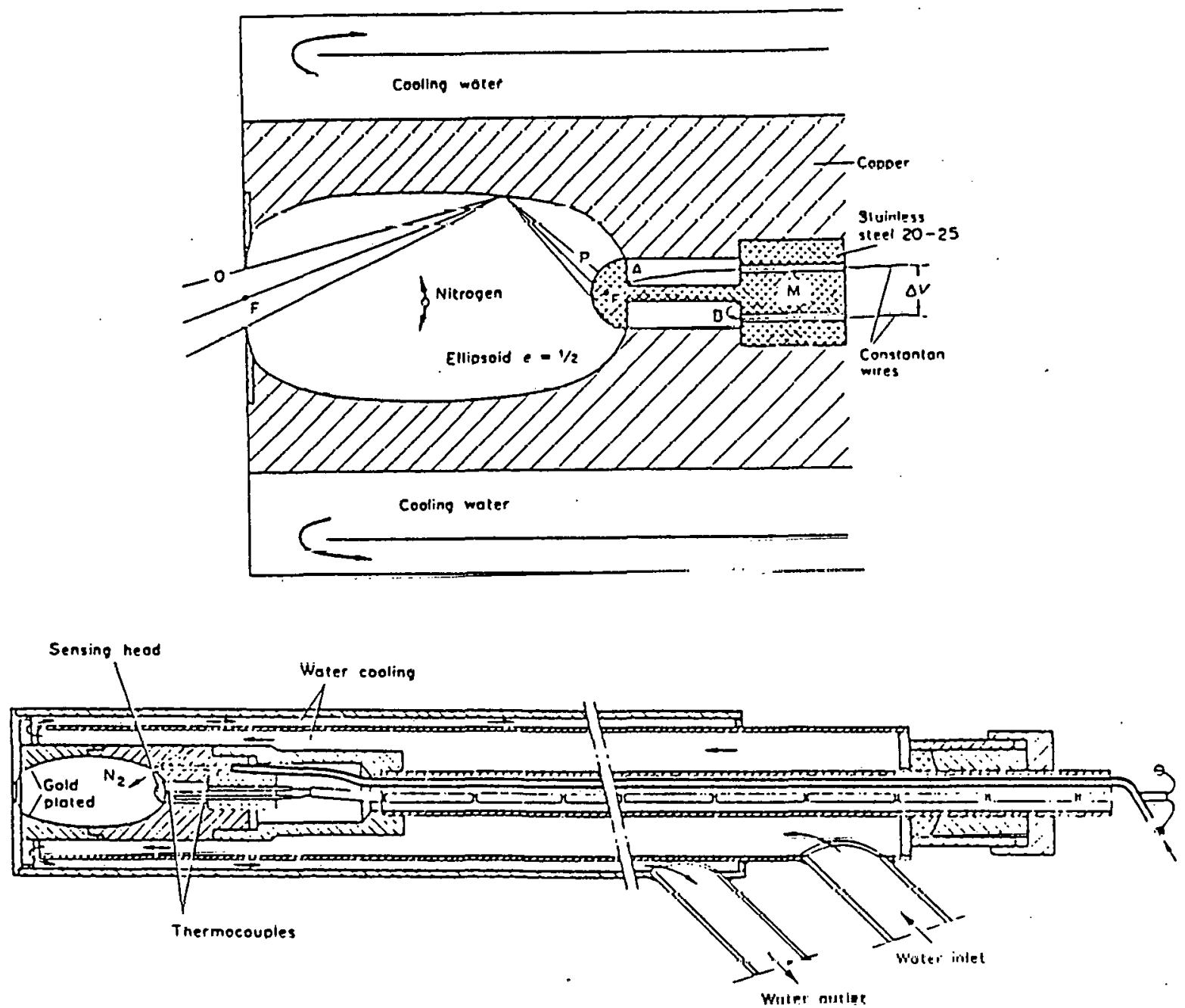

Figure 3.7 Hollow Ellipsoidal Radiation Probe, with Detail of P:obc Z1p 
incoming radiation of varying incident angles passes through a small orifice ( - 2-5 $\mathrm{mm}$ ) and is focused by the polished gold plated surfaces of an ellipsoidal cavity (see Figure 3.7 ) onto a thermopile.

The thermopile consists of a hemispherical receiving pellet, a cylindrical portion $A B$, and a cooled metal mass, $M$, all made of stainless steel (258 nickel and 258 chromium). Constantan wires are soldered at the base of the receiving pellet and at the base of the cylindrical portion $A B$, as shown in Figure 3.7. A thermocouple is in effect formed, which produces an electrical potential that is proportional to the amount of radiant energy received by the hemispherical pellet, provided that the temperature of the thermopile remains relatively constant and low (e.g., at room temperature). If the thermopile were to rise in temperature, radiative and convective heat losses would cause inaccuracies in the measurements. The probe and thermopile are designed so as to maintain a constant, relatively low temperature at all times.

Dry nitrogen is injected into the ellipsoidal cavity through a number of tiny holes for the purpose of preventing entry of combustion gases and particulates. These tend to form deposits which lower the reflectivity of the cavity surfaces, and alter the performance of the probe.

The ellipsoidal cavity and thermopile are housed in a water-cooled stainless steel shaft. The probe is calibrated by means of black body furnaces which have surfaces of known emissivity and which can be varied in temperature.

\section{THE NARROW ANGLE RADIATION PYROMETER}

A drawing of the narrow angle radiation probe is given in Figure 3.8. This probe measures the intensity of the radiation received at a small surface element from a epecifled direction. The solid view angle of the 


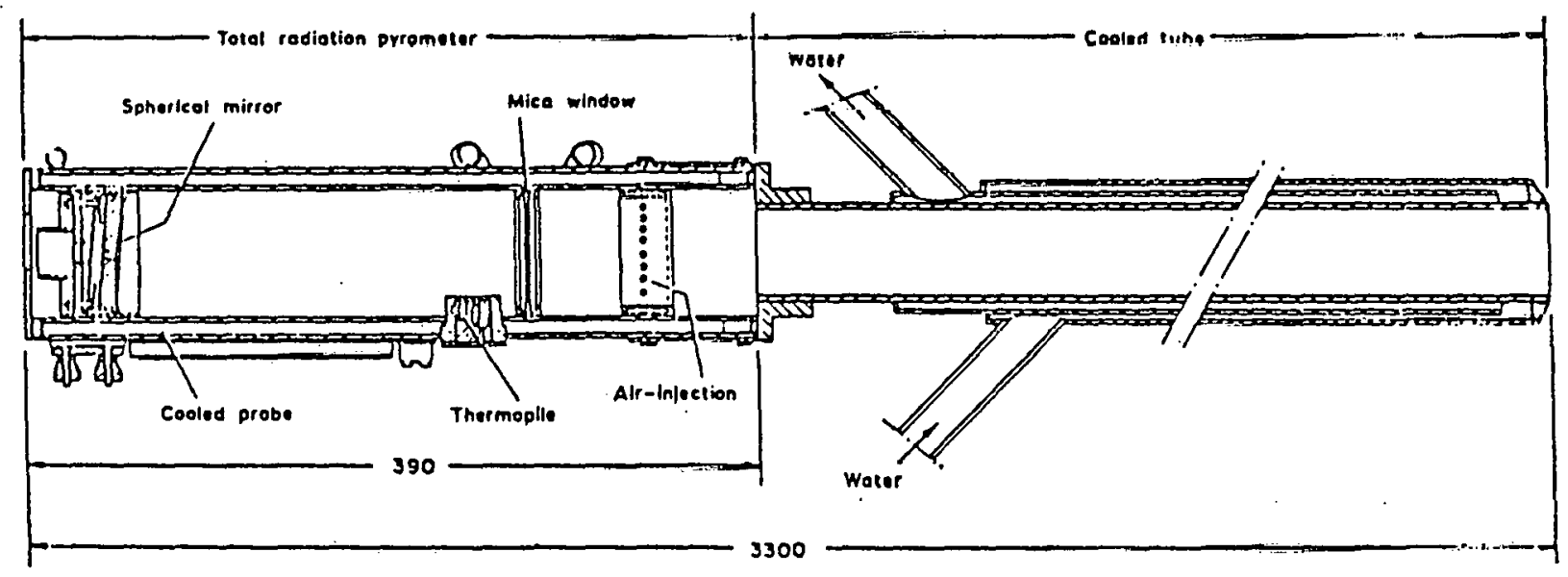

Figure 3.8 Narrow Angle Total Radiation Pyrometer 
instrument is very narrow $(\sim 0.02$ steradians); in the case of radiation measurements at the MIT-CRF, the viewing path-length is normally on the order of $1.2 \mathrm{~m}$ and the diameter of the area 'seen' by the probe on the order of $20-40 \mathrm{~mm}$.

The narrow angle radiation probe is used at the MIT-CRF primarily in the determination of flame emissivities by the Schmidt method. The emissivity is determined on the basis of three radiation measurements as follows :

$$
\epsilon_{F}=1-\frac{\mathrm{R}_{2}-\mathrm{R}_{1}}{\mathrm{R}_{3}}
$$

where $R_{1}=$ the radiative flux measured by viewing a cold target through the flame

$\mathrm{R}_{2}=$ the radiative flux measured by viewing a hot target (of emissivity - 1) through the flame, and

$R_{3}=$ the radiative flux due to the hot target alone, as calculated from its measured temperature.

The narrow angle radiation pyrometer consists of a spherical concave mirror which focuses radiation received through the length of the sighting tube onto a thermopile. The mirror is pierced at its center to facilitate aiming of the probe at a desired radiation target. The sighting tube is purged of combustion gases which contain radiating/absorbing species by means of dry nitrogen injection. The probe is calibrated in a manner similar to the ellipsoidal probe, by means of black body furnaces.

\section{THE PARTICULATE SAMPLING PROBE}

Drawings of the water quench, gas and solids sampling probe are shown in Figures 3.9 and 3.10. Combustion gases along with particulates are drawn under vacuum through the probe and into a sampling train. A controlled flow of water is sprayed at the tip of the probe in order to quench the reactions 


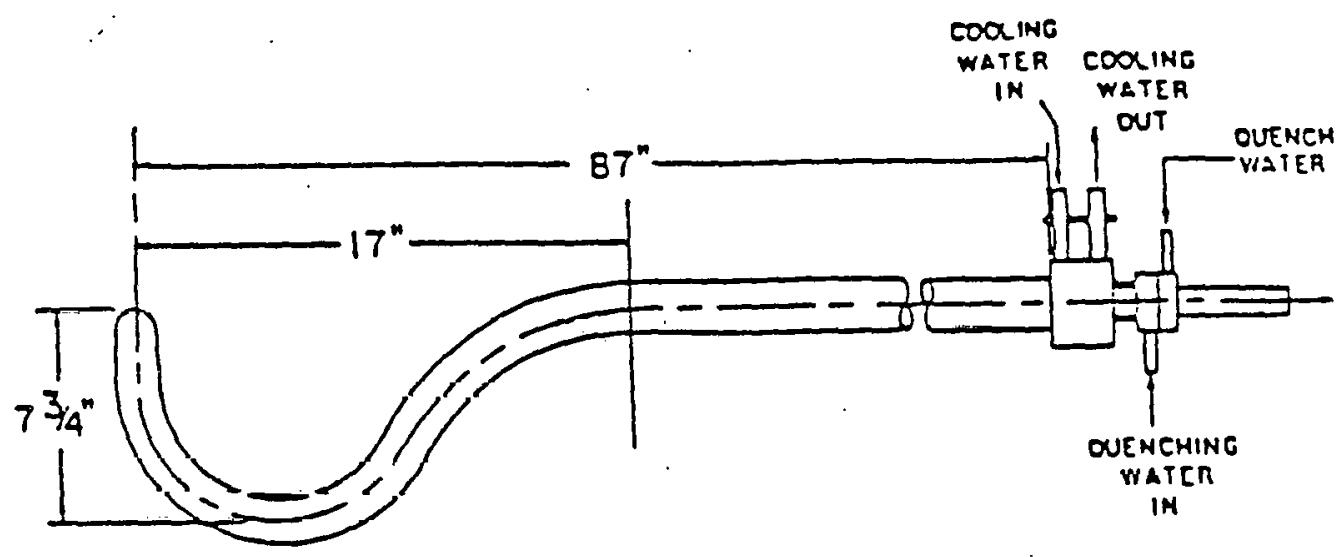

Figure 3.9. Water Quench Sampling Probe

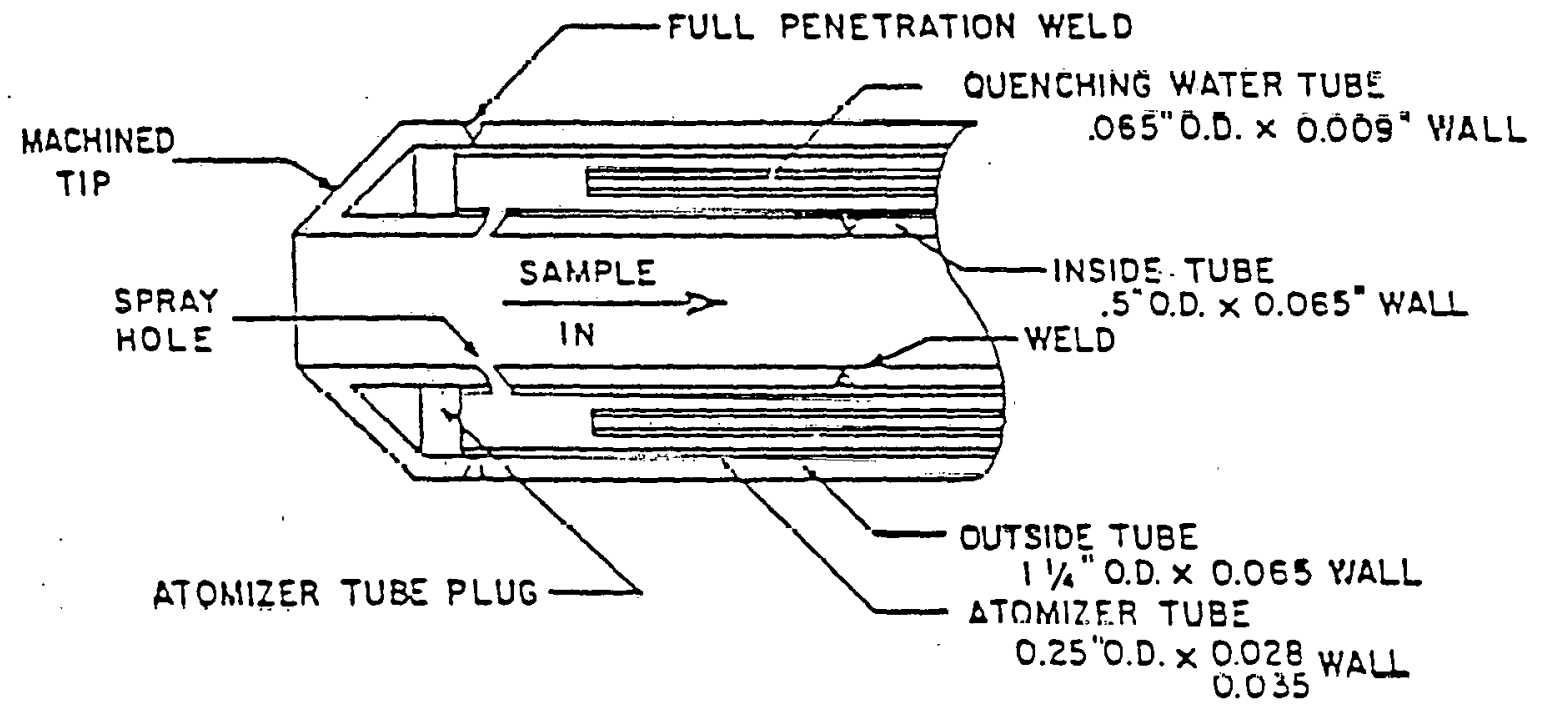

Figure 3.10 Detail of the Warer Quench Sampling Probe Tip 
occurring in the sample tube walls. The probe is constructed of stainless steel and is water-cooled.

The sample is comprised of the quench water, particulates and gases. This is run through a sampling train which consists of: 1) a filter paper for collection of solids, 2) absorption traps for various constituents of interest in the combustion gases, e.g., XAD-2 (polystyrene) traps for polycyclic aromatic hydrocarbon (PAH), and 3) a water trap for retention of any organics/organics of interest that may have been dissolved in the quench water.

The total gas drawn through the sampling train is measured with a volumetric gas flow meter so that the constituents of interest may be quantified as well as identified.

\section{FLY ASH SAMPLING SYSTEM}

A new addition to flame solids sampling mentioned earlier is an ash particle size sampler. In this system, the particles are withdrawn from the flame through a sampling probe having both a water cooled shell, and a steam heated sampling line to prevent condensation. The steam flowrate and pressure are adjusted to maintain the temperature of the gas/particle stream leaving the probe at $150^{\circ} \mathrm{C}$. Particles are separated from the gas in a cyclone followed by a cascade impactor (Pollution Control Systems, Mark III). The cyclone and cascade impactor are enclosed in an oven maintained at $160^{\circ} \mathrm{C}$. The mass distribution of "free ash" is determined by weighing the different size fractions collected. 


\section{Section 4 \\ Task 1. Results of Cold Flow Study}

\section{Introduction}

From previous studies of coal water fuel flames, the interaction of the fuel jet with the combustion air surrounding, it was found to be important in influencing flame ignition and stability. To determine the mixing process between fuel and air, a simulation experiment was carried out in which the interaction of an air assisted water jet with the combustion air was studied for the effect of different levels of swirl degree of the air flow.

\section{Experimental Input and Operating Conditions}

Two sets of experiments were carried out to characterize the effects of

(1) swirl degree of the combustion air

(2) atomizing air/fuel flowrate ratio

upon the mixing process in the region close to the fuel and air nozzles. The input conditions for these experiments are listed in Tables 2.1 and 2.2 and the results obtained in Tables A.1-A.9.

In the first set of experiments the swirl number which is defined as the normalized angular to linear momentum ratio of the airflow was varied from 0.0 to 2.24 and the decay of carbon monoxide introduced as a tracer with the water and atomizing air through the fuel nozzle was monitored by the measurements of $C O$ concentration at several axial distances from the fuel nozzle.

In the second set, the combustion air, atomizing air and water flowrates were varied and measurements of carbon monoxide and axial velocities were taken along the axis of the combustion chamber. 


\section{$\underline{\text { Results }}$}

\section{(1) Swirl degree}

The effect of swirl degree (S) upon mixing in the combustion chamber is shown in Figure (4.1). It is noteworthy that increasing the swirl number results in higher rates of mixing as evident from the increased decay of $c 0$ concentration with axial distance as the swirl degree is increased. For this particular burner a swirl number larger than 0.68 results in the development of an internal recirculation zone (IRZ) the intensity of which increases with increasing (S). The internal recirculation zone formed is beneficial in decelerating the coal water droplets as well as providing them with the needed energy feedback for evaporation devolatilization and burnout.

\section{(Atomizing air/fuel) flowrate ratio}

For determining the effect of the atomizing air/fuel mass flow rate upon the mixing process the amount of the atomizing air alone and in combination with water was varied in a series of experiments. The results obtained from this investigation are shown in Figures $(4.2-4.5)$ where the axial profiles of the co concentration and of the axial velocity are plotted for various flow rates of the atomizing air.

If the atomizing air is the only medium introduced through the fuel nozzle, a small flowrate would result in the attachment of the internal recirculation zone (IRZ) to the nozzle (Figures 4.2, 4.3). At.high flow rates of the atomizing airflow, however, IRZ is displaced further downstream.

A similar effect is illustrated in Figure 4.4 by the comparison of cases in which the atomizing air was introduced with and without water respectively. The addition of water increases the linear momentum of the 


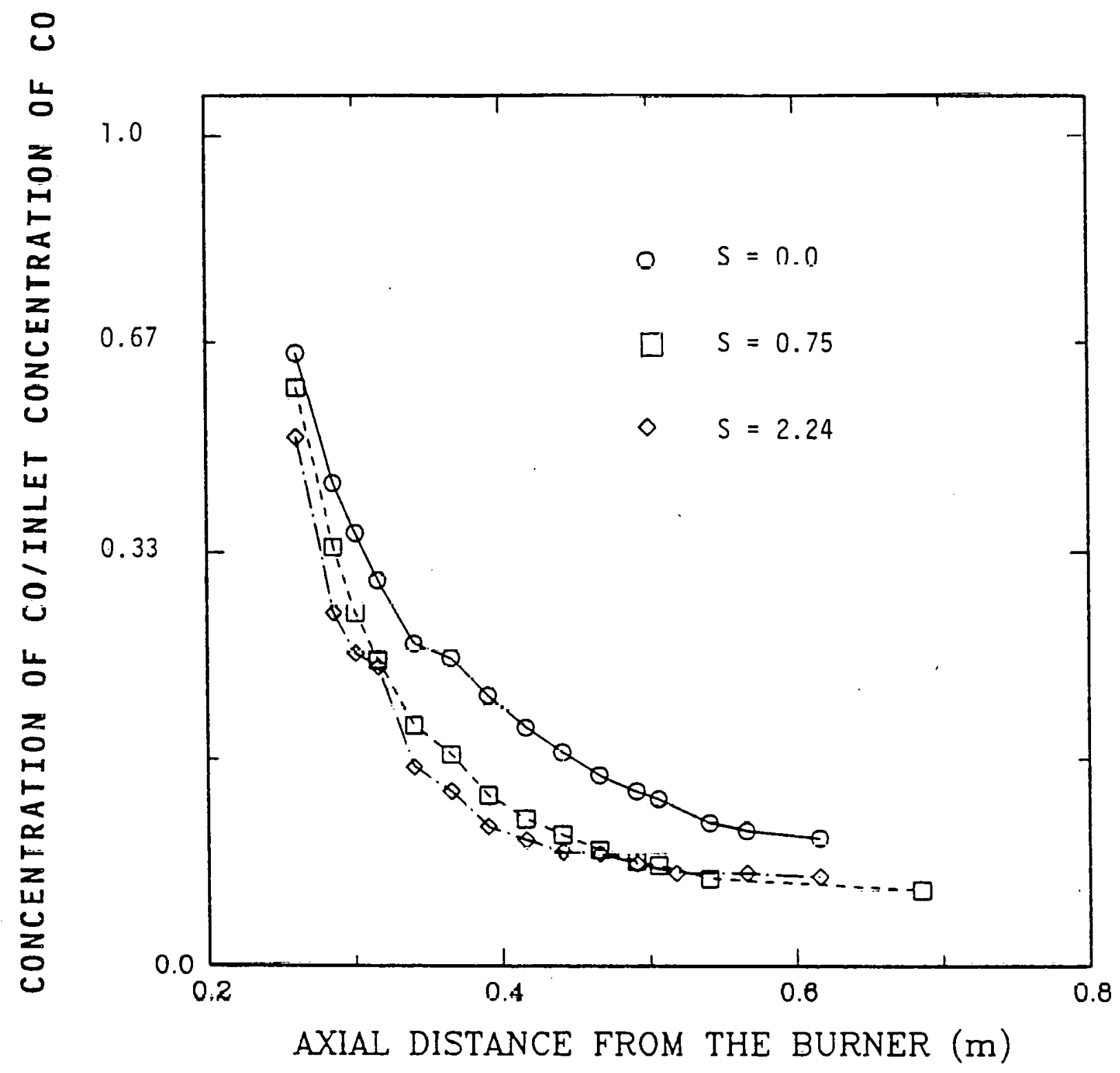

Figure 4.1 The effect of swirl number on $c 0$ concentration on the jet axis 


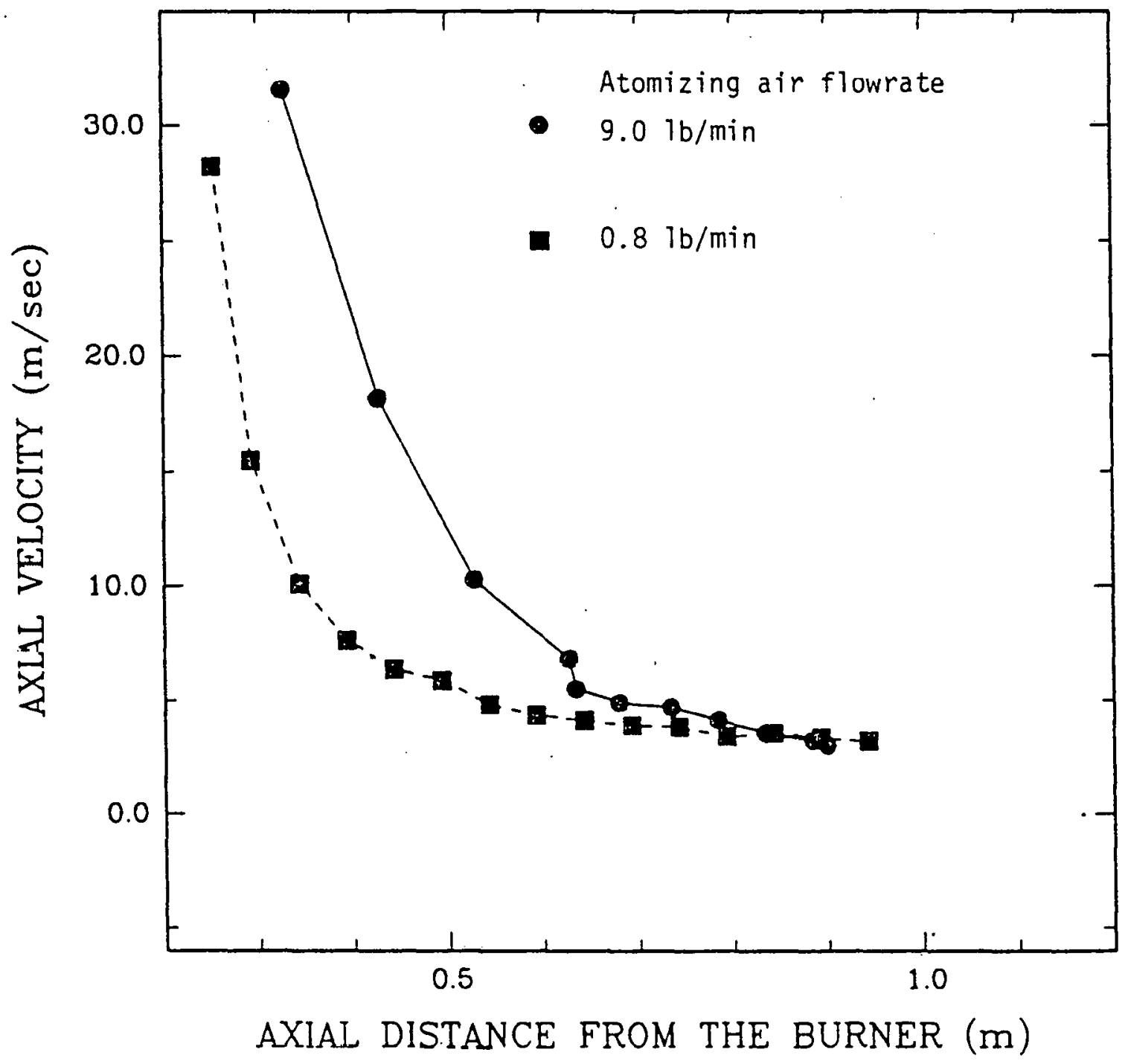

Figure 4.2. The effect of atomizing air flowrate upon axial velocities on the jet axis in a cold flow experiment corresponding to the conditions of a 1 MW flame. 


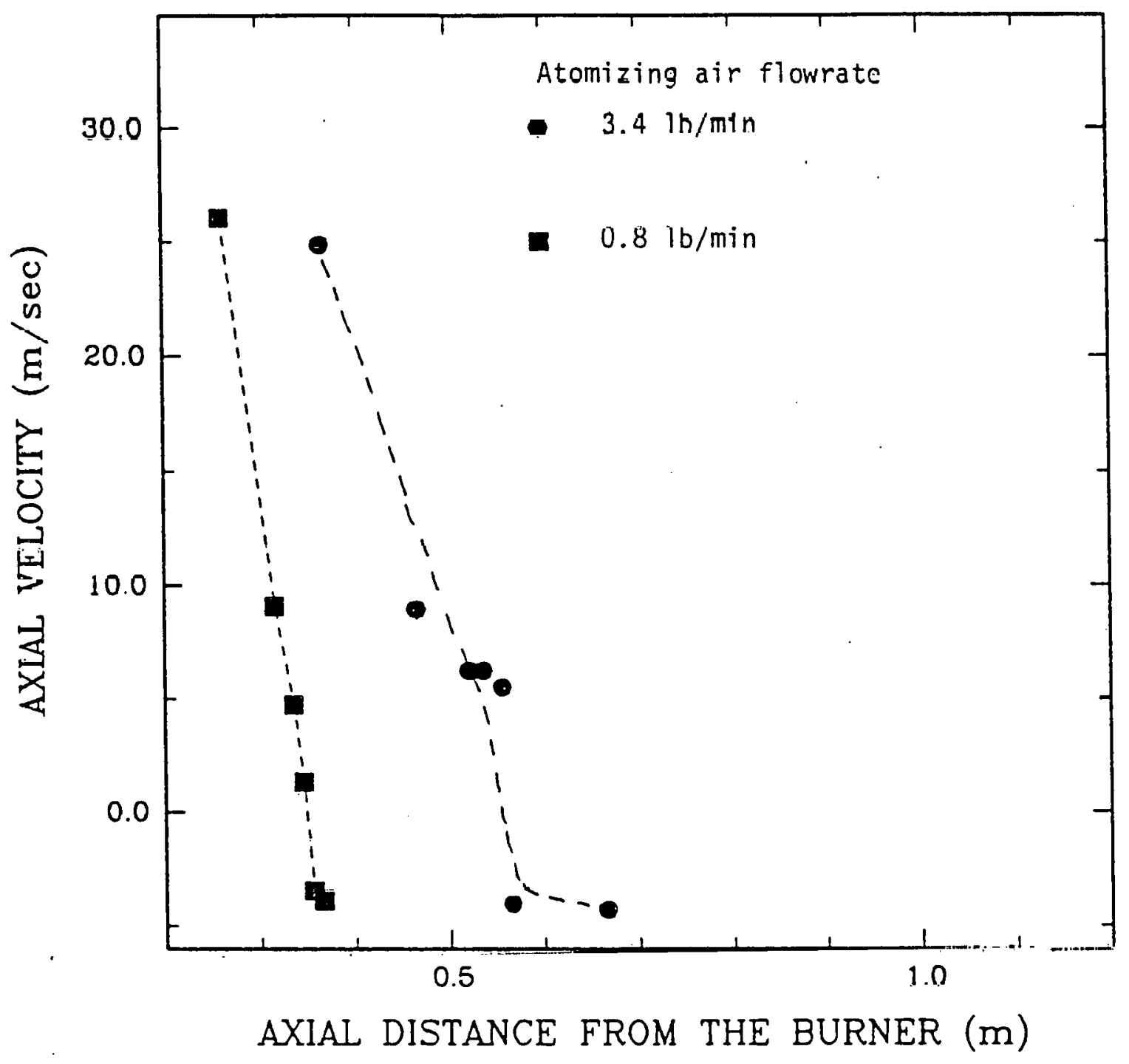

Figure 4.3 The effect of atomizing air flowrate upon axial velocities on the jet axis in a cold flow experiment corresponding to the conditions of a 0.7 MW flame condition 


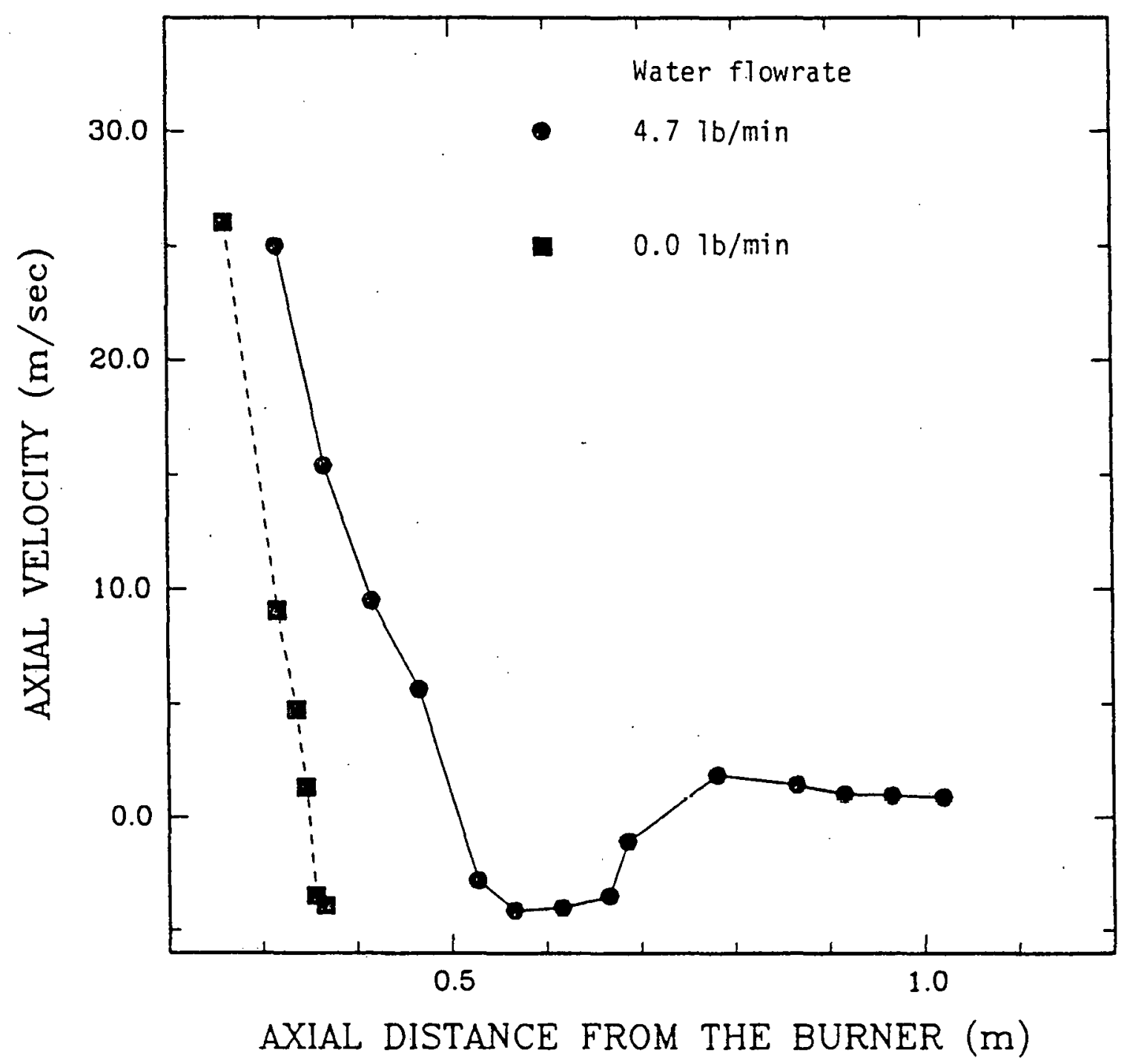

Figure 4.4. The effect of water injection upon axial velocities on the jet axis in a cold flow experiment corresponding to the conditions of a $0.7 \mathrm{MW}$ flame 
atomizing airflow and causes the stagnation point to move further downstream, and to slow the mixing of $\mathrm{CO}$ with the combustion air (Figure 4.5).

The results of the "fuel/air" mixing study have to be viewed in the context of the conflicting requirements for high momentum of the atomizing airflow to ensure good atomization on the one hand, and for reduced axial velocities of the fuel-atomizing air mixture so as to maintain the position of the upstream stagnation point of the IRZ sufficiently near the hurnar in ensure good flame stability, on the other. When a hollow cone wide angle spray ( $\alpha \geq 30 \%$ ) is used these conflicting conditione oan bc satisfied, except that care has to be taken to avoid impingement of the CWF on combustor walls. For narrow angle solid cone sprays - as in this study - a higher degree of swirl in the combustion air is necessary, as a result of which an annular recirculating flow develops between the fuel spray and the swirling combustion air jet ${ }^{8}$. 


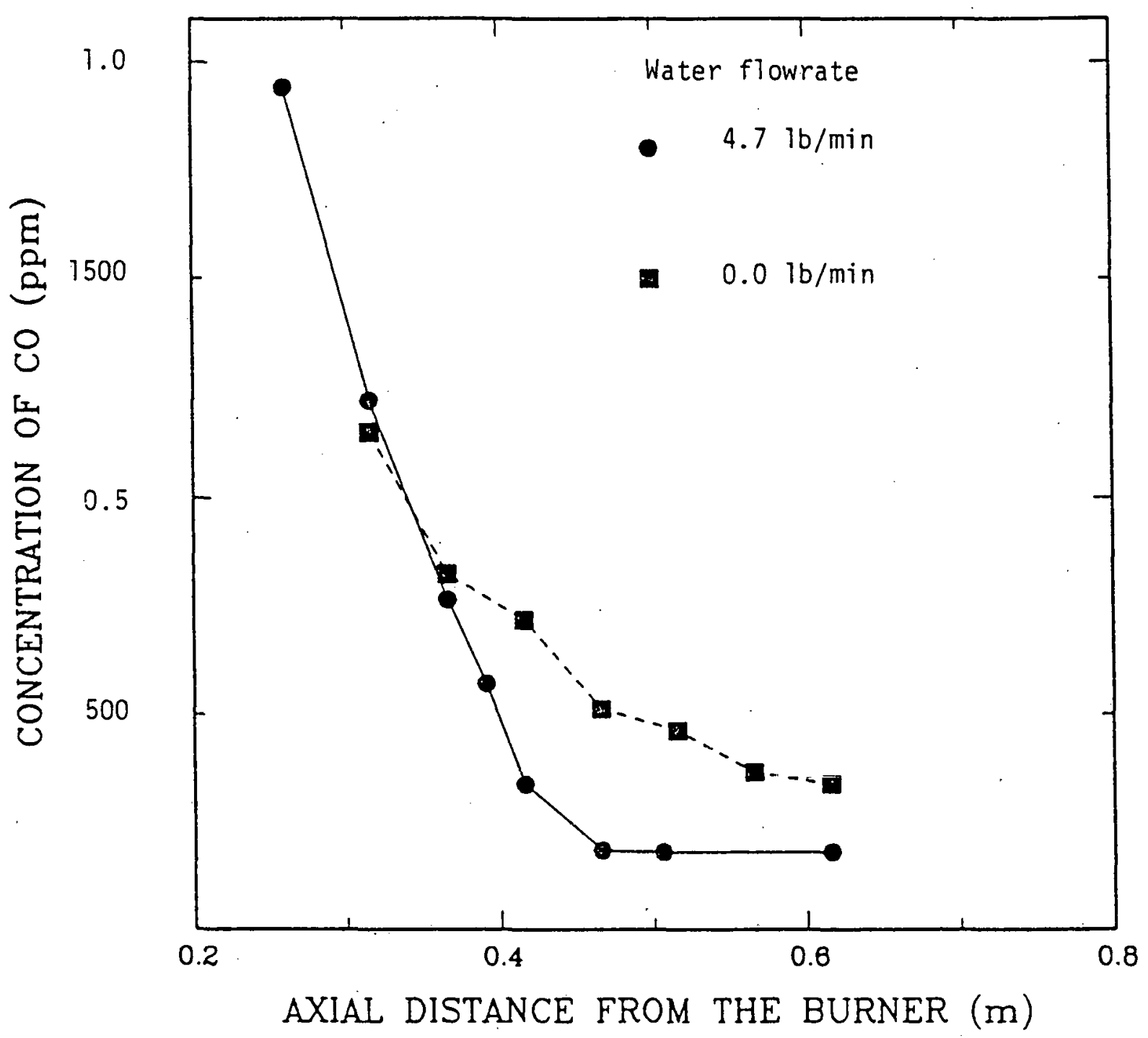

Figure 4.5 The effect of water injection upon the decay of co on the jet axis in a cold flow experiment corresponding to the conditions of a $0.7 \mathrm{MW}$ flame. 


\section{Section 5}

\section{Flame Studies}

\section{Scoping Experiments}

A series of experiments was carried out to find the burner operating variables (Figure 5.1) such as swirl degree, position of atomizing gun relative to the burner quarl and ratio of atomizing air and fuel flow rates, that will produce a stable flame with a minimum ignition delay. Relative flame stability was characterized by the distance of the flame front from the burner and by the presence or lack of low frequency oscillations of the flame front. Visual observation of the flame front was made while varying the above mentioned parameters. In Table 2.3 the input conditions of the two detailed flame characterization studies are listed.

\section{Results}

The data obtained in the two flames studied are 1isted in Tables B.1B.A. In Tables B.1. Alul B.2 cencerline gas temperature, axial velocity, gaseous and solids species concentrations are listed. In Tables B.3 and B.4, radial profiles of the above mentioned variables are given. The results 1isted in Tables B.1-B.2 are also shown in Figures 5.2-5.8.

\section{Flame Structure}

The flow and mixing pattern in the experimental flames (Fig. 5.9) is dominated by two major recirculation zones: one on the flame axis and another external to the burner airflow near the furnace wall. The central recirculation zone is the consequence of the strongly swirling burner air flow. The combination of the swirling air and the divergent burner exit (quarl) result in an adverse pressure gradient (rising pressure in the 


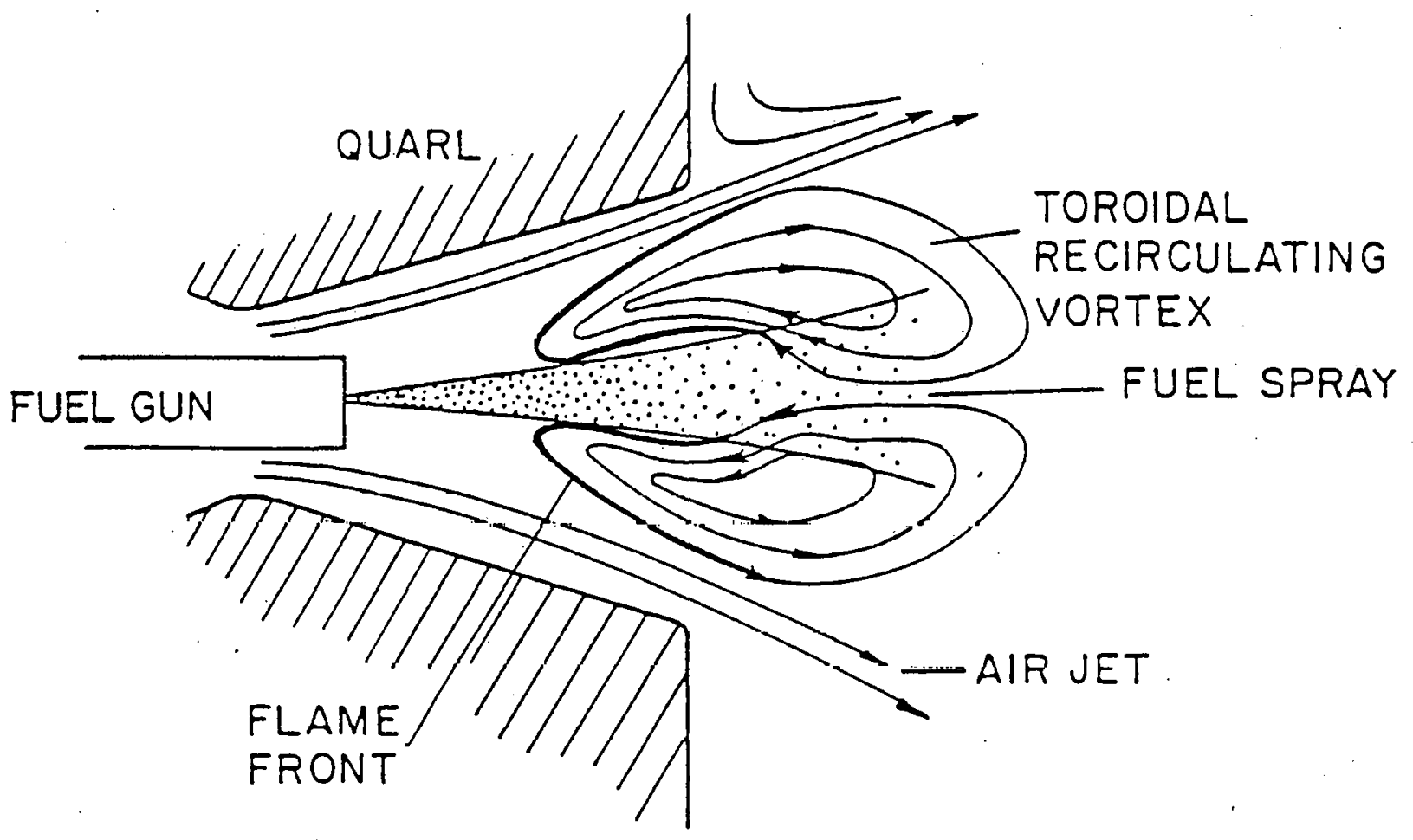

Figure 5.1 Schematic of the combustion research facility burner assembly 


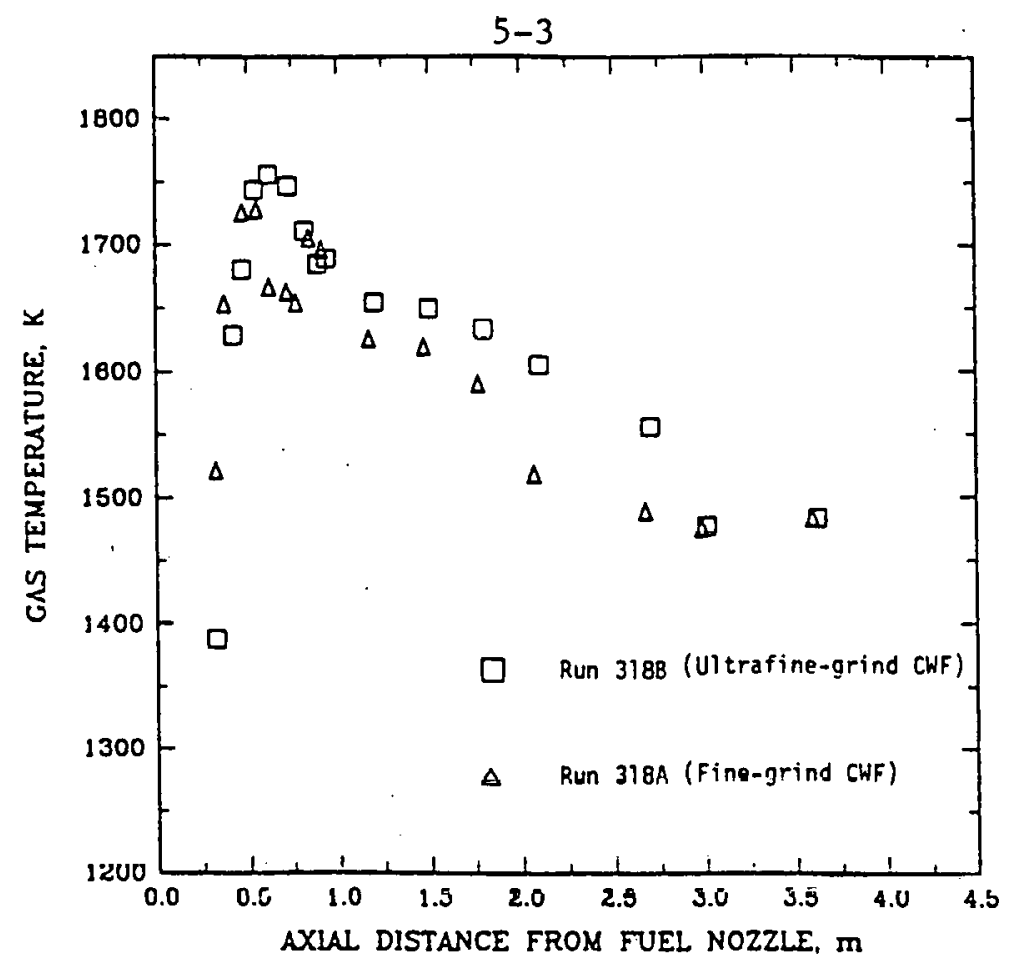

Figure 5.2 Gas temperature profile on furnace axis in flames $318 \mathrm{~A} \& \mathrm{~B}$

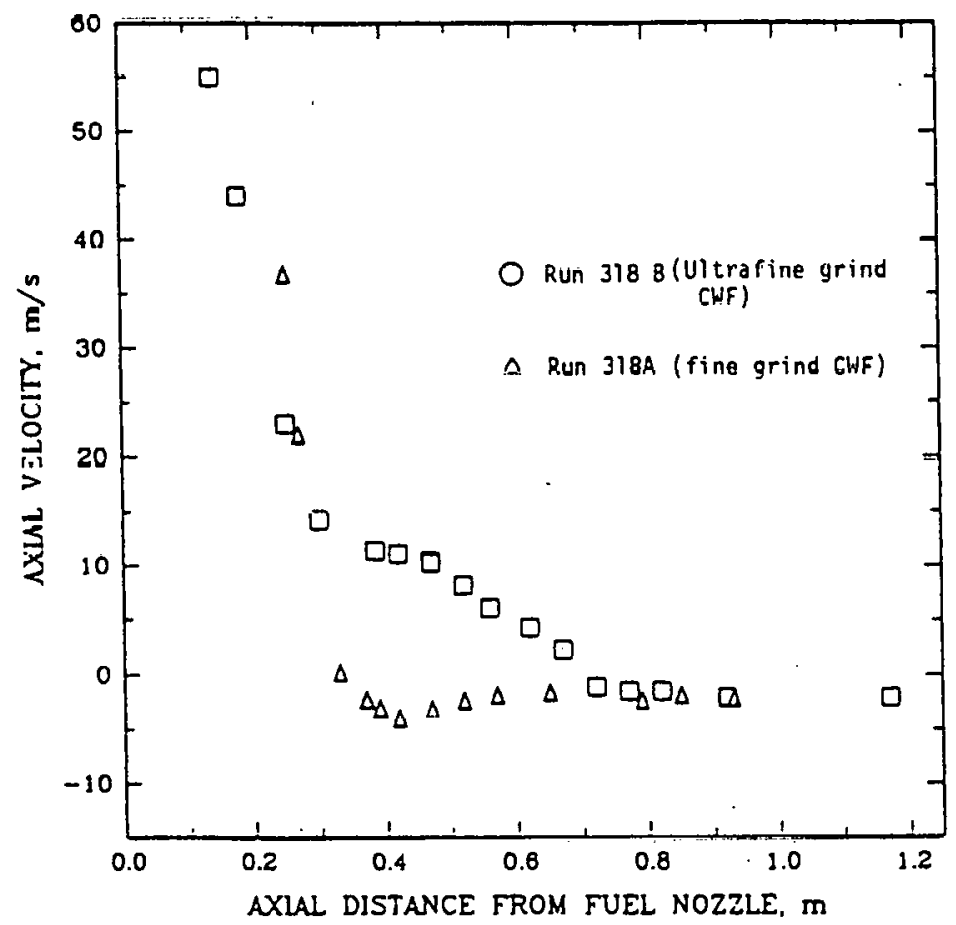

Figure 5.3 Axial velocity profile on furnace axis in flames $318 \mathrm{~A} \& \mathrm{~B}$ 


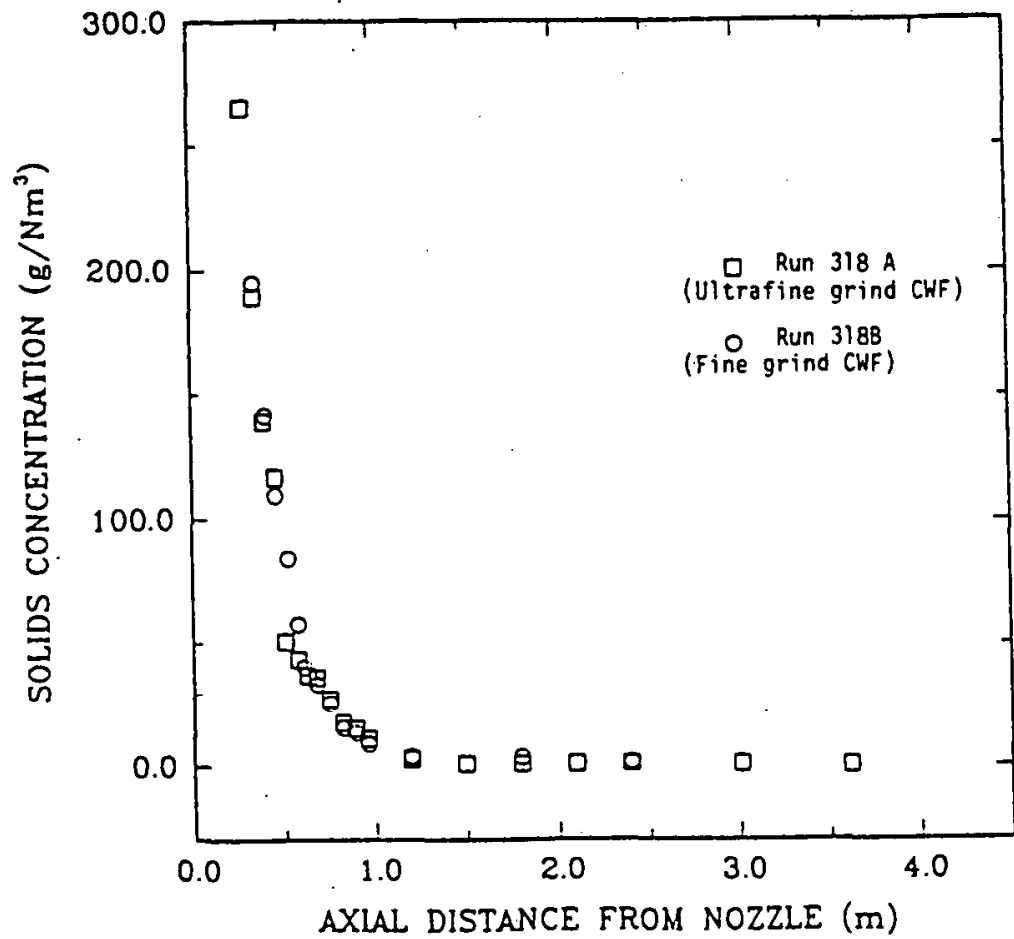

Figure 5.4 Concentration profile of solids on furnace axis in Flames $318 \mathrm{~A} \& \mathrm{~B}$

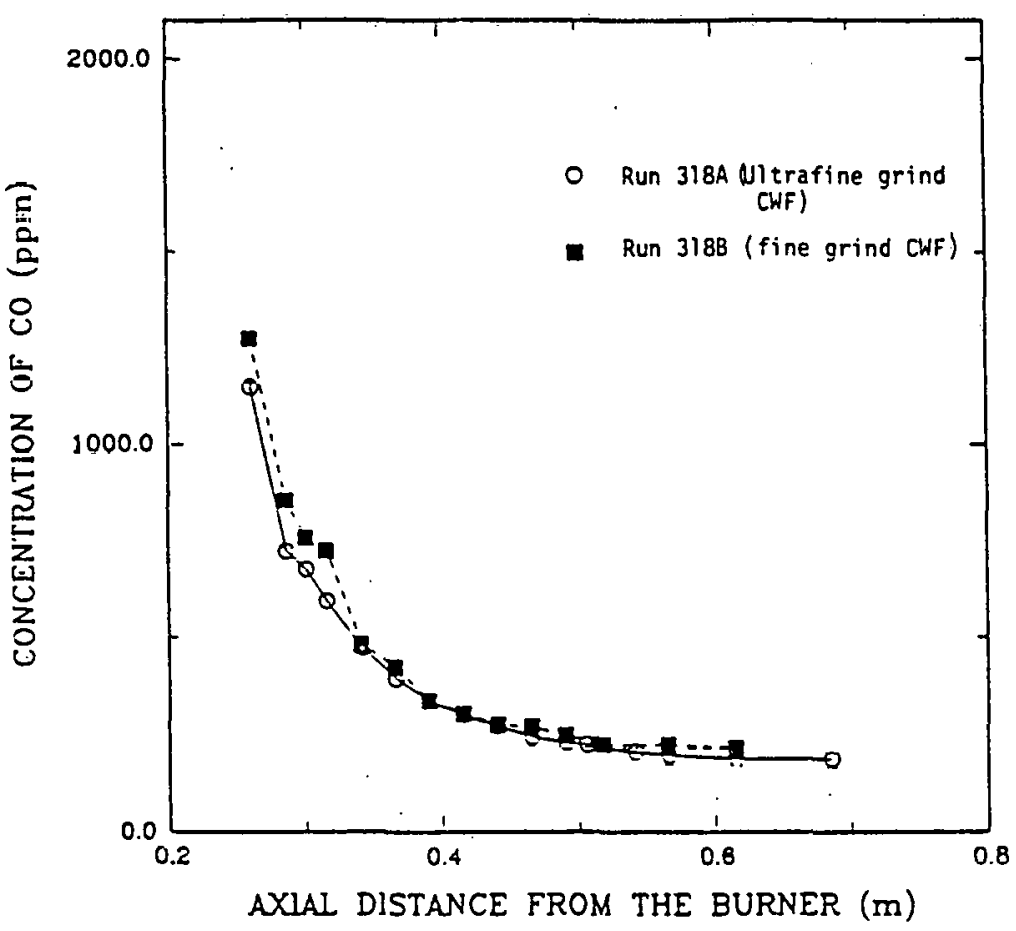

Figure 5.5 Concentration profile of $\mathrm{CO}$ on furnace axis in Flames $318 \mathrm{~A} \& \mathrm{~B}$ 


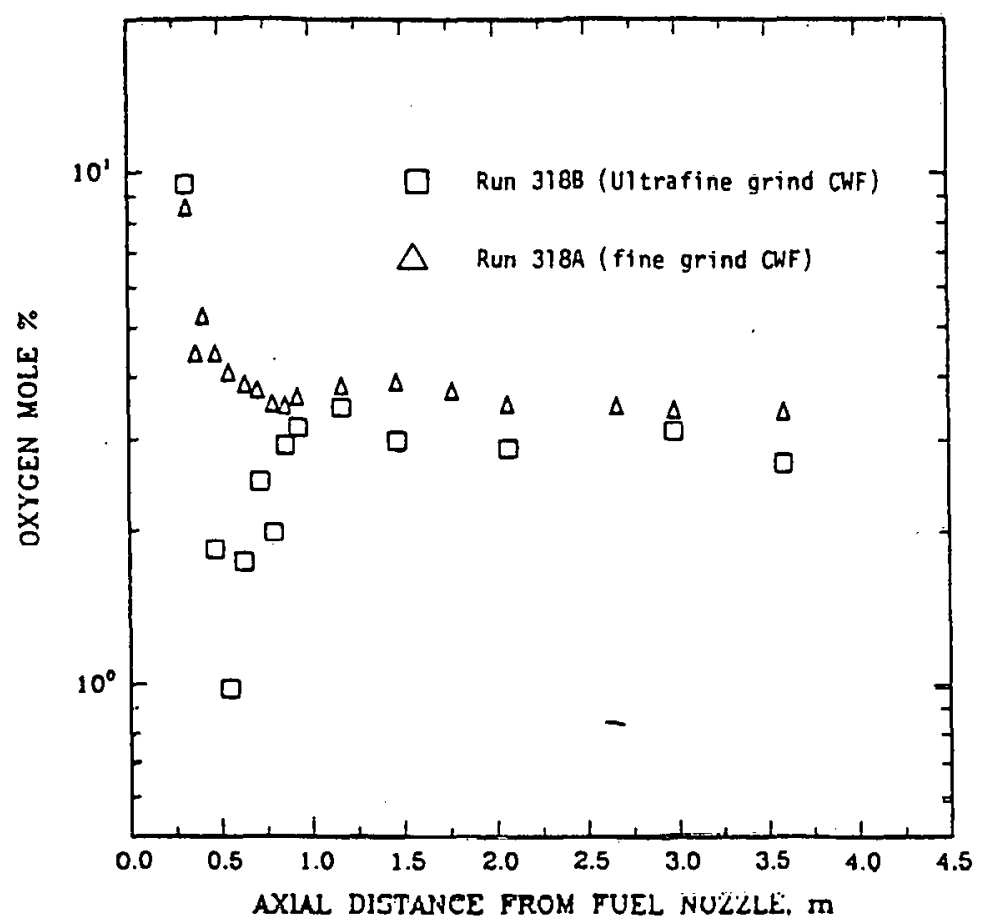

Figure 5.6 Concentration profile of $\Pi_{2}$ on furnace axis in Flames $318 \mathrm{~A} \& \mathrm{~B}$

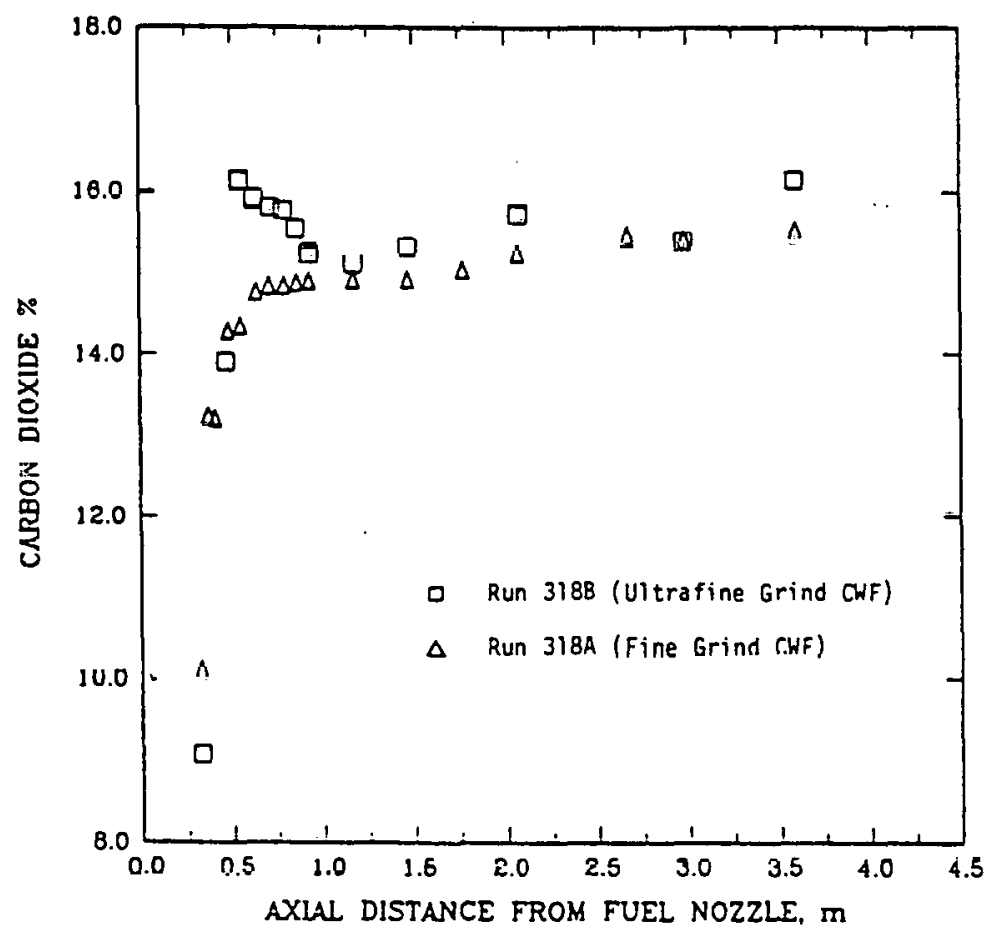

Figure 5.7 Concentration profile of $\mathrm{CO}_{2}$ on furnace axis in Flames $318 \mathrm{~A} \& \mathrm{~B}$ 


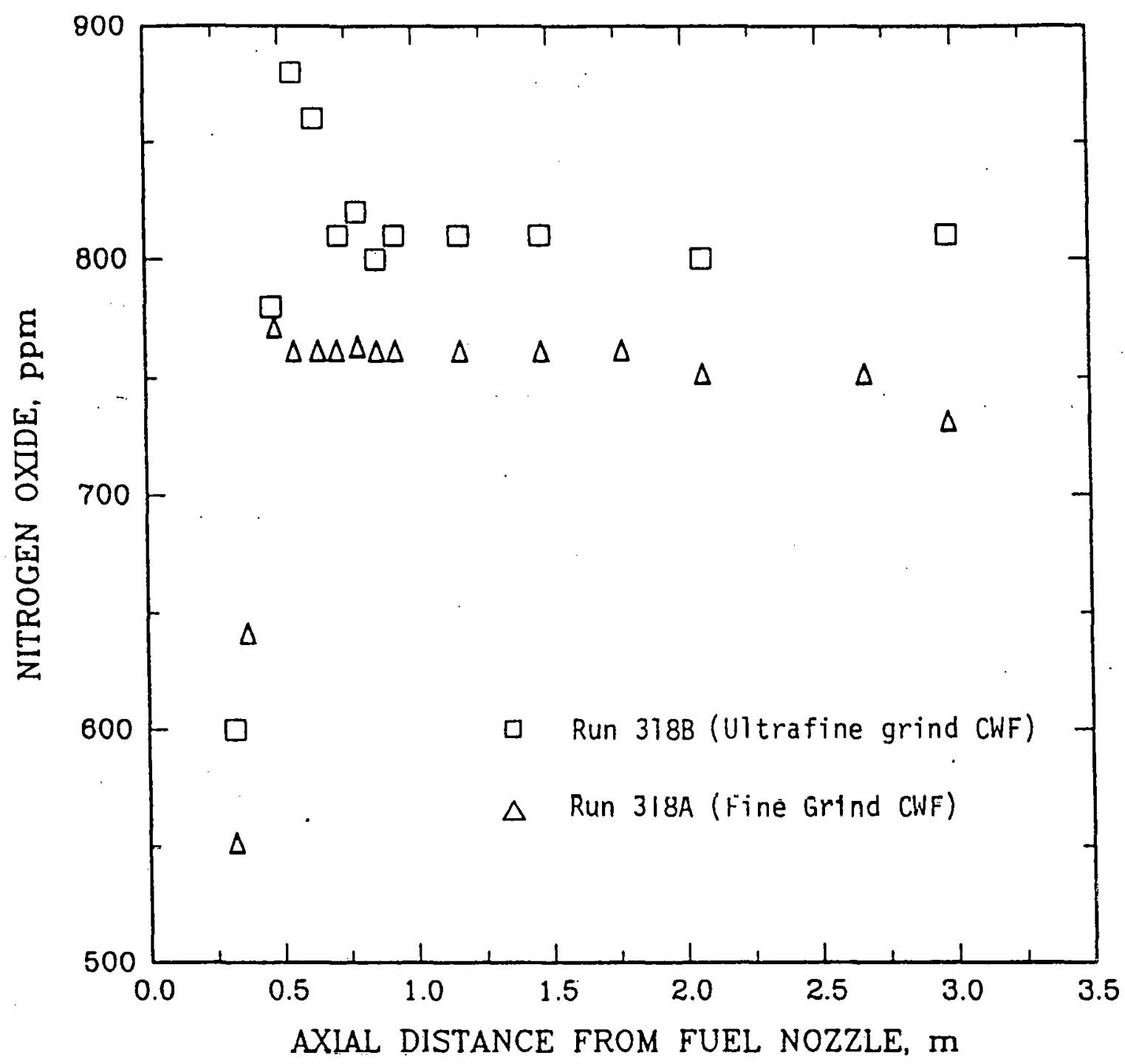

Figure 5.8 Concentration Profiles of $\mathrm{NO}_{\mathrm{X}}$ on Furnace Axis in Flames $318 \mathrm{~A} \& \mathrm{~B}$ 


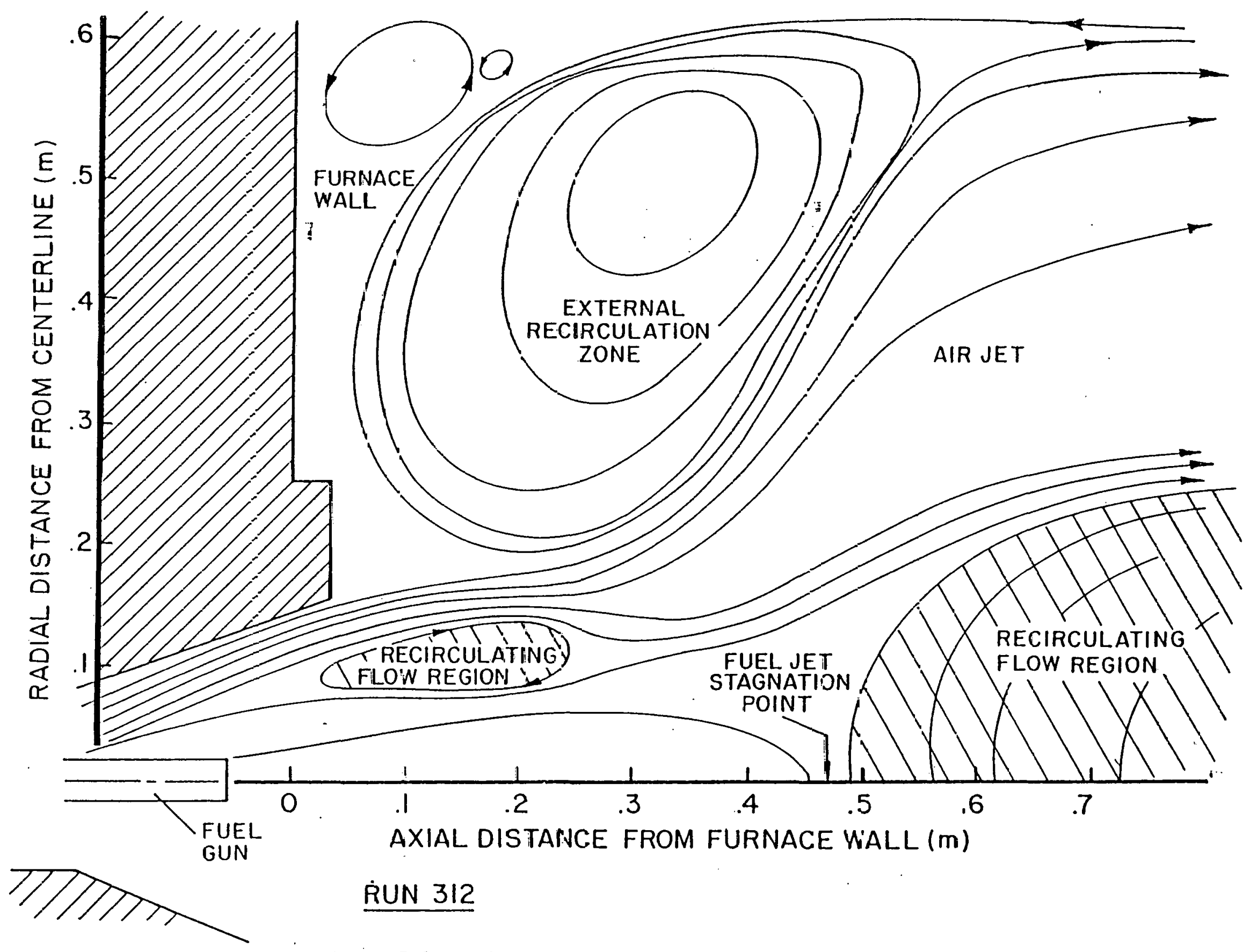

Figure 5.9 Scheratic of the flow field of a highly swirling 
direction of the flow) along the flame axis which causes a reverse flow to form when the swirl degree exceeds a critical value. The external recirculation zone is due to the confinement of the burner air and fuel jets by the furnace walls. Both recirculation zones play important roles in the stabilization of the flame and have effects also on the carbon conversion efficiency in the combustor. The angle and momentum of the fuel spray has to be matched with the flow pattern produced by the burner air flow. In the reported experiments a narrow angle (40-60 full angle) air blast atomizer was used. The fuel spray was therefore injected into the central recirculation zone which caused rapid deceleration of the droplets and speeded up their drying and devolatilization.

The spatial distribution of the major stable species concentrations in the flame region close to the burner together with those of velocity and gas temperature are the major elements of the flame structure. The species concentration traverses (Figs. 5.10-5.11) show high $C O$ and solid carbon concentrations on the flame axis, surrounded by a fuel lean envelope due to the burner air flow. Radially further away from the flame axis $\mathrm{O}_{2}, \mathrm{CO}_{2}, \mathrm{CO}$ and NO concentrations are similar to those found at the end of the flame. This cimilarity of the gas composition is due to the external recirculation surrounding the flame; fully burned combustion products from the tail end of the flame are entrained into the burner air flow near the burner exit.

While the above mentioned structure applies to both of the flames studied in our detailed investigations, there were differences in the flow and mixing pattern due to the differences in the coal particle size distribution and the viscosity and hence atomization fineness of the two coal-water fuels. 


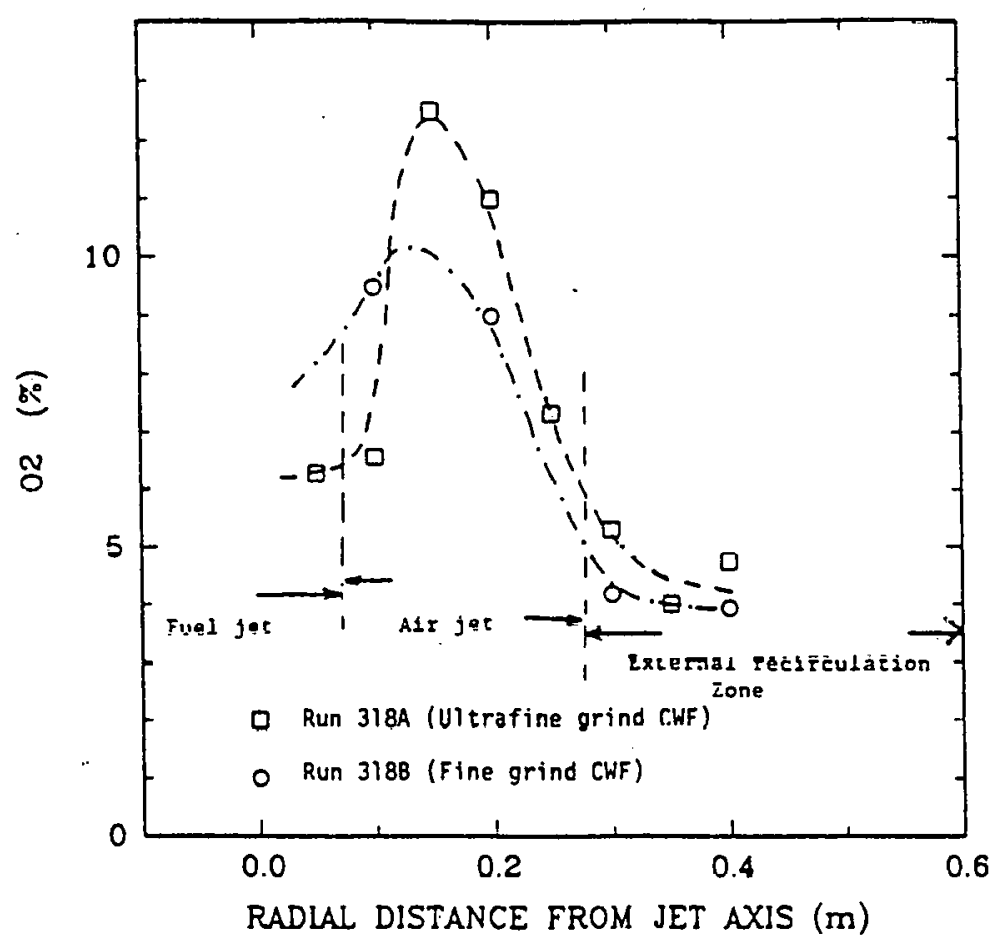

Figure 5.10 Radial profiles of $\mathrm{O}_{2}$ at an axial distance of 0.35 meters from the burner in Flames $318 \mathrm{~A} \& \mathrm{~B}$.

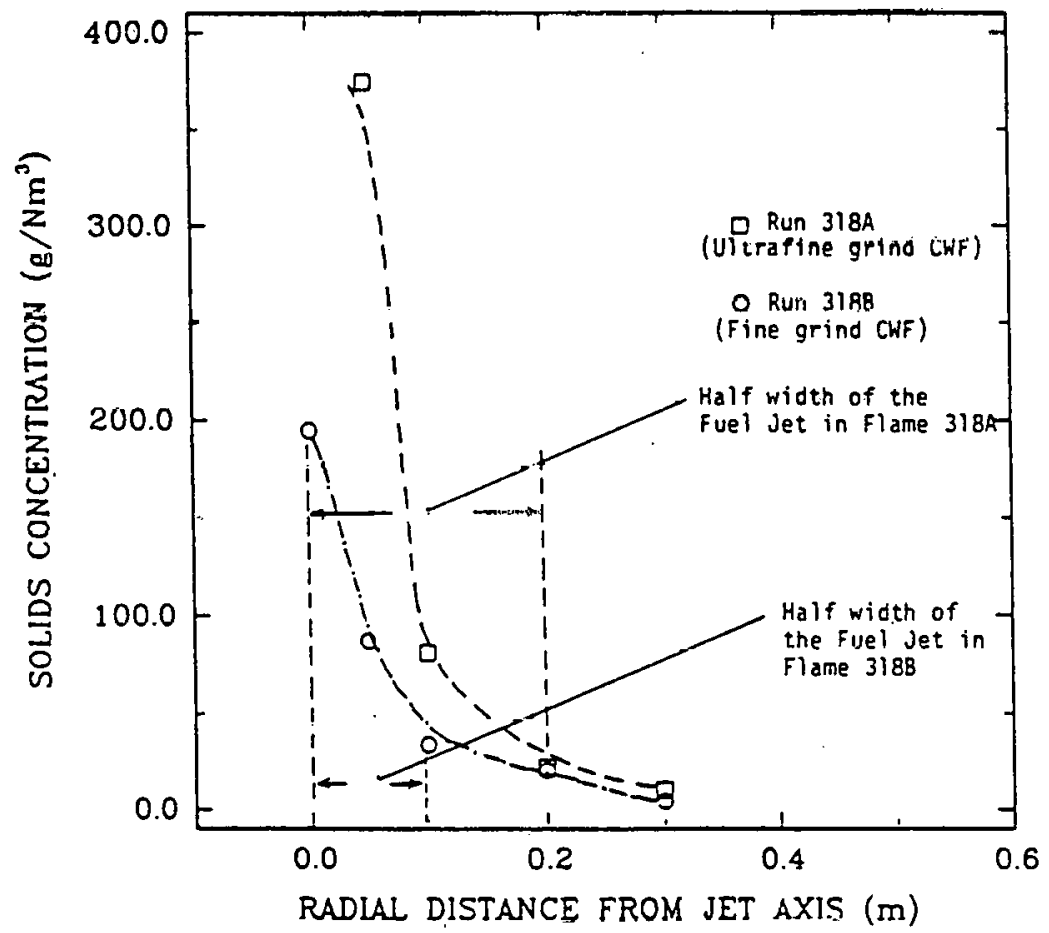

Figure 5.11 Radial profiles of solids concentration at an axial distance of 0.35 meters from the burner in Flames $318 \mathrm{~A} \& \mathrm{~B}$ 
The ultrafine CWF had a higher apparent viscosity and gave therefore a spray of somewhat coarser drop size distribution. This was compensated for by the finer coal particle size distribution with the result that the ultrafine CWF spray had a wider spray angle $\left(-60^{\circ}\right.$ against $\left.40^{\circ}\right)$ and a less penetration into the central recirculation zone (C.R.Z.) on the flame axis than the ARC fine-grind CWF spray (location of C.R.Z. = .35 m vs. $0.75 \mathrm{~m}$ from the fuel nozzle).

The wider spray angle of the ultrafine CWF resulted in the establishment of central recirculation zone further upstream, nearer to the burner. As a consequence of this the temperature rise on the axis of the ultrafine CWF flame was steeper, a larger mass fraction of the coal was devolatilized near the burner and the flame front is situated closer to the burner.

The reduced ignition distance in the ultrafine CWF flame, has not resulted in better carbon conversion efficiency. This is because the carbon conversion efficiency is strongly dependent upon the quality of atomization (Figure 5.14) which was poorer in the ultrafine CWF due to its higher viscosity for the same solids loading (548).

The degree of carbon conversion (burnout) along the axis of the two experimental flames is plotted in Fig. 5.12. Figure 5.13 shows scanning electron micrographs of samples taken at a distance of $3.62 \mathrm{~m}$ from the burner. In Figures 5.14 and 5.15 size distributions of particles collected close to the burner and at the end of the flame are compared for the effect of the two experimental fuels.

The particle size distributions in Figure 5.15 provide an explanation for the apparent contradiction between the reduced ignition delay but poorer burnout in the ultrafine CWF. As can be seen in Figurc 5.15 the ultrafine 


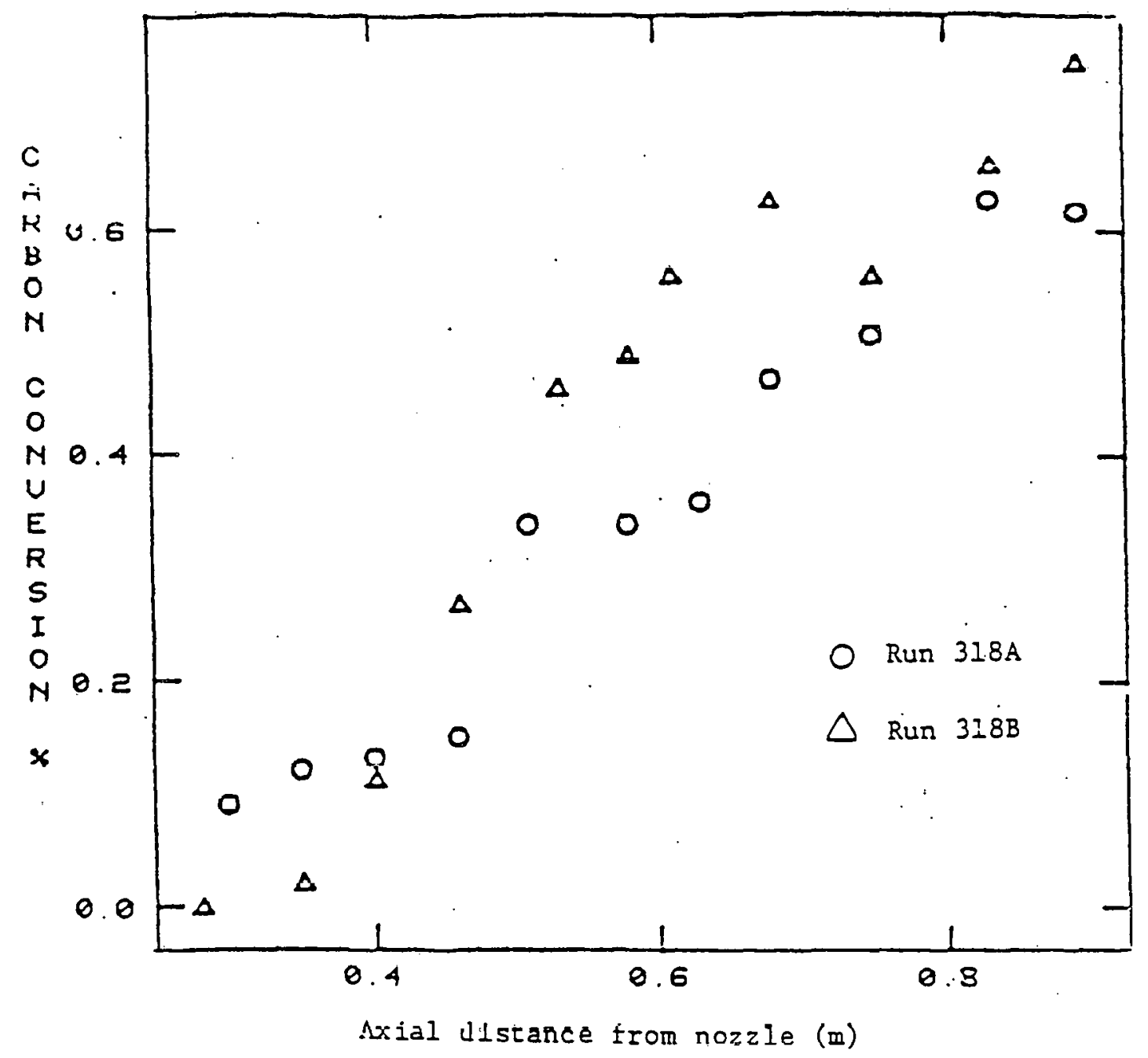

Figure 5.12 Carbon conversion efficiency of 75-90 $\mu \mathrm{m}$ particle size cut in Flames $318 \mathrm{~A} \& \mathrm{~B}$ 


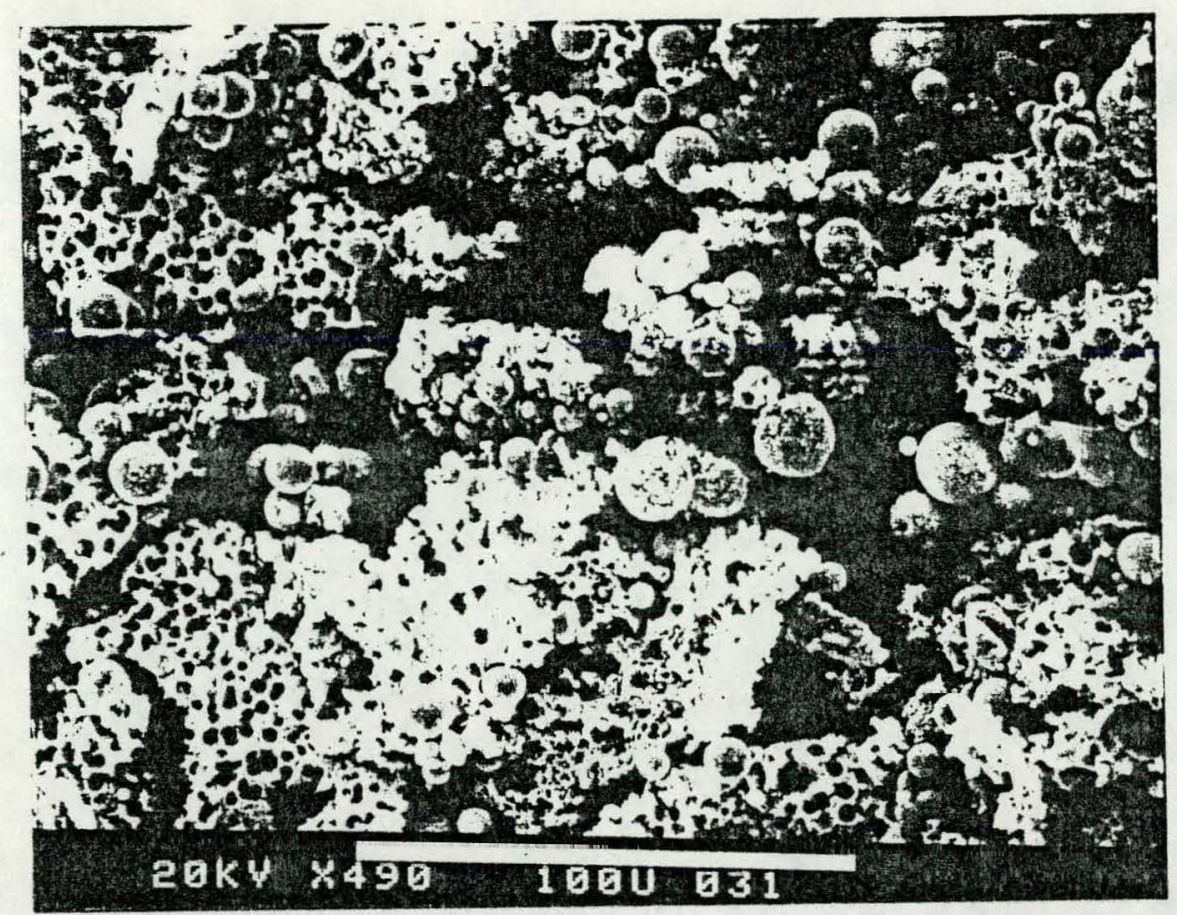

(a) Particles Smaller than $38 \mu \mathrm{m}$ in F.lame $318 \mathrm{~A}$.

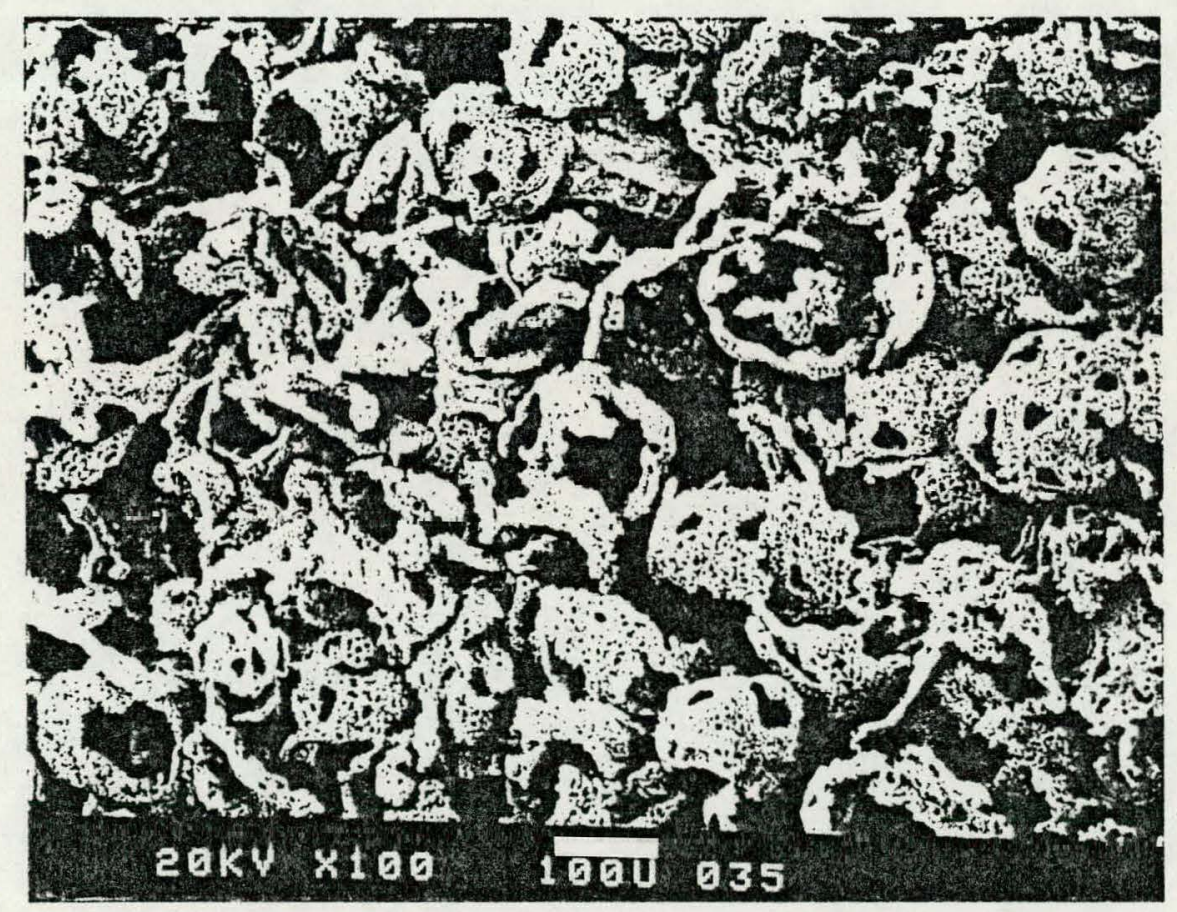

(b) Particles smaller than $150 \mu \mathrm{m}$ in Flame 318A.

Figure 5.13 SEM Thotographs of Char and $\Lambda$ sh Particles Collected at a Distance of 3.62 meters from the Nozzle in Flames $318 \mathrm{~A} \& \mathrm{~B}$. 


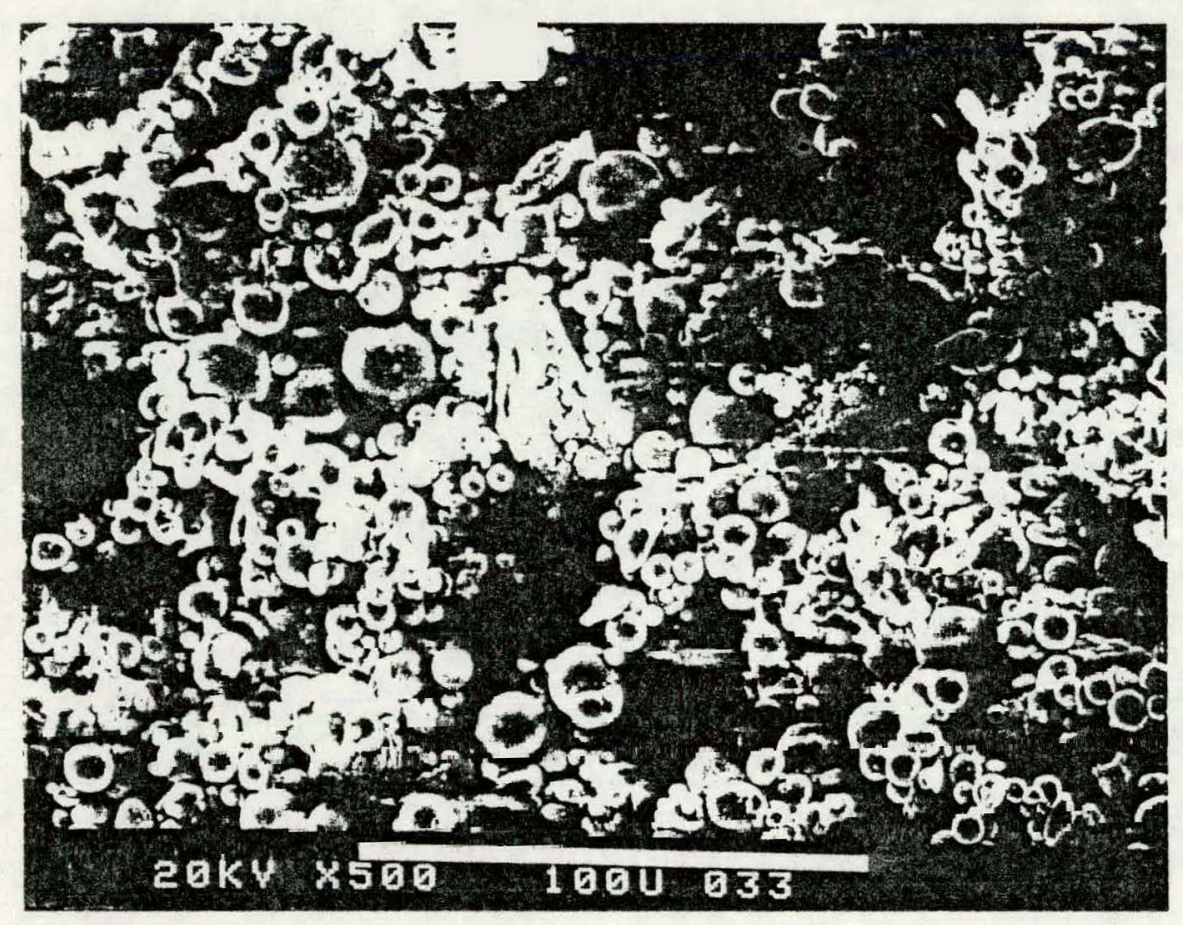

(c) Particles Smaller than $38 \mu \mathrm{m}$ in Flame $318 \mathrm{~B}$.

Figure 5.13 (Continued). SEM Photographs of Char and Ash Particles Collected at a Distance of 3.62 meters from the Nozzle in Flames 318A \& B. 

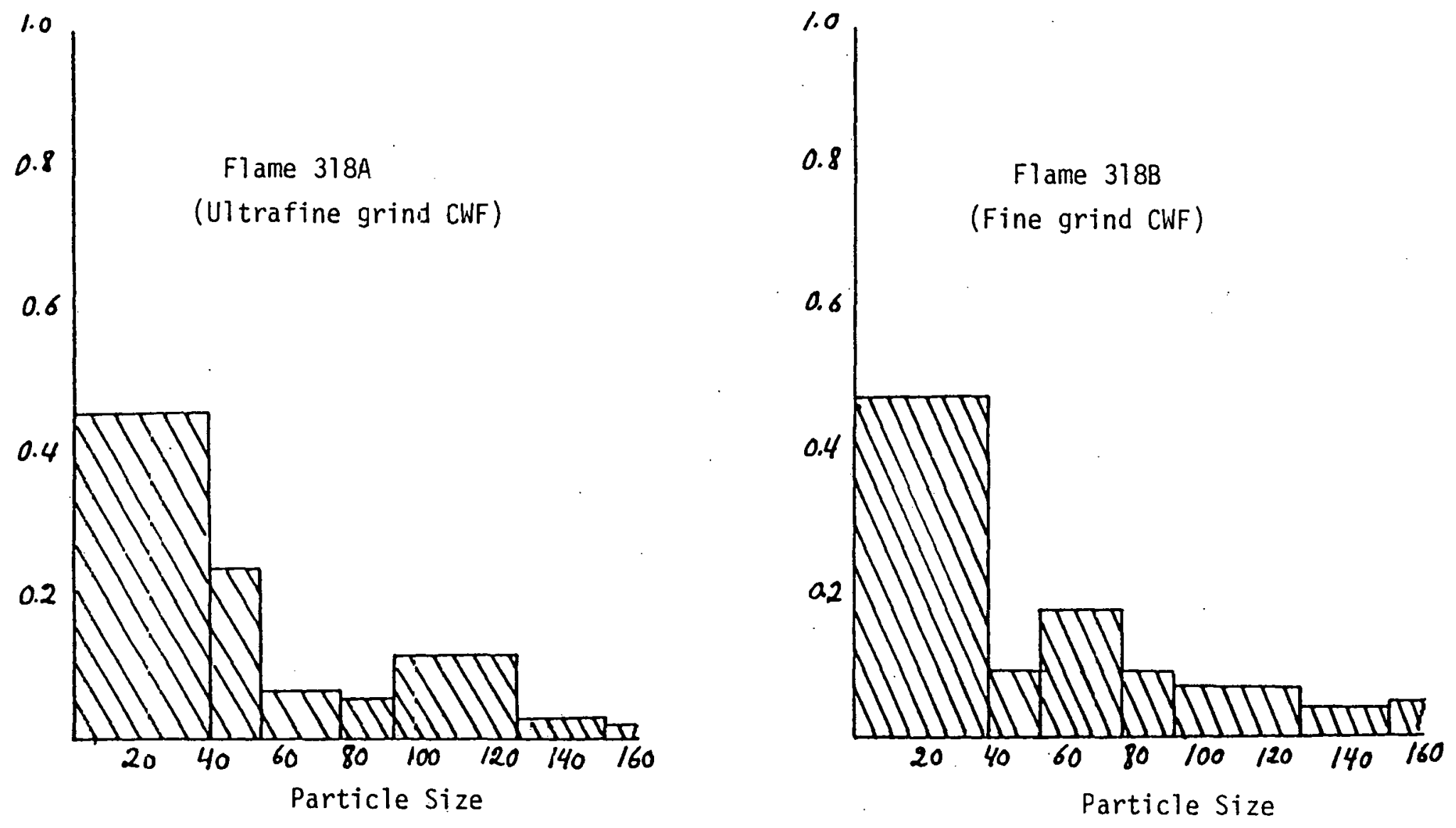

Figure 5.14 Size Distribution of Particles Collected at a Distance of $0.27 \mathrm{~m}$ from the Nozzle in Flames $318 \mathrm{~A} \& \mathrm{~B}$. 


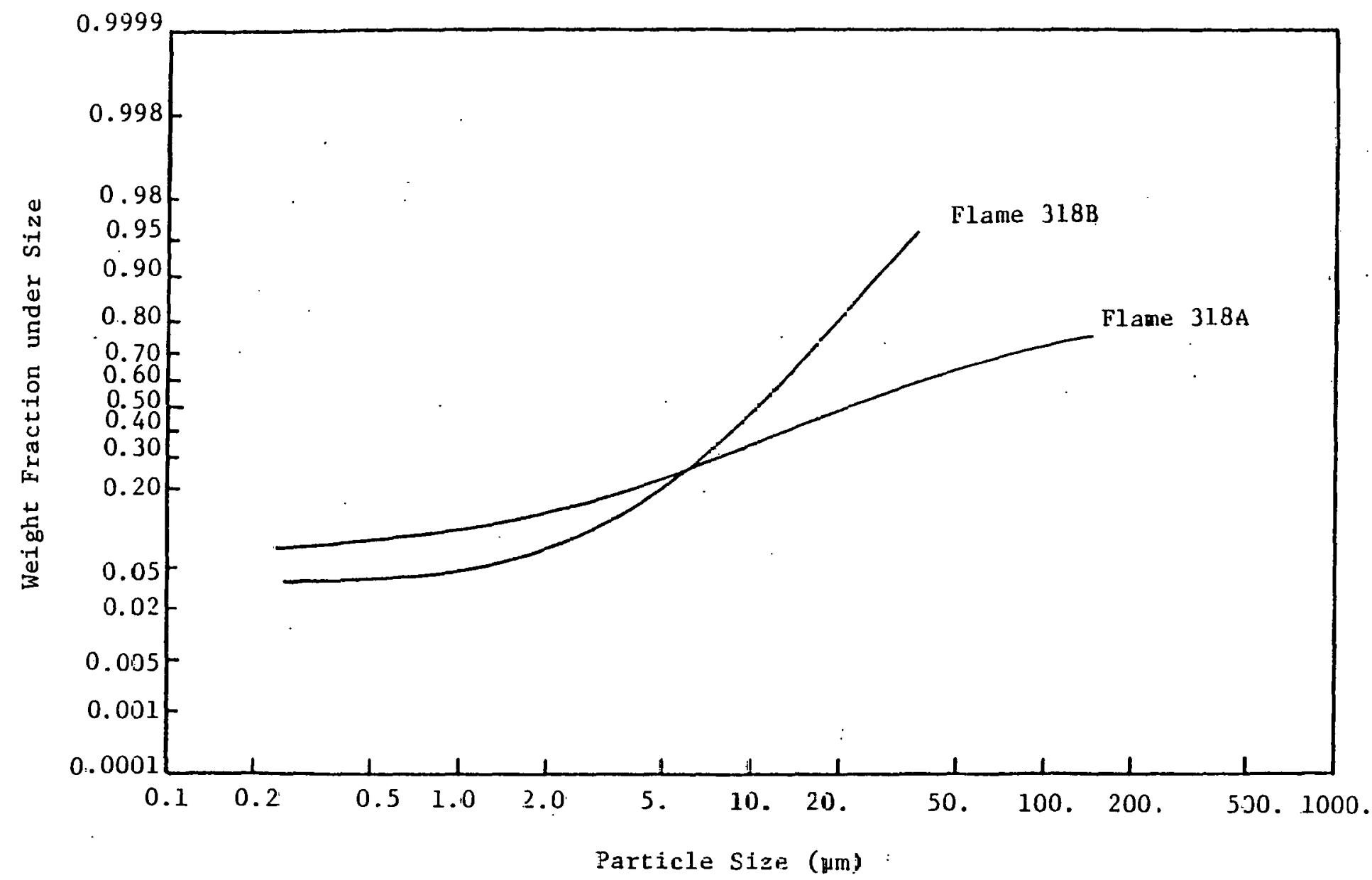

Figure 5.15. Mass Fraction of Differen: Sized Particles Collected at a Iistanze of 3.0 maters from the Burner in Flames 318A \&B. 
CWF gives a finer fly ash particle size distribution in the size range smaller than $6 \mu \mathrm{m}$. Although this is the case, a larger fraction of - particles in excess of $50 \mu \mathrm{m}$ are present in this flame than does the fine grind CWF flame. Particles larger than $50 \mu \mathrm{m}$ are usually carbonaceous; their relative abundance in the ultrafine CWF explains the poorer carbon conversion efficiency obtained with this flame.

In conclusion, the larger proportion of the fine particles in the ultrafine CWF helps in increasing the volatile yield and improves ignition, but the coarser atomization produces large droplets and hence, larger agglomerated char particles with the consequence of poorer char burnout at the end of the flame. 
Section 6

Task 4. Reduction of NO$\times$

Introduction

During the first stage of our work under this DOE-METC program, experiments were carried out in the MIT Combustion Research Facility in which CWF flames of $1.6 \mathrm{MW}$ (thermal) input were characterized in detail by in-flame measurements. The fuels used were formulated from a bituminous coal ground to two different finenesses; while the burn-out of these fuels was very good, the $\mathrm{NO}_{\mathrm{x}}$ emission levels were high (>9n! FFm $\left.252.98 \mathrm{O}_{2}\right)$. The research objective of the present series of studies was t.n use staged combustion-air injection for reducing the $\mathrm{NO}_{x}$ emission without any loss in carbon conversion efficiency.

The source of $\mathrm{NO}_{x}$ in coal flames is mainly the organically bound nitrogen in the fuel (FBN). While the rate of fixation of atmospheric nitrogen to form No in high temperature processes is primarily temperature dependent ("thermal NO"), the oxidation of FBN is a weak function of temperature; its rate is primarily dependent upon the local stoichiometry. In fuel-lean atmospheres the FBN converts to NO with high efficiency, while it can be made to form molecular nitrogen and hence to form less No in fuel-rich flames (Fig.6.1). Accordingly the design protocol for $\mathrm{NO}_{\mathrm{X}}$ emission reduction suggests a fuel-rich high-temperature primary flame zone with sufficient residence time for most of the FBN to evolve with coal volatiles. The fuel-rich primary flame zone is then followed by the injection of the rest of the combustion air. As a result of heat extraction from the flame and fast mixing of the secondary air with the products of the fuel-rich stage the temperature in the lean stage ought to stay below the level at which "thermal NO" is formed. However, the gas temperature has to 


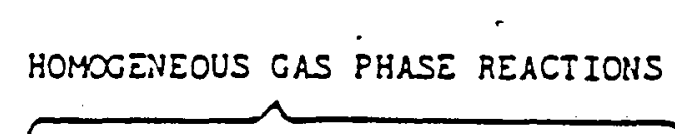

HETEROCENEOUS

REACTIONS

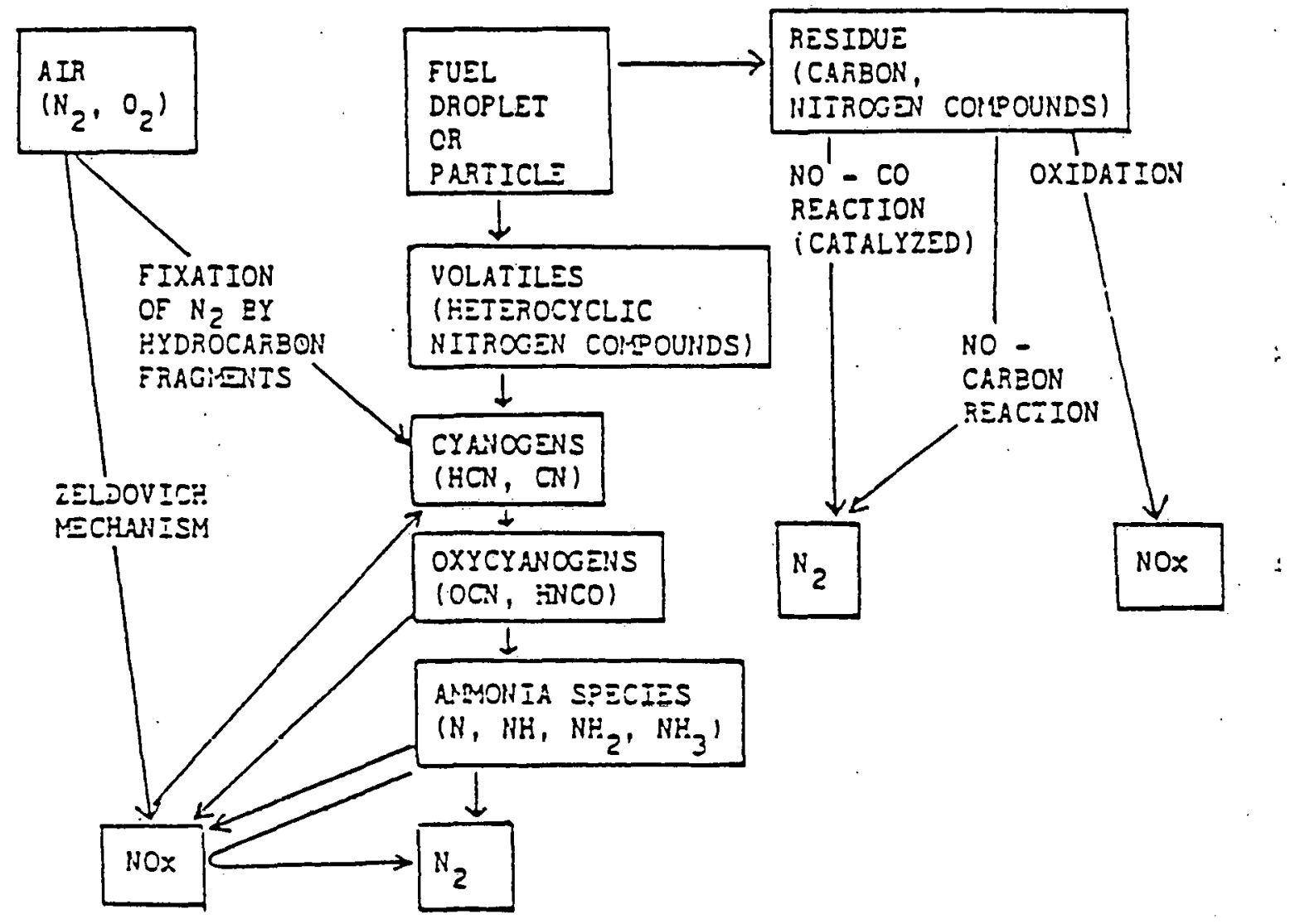

Figure 6.1 Mechanistic pathways of nitrogen oxides formation in fossil fuel combustion 
be sufficiently high for the combustible gas and solids to burn to completion.

\section{Experimental}

The experimental fuels used are characterized in Table 2.6, and the experimental input conditions are listed in Table 2.5

\section{Results}

Two out of the three flame conditions gave closely similar results for $\mathrm{NO}_{\mathbf{x}}$ reduction in the flame. In the third case, where the fuel-rich stage residence time was reduced relative to the other two flames, the $\mathrm{NO}_{\mathbf{x}}$ reduction was less effective. These flames are hest sharacterized by the axial temperatures, gas composition, solids concentration and carbon burnout data which are reported in the discussion section. The two variables which are pertinent to the discussion of these results are the position of the secondary air injection nozzle relative to the burner exit plane and the solids to water ratio in the fuel. The respective positions nf the secondary air injection are shown in Fig. 6.2.

\section{Discussion}

Experimental data obtained by in-flame measurements and analyses of gaseous and solid samples collected at points alning the flame axis are plotted in Figs. 6.3 to 6.7 . The $\mathrm{O}_{2}$ concentration distributions in Fig. 6.3a show that close to the burner, in the "fuel-rich" stage, the mixture is initially lean and becomes steadily richer as volatiles evolve and the fine char particles burn. Following the injection of the secondary air the $\mathrm{O}_{2}$ concentration increases at first, then the excess $\mathrm{O}_{2}$ is used up by reaction with products of the fuel-rich stage, and a decrease of $\mathrm{O}_{2}$ concentration along the flame axis to the exit value of $\mathrm{O}_{2}=2.88$. 

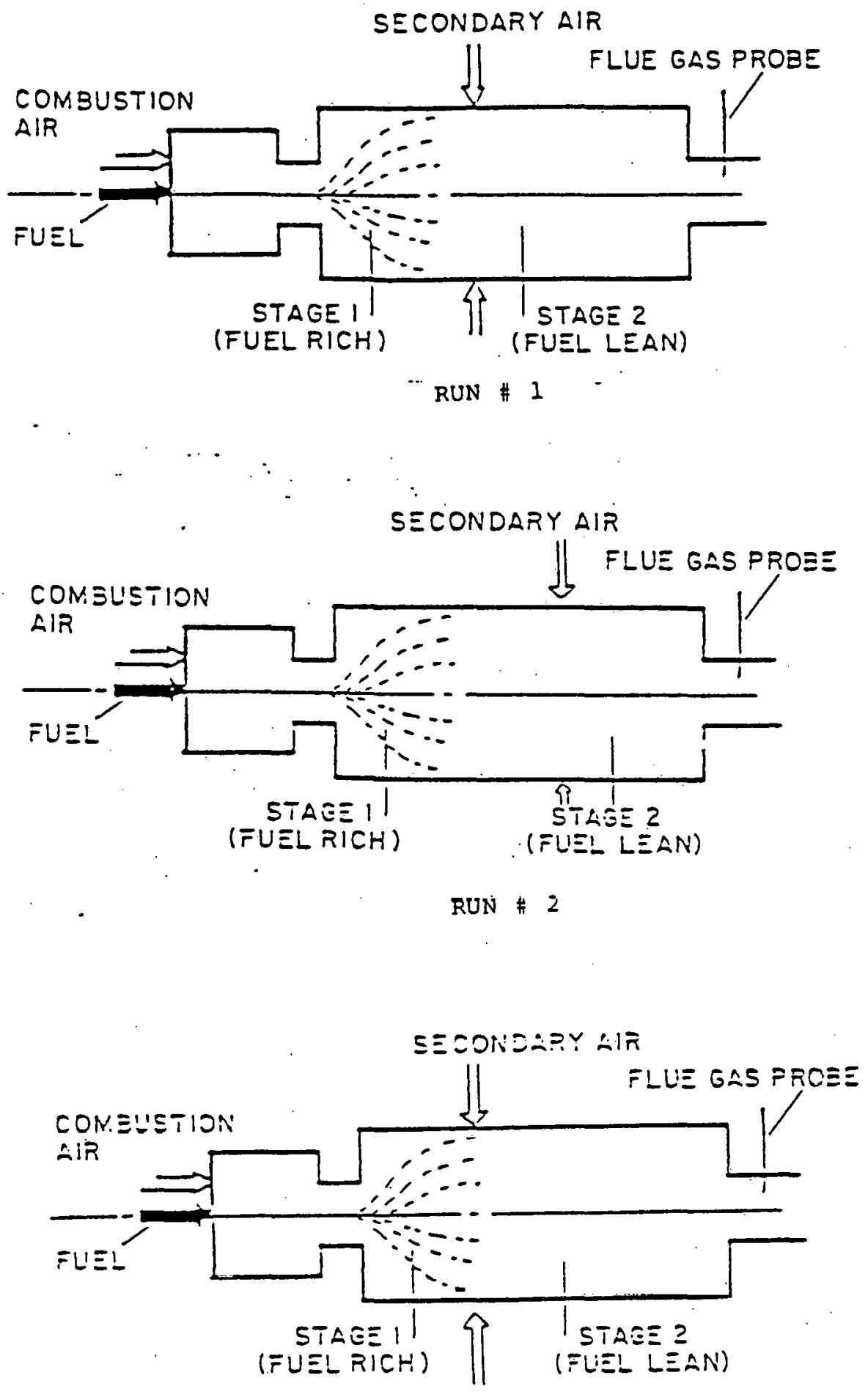

RUN $\# 3$

Figure 6.2 Schematic of the staged combustion configuration used in this study 


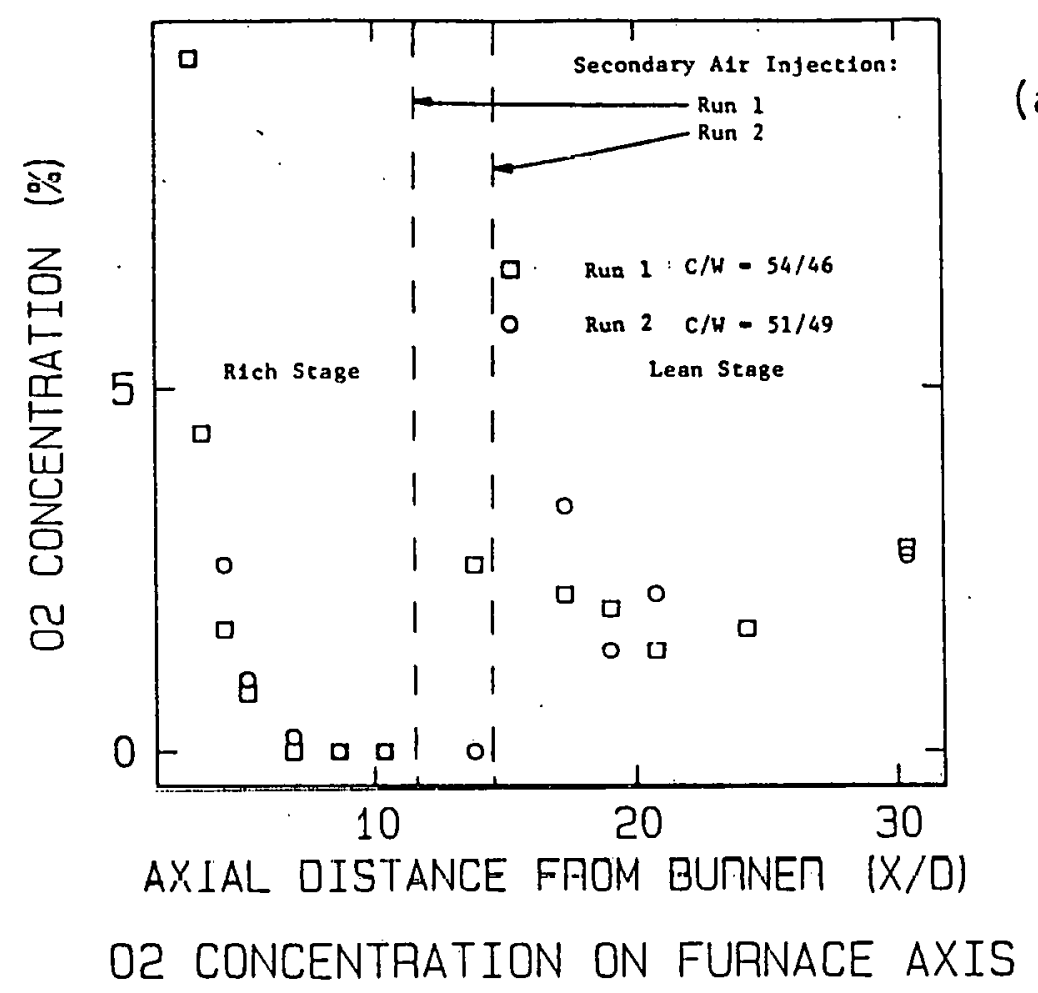

(a)

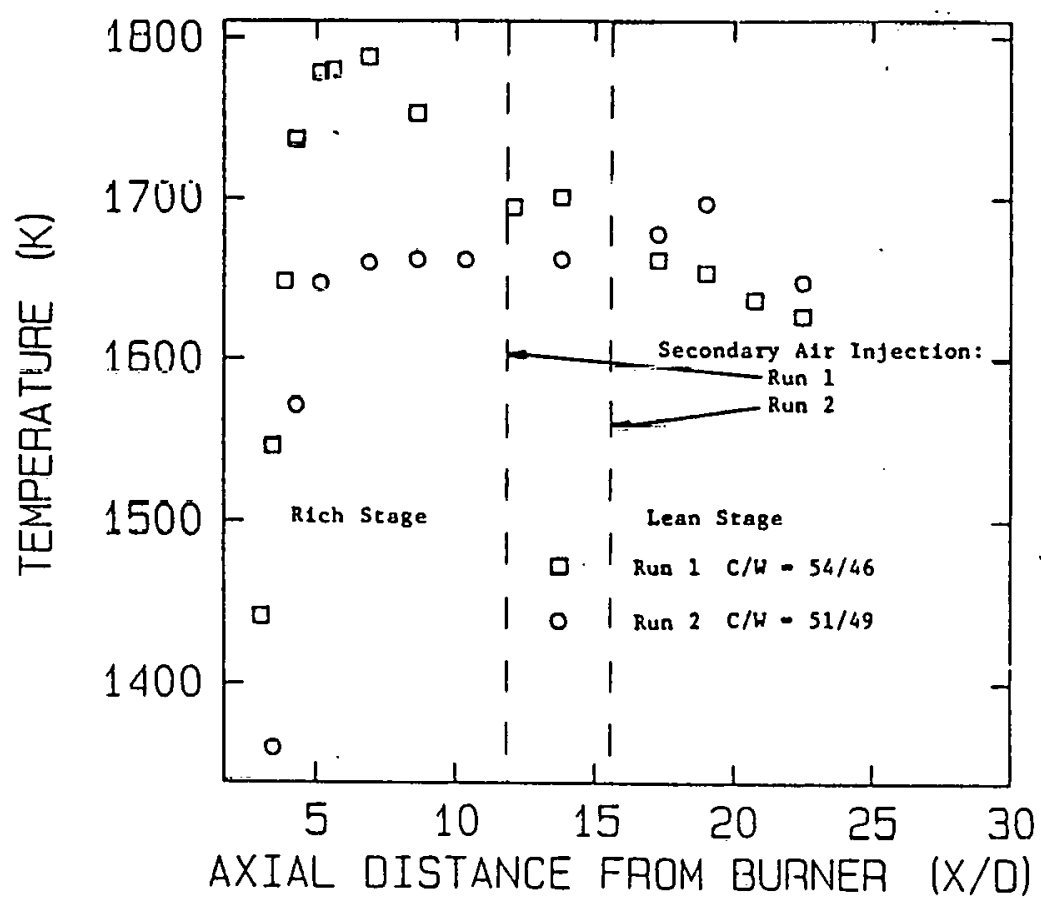

(b)

GAS TEMPERATURES ON FURNACE AXIS

Figure 6.3 (a) The effect of water content of the CWF on $\mathrm{O}_{2}$ concentration

(b) The effect of water content of the CWF on gas Temperatures 
The gas temperature peaks immediately upstream of the secondary air injection and the effect of the increased water content in the CWF for run \#2 can be seen in the reduced value of the peak temperature and the more uniform temperature distribution due to the more prolonged burn-out of the coal.

The volatile fraction of in-flame solids samples and $\mathrm{NO}_{x}$ concentration distribution along the flame are shown in Fig. $6.4(a \& b)$. As the first combustion stage becomes fuel-rich the evolved fuel nitrogen is reduced to $\mathrm{N}_{2}$. Compared to the single stage case, with uncontrolled $\mathrm{NO}_{x}$ emission of about $900 \mathrm{ppm}$, the $\mathrm{NO}_{\mathrm{x}}$ is reduced by staging to a low value of $270 \mathrm{ppm}$. The slight difference between the two flames can be attributed to the increased amount of water vapor content of the combustion products in run \#2. The reduced gas temperature due to the increased water content of the fuel is compensated for by improved atomization of the CWF (with reduced solids content) so that there is little difference between the carbon burnout in the two flames (Runs 1 and 2).

The ratio of nitrogen to carbon found in the solid samples along the flame is plotted in Fig. $6.4(\mathrm{c})$. The nitrogen evolution at first lags hehind that of the carbon but after initial devolatilization it leads the evolution rate of carbon. This behavior during coal pyrolysis is consistent with laboratory scale experimental results obtained by Pohl and Sarofim ${ }^{9}$. It is thought that in the early stages of coal devolatilization the process is dominated by the break of nitrogen-poor side chains and aliphatic links in the coal molecule. On further pyrolysis aromatic rings in the coal structure decompose and release their nitrogen at a rate slightly exceeding that of carbon. In the oxidizing flame zone the nitrogen remaining in the coal char is oxidized with no preference between nitrogen and carbon so that 

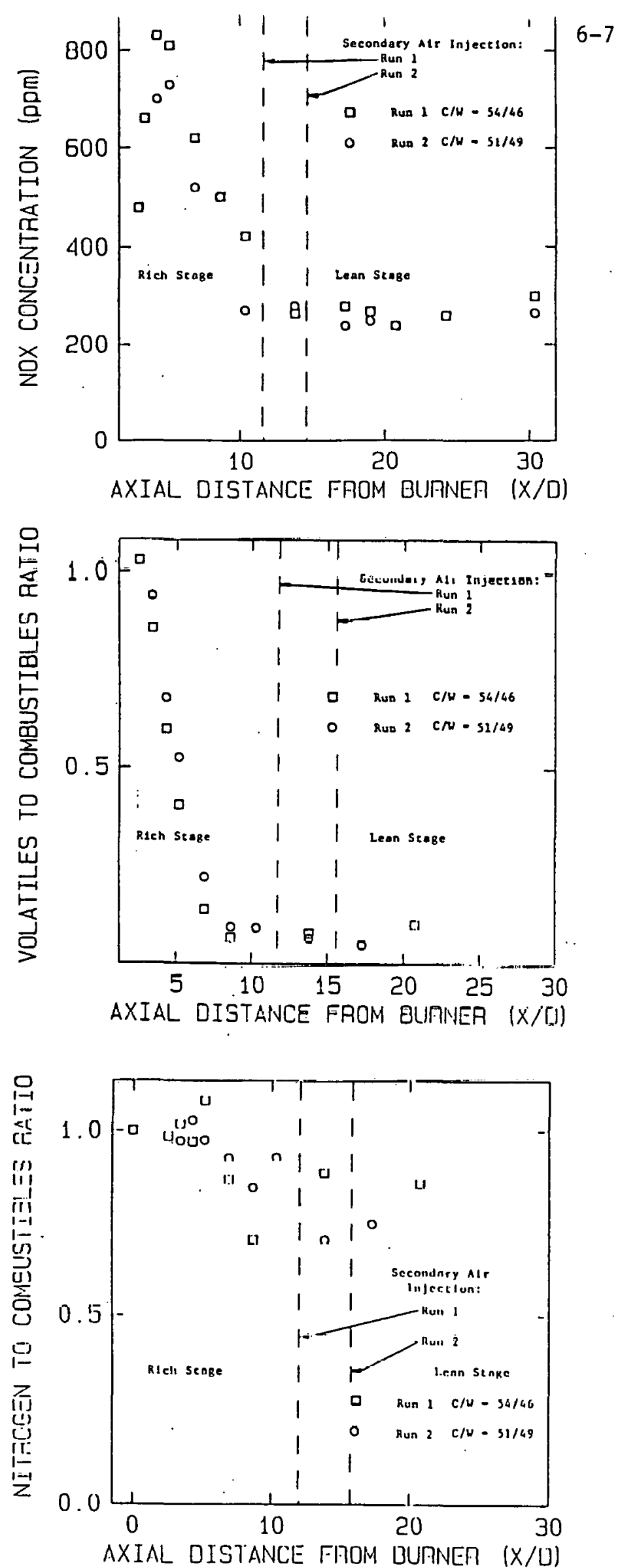

Figure 6.4 (a) The effect of water content of the CWF on NOx concentration in the flame.

(b) The effect of water content of the CWF on volatile fraction in in-flame particulate samples.

(c) Normalized nitrogen to combustibles ratio 
the $N / C$ ratio remains constant along the final burn-out stage of the flame.

Only the nitrogen that is evolved in the fuel-rich flame stage can be converted to molecular nitrogen, $\mathrm{N}_{2}$. Information on the kinetics of nitrogen evolution, therefore, is necessary for determining the minimum residence time of the fuel in the fuel-rich combustion stage.

The importance of the residence time in the rich stage in the reduction of $\mathrm{NO}_{\mathrm{x}}$ emission is illustrated by results of the third experiment. In this run the fuel-rich combustion space was reduced by the injection of the secondary air closer to the burner (see Fig. 6.2). In Figures 6.5a and b the $\mathrm{NO}_{x}$ concentration, the volatile fraction of in-flame solids samples, and the $\mathrm{N} / \mathrm{C}$ ratio, respectively, are plotted for runs $\# 1$ and $\# 3$. Due to the reduced space and residence time in the fuel-rich stage the FBN conversion to $\mathrm{N}_{2}$ is less complete in run $\# 3$ than in run $\# 1$ with the consequence of increased ${ }^{N O} \mathrm{X}$ emission (485 ppm).

Our results indicate the complex relationships between the rates of temperature increase and of oxygen entrainment into the fuel jet, the residence time and the fuel equivalence ratio in the rich stage. The reduction of $\mathrm{NO}_{\mathrm{x}}$ emissions by staged combustion depends on the control of these variables, especially the temperature and residence time in the fuel-rich combustion stage.

In all three runs, the volume mean particle size inttially increases from a value of approximately $14 \mu \mathrm{m}$ to around $50 \mu \mathrm{m}$ (Fig. 6.6). This is followed by a reduction in the mean particle size back toward $14 \mu \mathrm{m}$ in the tail end of the flame. The increase is attributable to the preferential burnout of the small particles in the flame and the eventual fragmentation of the burned out fly ash. This progressive development of the particle size of the flame solids is shown by results of particle size analyses made 

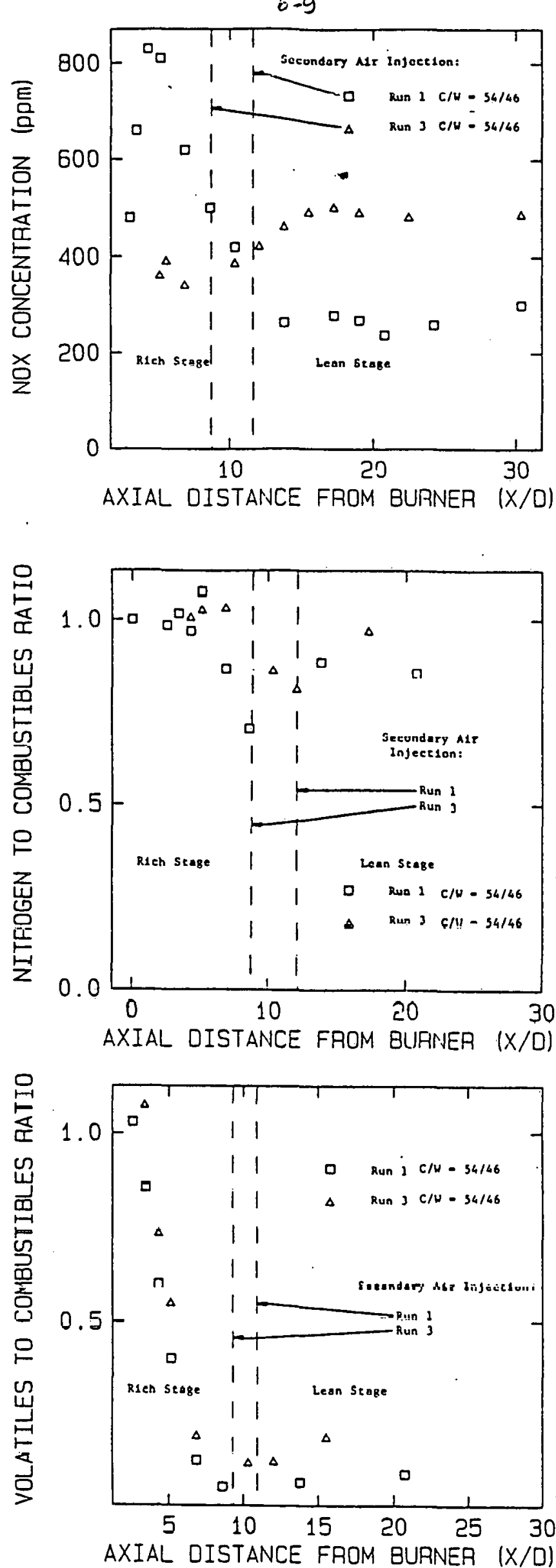

Figure 6.5 (a) The effect of secondary air position on $\mathrm{NO}_{\mathrm{x}}$ concentration

(b) The effect of secondary air position on volatile fraction of in-flane solids samples

(c) normalized nitrogen to combustibles ratio 


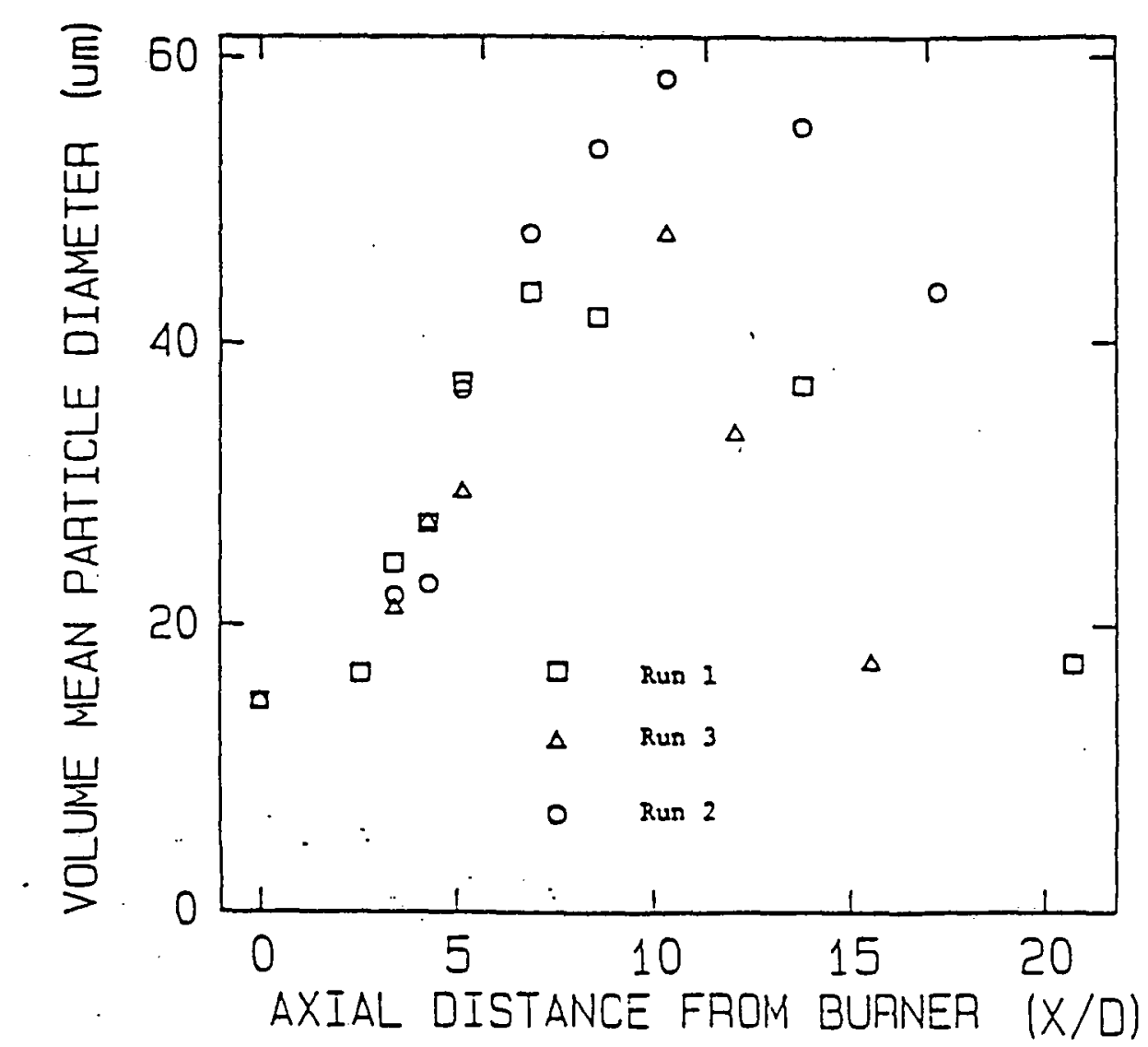

Figure 6.6 Volume mean particle diameter as a function of axial distance in CWF flame samples
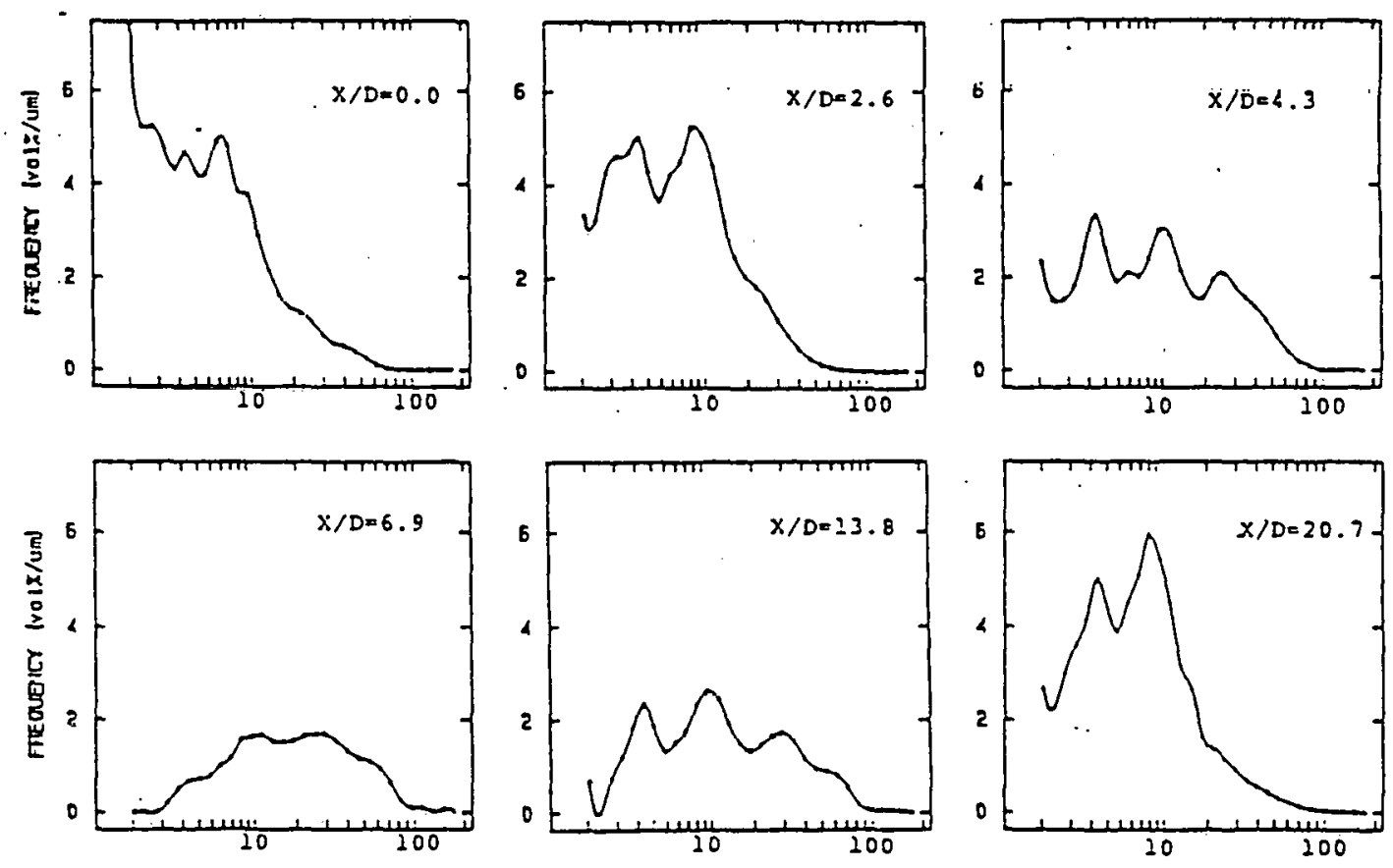

PLATICLE OIAMETER lum: $(0, \times 0)^{1 / 2}$

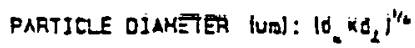

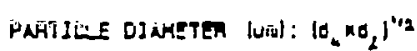

Figure 6.7 Farticle size distribution at different axial distances from the burner in Run \#1 
using a Malvern laser diffraction particle size analyser (Fig. 6.7).

It has been surprising to the authors to find how well the characteristics of the raw coal size distribution (e.g. peaks around 4 and $12 \mu \mathrm{m}$ ) are preserved in samples taken from the flame. It was thought that the flame solids size distribution is determined by the atomized drop size distribution rather than that of the coal in the CWF. The results, however, can be explained by the high quality atomization due partly to the strong dilution and hence low viscosity of the fuel, and partly by the relatively high atomizing air/CWF ratio (0.3) which brings the droplet size distribution very close to the size distribution of the constituent coal.

Less surprising is the multimodal size distribution of the flame solids; fly ash particle sizes peaking at 4 and $14 \mu \mathrm{m}$ and carbon-containing particles above $50 \mu \mathrm{m}$. The reduction of fly ash particle size can be seen therefore to require high carbon conversion efficiency, generally higher than that needed for satisfactory cycle efficiency (99.5\%). 
Section 7

Mechanism of Coal Water Fuel Droplet-Particle Combustion

Scanning electron micrographs of particles sampled in various CWS flames suggest that the life history of a CWS droplet can be considered to be divided into five stages - evaporation of the liquid film, evaporation of the "interstitial" moisture, particle heat up, coal devolatilization, and char oxidation ${ }^{10}$. On entering the combustion chamber, the drop temperature rises until the wet-bulb temperature is reached. Evaporation rates during this unsteady state period are small and controlled by mass transfer. Following this, the droplet temperature remains constant, the evaporation rates are high, and are controlled by the rate of heat transfer.

A model is proposed to describe the combustion mechanism of a côl water slurry droplet. In the model particle temperature begins to rise once the liquid film is removed. A major fraction of the water in large droplets is evaporated at the wet-bulb temperature. Droplet heat up times (1.6 ms for $90 \mu \mathrm{m}$ agglomerate) can be reduced by preheating the slurry. This would reduce evaporation distances considerably, since initial droplet velocities are high.

\section{Theory of Coal Water Fuel Droplet Combustion}

The life history of a slurry drop can be divided into three main phases: water evaporation, coal devolatilization; and char oxidation. The models that describe quantitatively the physical and chemical transformations of a CWS drop in a flame is now discussed. In the liquid film surrounding the coal particle is removed first, with the consequence that the coal particles at the surface of the droplet are exposed to the hot gas. The interstitial water is then vaporized at a radially shrinking 
spherical interface. Temperature in the spherical annulus, between this interface and the outer radius, starts to rise, and the coal particles within the shell soften and devolatilize. A schematic of the combustion history of a droplet according to this scenario is depicted in Figure 7.1.

The particles are assumed to be spherical, with uniform properties, and composed of some or all of the following components: water, coal, char and ash. $\Lambda$ sh is inert, and remains within the particle. The rate of change of mass of the particle is the sum of evaporation, volatile evolution, and char oxidation rates (Eq. 7.2). The droplet is first heated to the wet-bulb temperature after which the evaporation rate is determined solely by rate of heat transfer (Eq. 7.4). Corrections to heat and mass transfer coefficients due to surface transpiration are represented by the stagnant film theory ${ }^{11}$. The rate of agglomerate swelling is taken to be proportional to the rate of interstitial moisture removal.

The particle heating rate is determined by a balance between the convective and the radiative energy exchange with surroundings, the heat generated by char oxidation, and the heat removed by evaporation (Eq. 7.10). Radiation is exchanged with constant temperature surrounding $(1400 \mathrm{~K})$, and an emissivity of 0.7 is assumed for the coal particles (12). It. is noteworthy that the results obtained by Kolb et al. (13) show that in a confined turbulent coal water fuel diffusion flame a coal water fuel droplet exchanges energy with the surroundings mainly by convection.

It is assumed that all the water evaporated at the interface is removed from the droplet surface instantaneously, since any significant holdup would disintegrate the agglomerate due to build-up of large internal pressures. Assumption of quasi-steady state for processes within the she11, leads to the exclusion of the transient term from the heat balance. The energy equation can then be integrated between $r_{i}(t)$ and the outer 


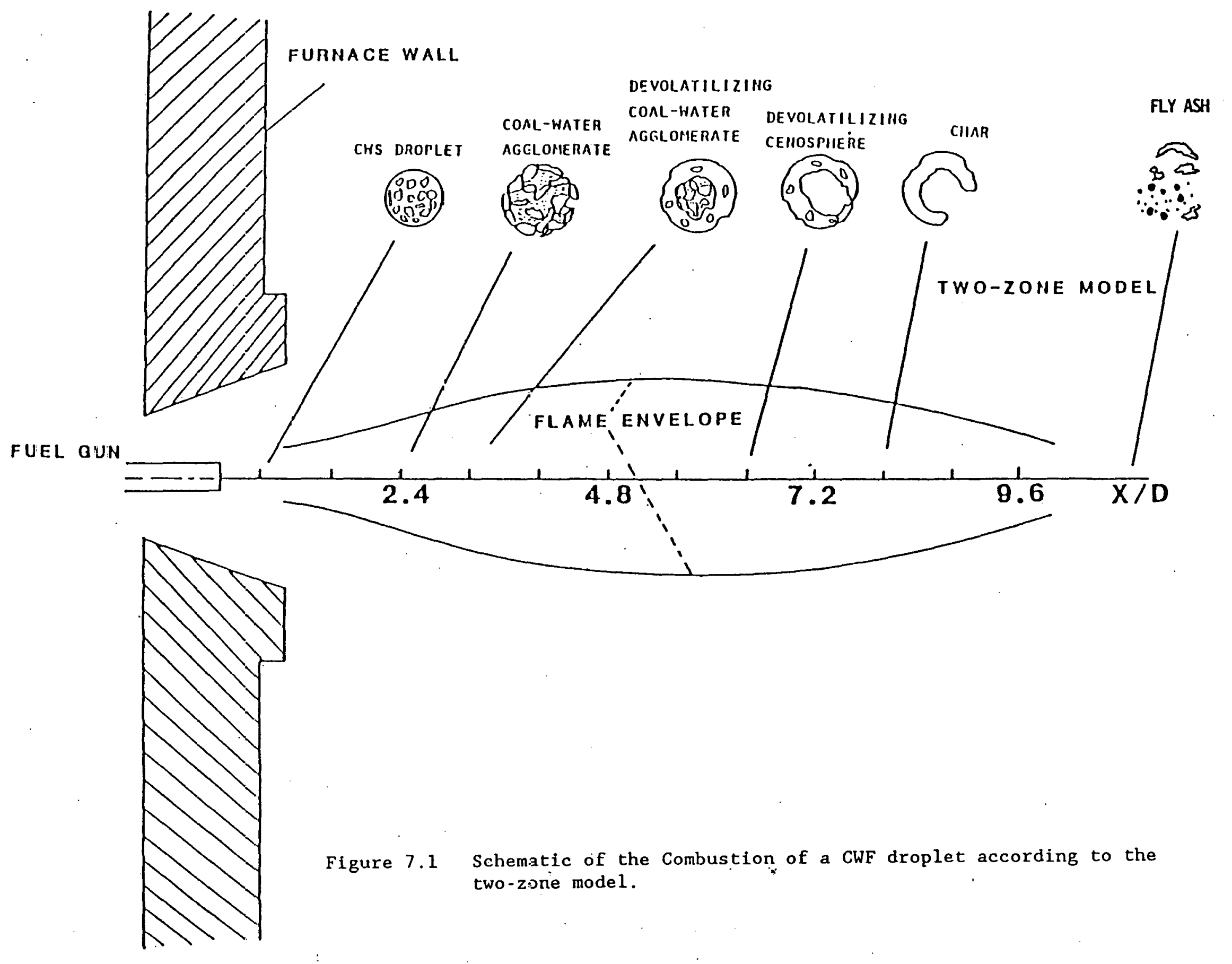




\section{EQUATIONS}

DROPLET MASS

$$
\begin{aligned}
& m=m_{w}+m_{c}+m_{h}+m_{a} \\
& \frac{d m}{d t}=-r_{w}-r_{v}-r_{h} \\
& r_{t}=r_{w}+r_{v}+r_{h}
\end{aligned}
$$

\section{Evaporation}

When $T_{p}=$ constant

$$
\begin{aligned}
& r_{w}=\frac{\left[\dot{h}\left(T_{g}-T_{p}\right)+\sigma \epsilon\left(T_{r}^{4}-T_{p}^{4}\right)\right] \pi d^{2}}{L_{w}} \\
& \frac{d m_{w}}{d t}=-r_{w}
\end{aligned}
$$

Devolatilization

$$
\begin{aligned}
& r_{v}=\left(k_{v 1} Y_{1}+K_{v 2} Y_{2}\right) m_{c} \\
& k_{v 1}=A_{1} \exp \left(-E_{1} / R T_{p}\right) \quad k_{v 2}=A_{2} \exp \left(-E_{2} / R T_{p}\right) s^{-1}
\end{aligned}
$$

Char Oxidation

$$
\begin{aligned}
& r_{h}=\frac{{ }_{p} C_{o g}}{\left[\begin{array}{c}
\text { Kinetic } \\
\text { Resistance }
\end{array}\right]+\left[\begin{array}{c}
\text { External } \\
\text { Mass Transfer } \\
\text { Rçistance }
\end{array}\right]+\left[\begin{array}{c}
\text { Net } \\
\text { Convective } \\
\text { Ilux } \\
\text { Resistance }
\end{array}\right]} \\
& A_{p}=\pi d^{2} \quad k_{h}=\frac{75.5 T_{p}}{\phi} \exp \left[\frac{-21,900}{R T}\right] \\
& \text { Kinetic Resistance }=1 /\left(\xi_{j} k_{h}\right) \\
& \text { External mass transfer resistance }=1 / \dot{k}_{c} \\
& \text { Net convective flux resistance }=\frac{r_{t}}{\left(\xi_{j} k_{c} \dot{k}_{h} A_{p} \rho_{g s}\right)}
\end{aligned}
$$




$$
\frac{d m_{h}}{d t}=\left[k_{v 1}\left(I-Y_{1}\right)+k_{v 2}\left(1-Y_{2}\right)\right] m_{c}-r_{h}
$$

\section{DROPLET ENERGY}

$$
m C_{p s} \frac{d T_{p}}{d t}=\left[\dot{h}\left(T_{g}-T_{p}\right)+\sigma \epsilon\left(T_{r}^{4}-T_{p}^{4}\right)\right] \pi d^{2}+r_{h} H_{h}-r_{w} L_{w}
$$

DROPLET MOMENTUM

$$
\begin{aligned}
& \text { m } \frac{d v_{p}}{d t}=\frac{1}{2} C_{D} \rho_{g} \frac{\pi d^{2}}{4}\left|v_{g}-v_{p}\right|\left(v_{g}-v_{p}\right) \\
& C_{D}=C_{D}\left(\operatorname{Re}_{r e}\right) \quad R_{r e}=\frac{\rho_{g} d\left|v_{g}-v_{P}\right|}{\mu_{r e}} \\
& \mu_{r e}=\mu_{r e}\left(T_{r e}\right) \quad T_{r e}=T_{p}+\frac{{ }^{1}}{3}\left(T_{g}-T_{p}\right)
\end{aligned}
$$

"TWO-ZONE" MODEL EQUATIONS

$$
\begin{aligned}
& \eta=\frac{r}{(d / 2)} \quad \eta_{i}=\frac{r_{i}}{(d / 2)} \quad d_{i}=2 r_{i} \\
& p=r_{w} C_{p w} /\left(2 \pi k_{s} d\right)
\end{aligned}
$$

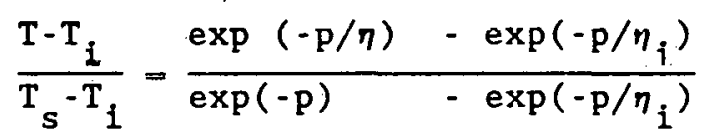

$$
\begin{aligned}
& Q=\int_{r_{i}}^{d / 2}(t) \rho_{s} C_{p s}\left(T-T_{i}\right) r^{2} d r \\
& T_{p}=T_{i}+\frac{Q}{\frac{\pi}{6}\left(d^{3}-d_{i}^{3}\right) \rho_{s} C_{p s}} \\
& \frac{d r_{1}}{d t}=\frac{\left[\frac{d}{h}\left(T_{i}-T_{s}\right)+\sigma \epsilon\left(T_{r}^{4}-T_{s}^{4}\right)\right] \pi d^{2}}{\frac{d Q}{d r_{i}}-4 \pi r_{i}^{2} \rho_{i} \omega_{w}\left[L_{w}+C_{p w}\left(T_{s}-T_{i}\right)\right]} \\
& r_{w}=-4 \pi r_{i}^{2} \quad \rho_{i} \omega_{w} \frac{d r}{d t}
\end{aligned}
$$




$$
\frac{d}{d r}\left[r^{2}\left(-k_{s} \frac{d T}{d r}+\frac{r}{\pi d^{2}}\left(H_{w i}+C_{p w}\left(T-T_{i}\right)\right)\right)\right]=0
$$

radius $d$, to yield the temperature profile within the shell (Eq. 7.14).

Once the steady state temperature profile is evaluated, the temporal variation of the interface position $r_{i}(t)$ is determined by requiring the heat entering at the outer surface to be partitioned between heating the shell to the new steady state, and evaporating the water at the interface and heating the vapor to the surface temperature (Eq. 7.17). An average temperature for the sheil is used to determine devolatilization rates (Fr. 7.16). Since the heat transfer coefficient ( $h$ ) is a function of the mass afflux rates $\left(r_{j}\right)$, solution for $h, T_{p}, T_{s}$, and $r_{w}$ must be iteratively determined.

The rate of devolatilization is modelled by two parallel, first-order reactions ${ }^{14,15}$. The low-activation energy reaction is assumed $t$ form volatiles in accordance with the low-temperature pyrolytic behavior of coal. The high-activation energy reaction, which dominates the volatile yield at the higher temperatures, is assumed to form lesser amounts of char. In the present study the parameter values for Kobayashi et al. ${ }^{14}$ are used, since those of Ubhayakar et al. ${ }^{15}$ gave volatile evolution rates much in excess of what is observed in the experiments. The reaction scheme is given below (also Eq. 7.6).

$$
\begin{aligned}
& A_{1}=2 \times 10^{5} \mathrm{~s}^{-1} \text { Volatile } 1^{+} \text {Char } \\
& 25 \mathrm{kcal} / \mathrm{mole} Y_{1}=0.3 \quad\left(1-Y_{1}\right)=0.7
\end{aligned}
$$

Raw Coal

$$
\begin{gathered}
\text { Volatile } 2+\text { Char } \\
40 \mathrm{kcal} / \mathrm{mole} \mathrm{Y}_{2}=1.0 \quad\left(1-\mathrm{Y}_{2}\right)=0.0
\end{gathered}
$$




$$
A=1.3 \times 10^{7} s^{-1}
$$

The char oxidation kinetics are obtained from Field. ${ }^{16}$ The reaction and the diffusion steps are coupled and represented by a reaction rate based on the external surface of the particles. The rate of char oxidation is given by Eq. $7.7^{17}$. The amount of char in the particle is determined by the rate at which it is formed from the devolatilization reactions, and the rate at which it is consumed by oxidation (Eq. 7.9).

Droplet dynamics are modelled by using a drag law. Yuen and Chen ${ }^{18}$ showed that the drag coefficient was well correlated with the "standard drag" curve if the free stream density and the characteristic viscosity given by the $1 / 3$ rule were used to determine Reynolds number (Eq. 7.11). The momentum equation must be solved to translate the time variable into distance, so that modelling results can be compared with experiments. The effects of swelling on particle behavior is considered in the modelling calculations and it is represented by a swelling factor. This parameter is defined as the ratio of the final to initial droplet dismeter. The selling factor will determine the surface area of the swollen particle and thus the heat transfer rates to the particle surface and in turn the oxidation rate will be affected.

\section{Solution Technique}

- The five conservation equations for each particle size (conservation of mass, species (water, char), energy, and momentum) were solved using the Runge-Kutta-Verner fifth and sixth order method. All equations were suitably non-dimensionalized before being solved in that form. The initial conditions were determined from flame input parameters. The initial droplet velocity was estimated by measuring the velocities of inhomogeneities in the 
spray, visible in high speed cine films ${ }^{19}$. Initial droplet temperatures were taken as $325 \mathrm{~K}$. Experimentally determined gas velocities, temperatures and gaseous species concentrations were used to determine the environment under which the CWS droplets travel and undergo vaporization, pyrolysis, and oxidation.

A comparison of the experimental results with the modelling calculations is discussed next.

\section{Modeling Results and Discussion}

Computations were made to describe the transformations of CWS particle properties during combustion. The experimentally determined carbon conversion values for different particle size ranges are compared with the numerica1 results.

In the model the particle temperature remains constant until all the Iiquid film surrounding the particles has evaporated. During this time the coal-water droplet mass decreases as shown in Figure 7.2. After the water evaporation step, the particle temperature increases. The char fraction in the particle starts to increase when the coal begins to devolatilize. Only about 358 of the coal is converted to char with the remaining 658 converted to volatiles. The volatiles from the particle burn as a diffusion flame in the bulk gas rather than as an envelope flame around the droplet.

A comparison of the experimentally determined carbon conversion efficiency values of various particle sizes with theoretically predicted burnout curves using the above mentioned model are shown in Figure 7.3. Four size curs have been included in this analysis. The size cuts chosen are: 


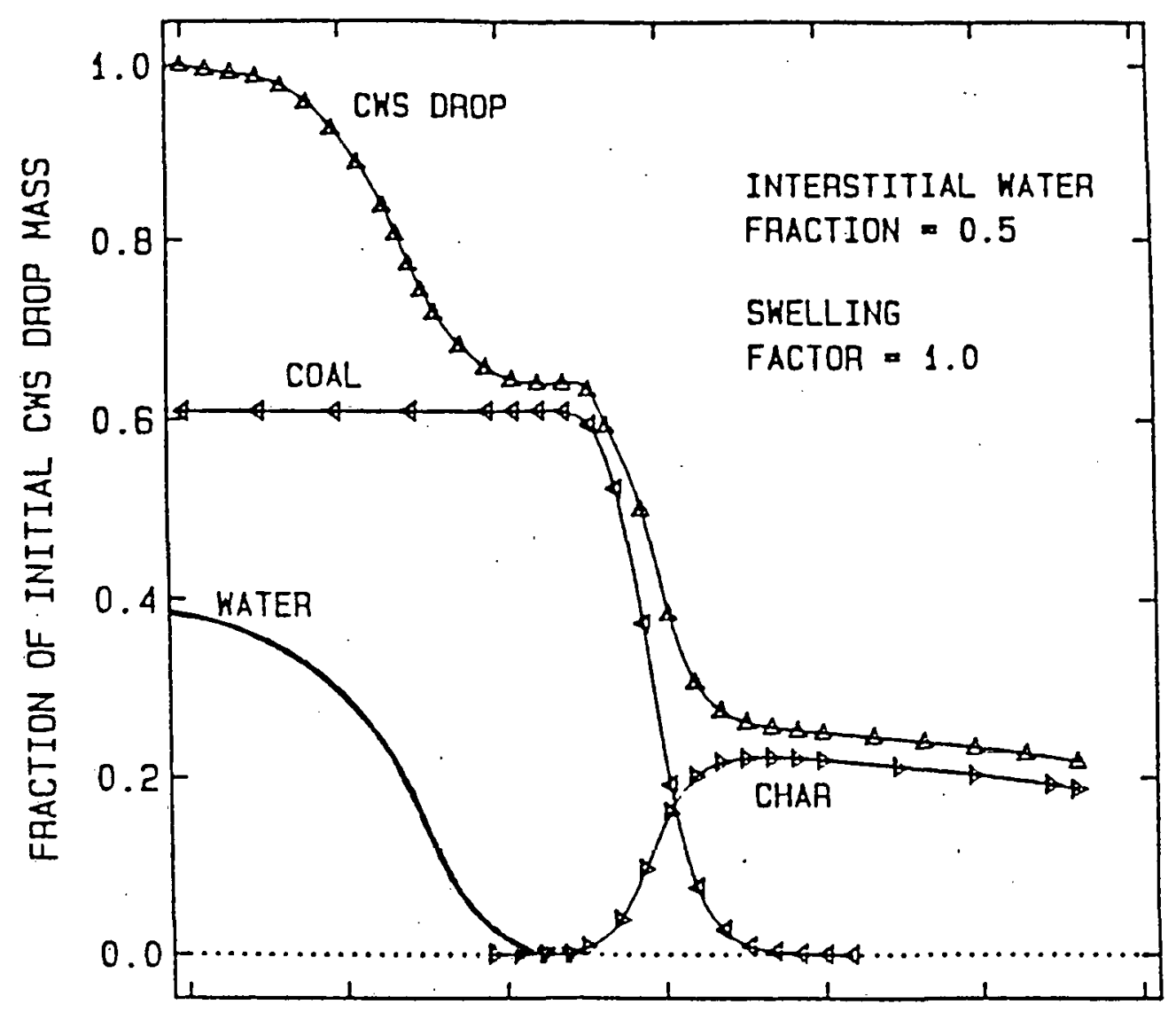

Figure 7.2 Predicted behavior for water evaporation and volatile generation from a $53 \mu \mathrm{m}$ drop 


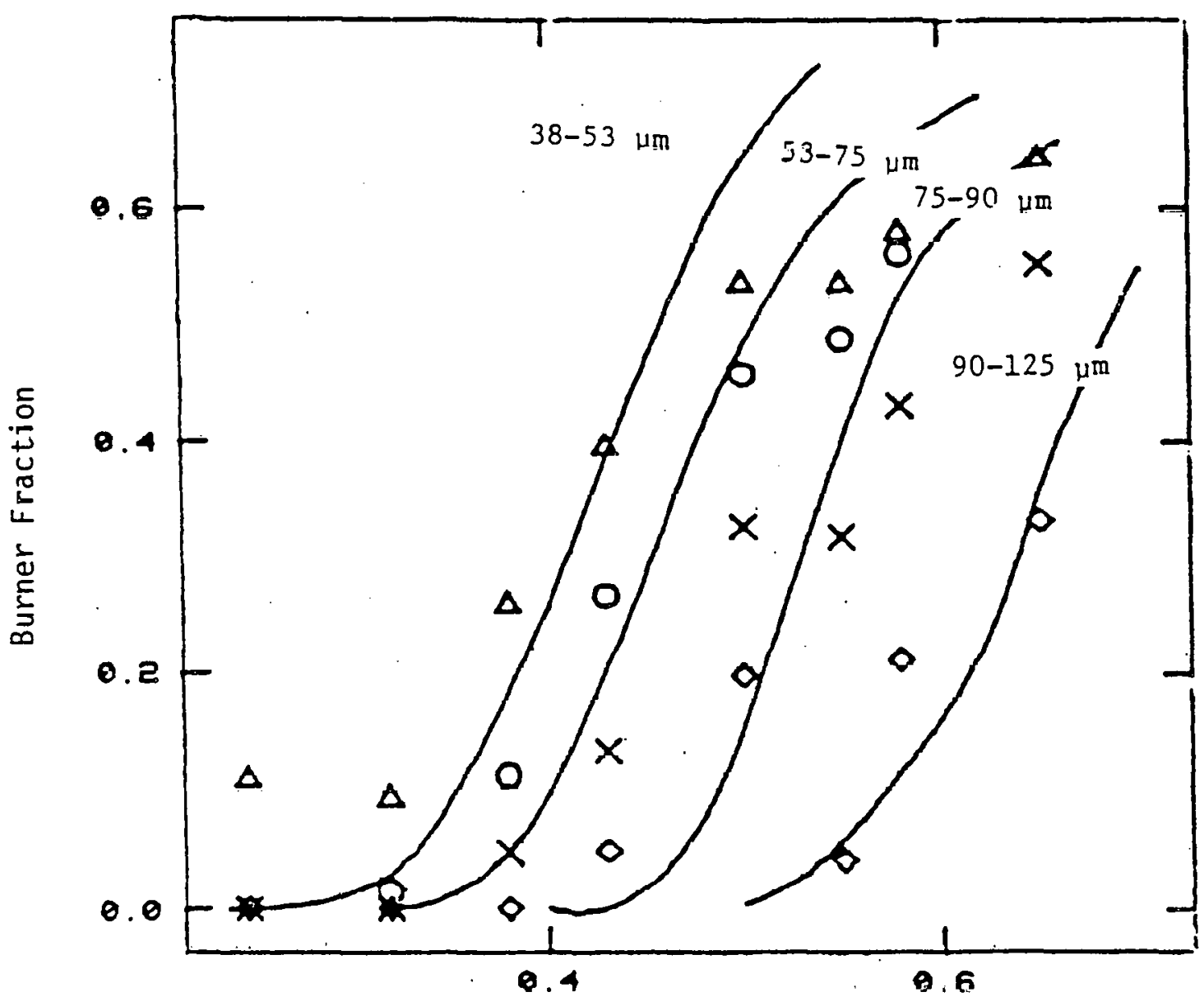

Axial Distance from Burner $(\mathrm{m})$

Flgure 7.3 earbon burnout curves for Fldilles $318 \mathrm{~B}$ 
$38-53 \mu \mathrm{m}$

$53-75 \mu \mathrm{m}$

$75-90 \mu \mathrm{m}$

$90-125 \mu \mathrm{m}$

Good agreement prevails between the model prediction and the experimental measurements except at high carbon conversion efficiency values $(\sim 0.65)$. The measured carbon conversion efficiency data starts to level off at high values, whereas the computer calculations show that the carbon burnout keeps increasing at large distances. Two reasons might explain the discrepancy between the model and the measured data:

(1) The calculations assume that ash is conserved in the coal water droplet while the particles' various transformations in the flame. In other words, the ash is not given up by the coal agglomerate as the particle devolatilizes and burns. In reality this is not the case. The ash droplets are shed from the coal and char particles as they react.

(2) The char oxidation kinetics used to calculate the char reaction rate might be fast. Thus at distances greater than $0.4 \mathrm{~m}$ from the nozzle, where measured temperatures and $\mathrm{O}_{2}$ concentrations are high, the oxidation rates dominate over the devolatilization rates in that region. Consequently, the estimated carbon conversion efficiency keeps increasing in that flame zone. 
Section 8

Radiation Study

\section{Introduction}

Knowledge of radiative heat flux distribution in furnaces and combustors is of great interest for designers. In furnaces the usual objective is to ensure that a large fraction of the heat generated is transferred to the heat transfer surfaces by radiation. In gas turbine combustors the opposite is the design objective, i.e., to minimize radiative heat transfer to the combustor walls. In both cases, however, it is important to have the ability to predict radiative heat transfer and to relate it to design and operating variables of the furnace or combustor.

The combustion performance of gas turbine combustors operated at elevated pressure, the flame structure and the radiative properties of flames are all pressure dependent. Methods of predicting radiative heat flux distribution in furnace flames has reached a level of high sophistication. The modeling has benefited from detailed flame structure data and radiation measurements in furnace flames. The research objertịve is to take advantage of the developments in radiation modeling and apply them to gas turbine combustor conditions. In this study calculations are made of radiative heat flux distribution of ultrafine coal-water fuel furnace flames at atmospheric pressure. These predictions are then compared with measurements of radiation incident on elements of the hounding surfacec of the combustion chamber. Once a successful calculation method has been developed, the application to gas turbine combustor conditions will follow. The limited gas turbine combustor measurement data will be combined with atmospheric pressure detailed flame structure measurements to determine radiative species concentration and temperature distribution in an ultrafine 
CWF fired gas turbine combustor. Based on these data, calculations could be made of the best flux distribution in the gas turbine combustor working at elevated pressure.

In the present research program calculations of radiative heat flux distribution in CWF flames are performed and comparison of calculated and measured radiative flux along the experimental flames, is presented.

\section{Modeling of Furnace Performance}

The MONTCL computer program was developed to predict the surface and gas temperatures in a combustion chamber; as well as the heat exchange taking place between the combustor walls and the enclosed gases.

The model is based on the zone method of analysis in which the furnace is divided into many volume and surface zones. The properties of each zone are considered uniform and constant, and the radiative exchange areas between the zones are determined based on measured concentration of absorbing species in each zone. Given fluid flow and combustion patterns, a system of nonlinear energy balance equations can be set up and solved for $\therefore$ the unknown temperature of each zone, allowing the radiative heat flux distribution to be predicted.

In order to overcome the difficulty of determining the exchange areas the model applies the Monte Carlo technique. The probabilistic Monte Carlo method, in which a zone's energy emission is divided into several thousand "particles" that are tracked as they are reflected and absorbed throughout the furnace, allows considerable flexibility in choosing zone size and shape. The zone shapes can be made physically realistic, thus allowing a smaller number of zones to be used in the model while still retaining the samo degree of accuracy. For example, the zones contalning the flame itself 
can be shaped as truncated cones, which more accurately represent the shape of the flame.

To take advantage of the flexibility of the Monte CArlo method in choosing zone shape and size, the zoning system shown in Figure 8.1 is used. This zoning system consists of 11 volume (gas) zones and 10 surface zones arranged in a paralielepiped. The volume zones included 3 well-stirred volume zones in the shape of truncated cones, surrounded by 6 well-mixed recirculation zones. These well-stirred volume zones are follnwed by 2 plug-flow zones which are considerably larger to take advantage of the much smaller changes occurring far from the flame.

\section{Gas Emissivity}

In order to model the emissivity of the real gases, the program uses a weighted sum of 3 gray gases:

$$
\begin{aligned}
& \xi_{\bar{g}}=\sum_{n=1}^{3} \quad{ }_{g, n}\left(1-\exp \left[-K_{n} L\right]\right) \\
& 3 \\
& \text { Subject to } \sum_{n=1} a_{g, n}=1 \quad a_{g, n}>0 \\
& \mathrm{~K}_{\mathrm{n}}=\mathrm{k}_{\mathrm{s}, \mathrm{n}} \mathrm{r}_{\mathrm{s}}+\mathrm{k}_{\mathrm{a}, \mathrm{n}} \mathrm{ca}+\mathrm{k}_{\mathrm{g}, \mathrm{n}}\left(\mathrm{P}_{\mathrm{CO}_{2}}+\mathrm{F}_{\mathrm{H}_{2} \mathrm{O}}+\mathrm{P}_{\mathrm{CO}}+\mathrm{P}_{\mathrm{SO}_{2}} ;\right.
\end{aligned}
$$

where

$$
\begin{aligned}
& \mathrm{k}_{\mathrm{n}}>0 \\
& \mathrm{a}_{\mathrm{g}, \mathrm{n}}=\text { weighting factors } \\
& \mathrm{k}_{\mathrm{n}}=\text { absorption coefficient of the nth gray gas } \\
& \mathrm{k}_{\mathrm{s}, \mathrm{n}} ; \mathrm{k}_{\mathrm{a}, \mathrm{n}}=\text { extinction (absorption) } \\
& \quad \text { coefficients of soot and ash }+ \text { char, } \mathrm{m}^{2} /(\mathrm{kg})
\end{aligned}
$$



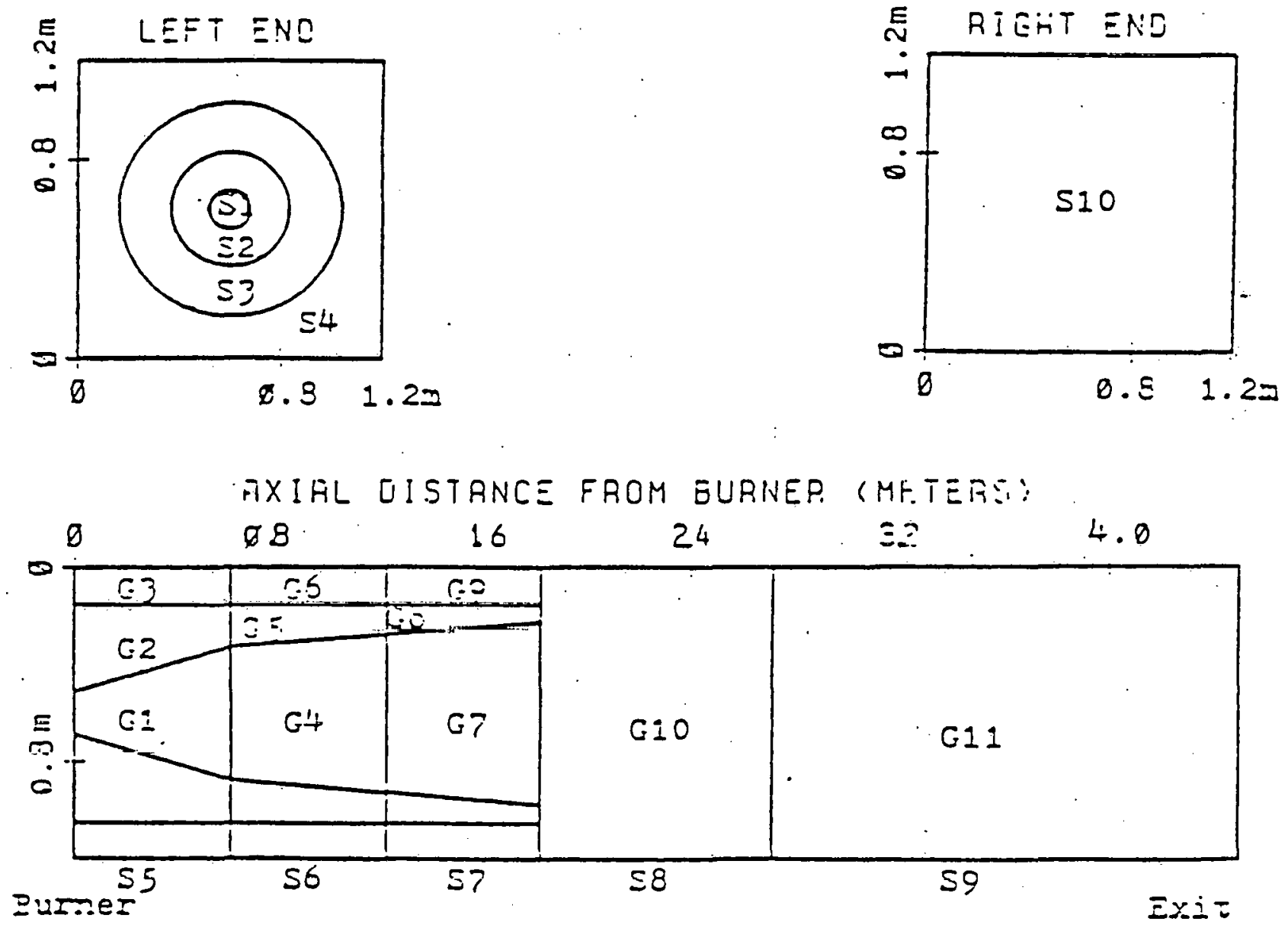

11 Cas zones

10 Surface zones

Figure 8.1 Zoning system of the MIT-CRF for use in the Monte Carlo Zone Method Program 


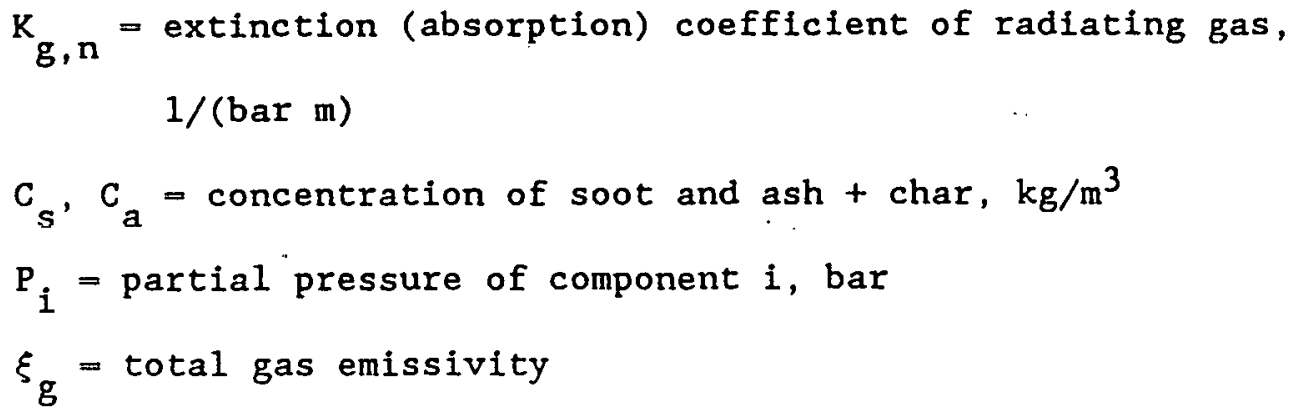

In order to take into account the effect of temperature the weighting factors $a_{g, n}$ take the following form:

$$
a_{a, n}=b_{1, n}+b_{2, n} \mathrm{r}_{2}
$$

where $b_{1, n}$ and $b_{2, n}$ are constants subject to:

$$
\begin{array}{rr}
\sum_{n=1}^{3} & b_{1, n}=1 \\
\underset{n=1}{3} & b_{2, n}=0
\end{array}
$$

where: $\mathrm{T}_{\mathrm{g}}=$ gas temperature

In the present study, a nonlinear least-squares regression analysis based on Powell's method was used to solved simultaneously for the weighting factors and absorption coefficients. These nine unknowns $\left(b_{1,2} ; b_{1,3} ; b_{2,2}\right.$; $\mathrm{b}_{2,3} ; \mathrm{k}_{\mathrm{g}, 2} ; \mathrm{k}_{\mathrm{g}, 3} ; \mathrm{k}_{\mathrm{s,1}} ; \mathrm{k}_{\mathrm{s,2}, 2} ; \mathrm{k}_{\mathrm{s}, 3}$ ) were found at a given value of (Partial Pressure of water/particle pressure of $\mathrm{CO}_{2}$ ) and a given value of carbon to hydrogen ratio $(\mathrm{C} / \mathrm{H})$ soot by fitting Equation 8.1 to 70 data points. The gas emissivity data points were measured at temperatures between $1300 \mathrm{~K}$ and $1800 \mathrm{~K}$ and at a large range of values $\left(P_{w}+P_{c}\right) L$. The limits chosen were those in which virtually all of the gas radiation occurs in the MIT-CRF. The soot emissivity data points were for temperatures between $1600 \mathrm{~K}$ and $1750 \mathrm{~K}$, and fur CL between 0.0002 and $0.002(\mathrm{~kg} \mathrm{~m}) / \mathrm{m}^{3}$. Since most soot exists in the hot flame region, most soot radiation exists within these 
limits. For higher values of CL, soot emissivity is so close to unity that there is no need to fit the equation carefully at very high values of CL.

\section{Comparison of Model Predictions and Experimental Results}

\section{Ultrafine and Fine Grind CWF Flames}

The incident radiative flux measurements in Runs $318 \mathrm{~A}$ and $\mathrm{B}$ were compared with the model predictions for the two cases and are shown in Figures 8.2 and 8.3 respectively. The shapes of the curves predicted by the model agree well with those measured in the experiments. The temperature peaks at the same axial position for both flames. A sharp fall is observed for both flames due to the presence of water cooled sections at a distance of 2.1 and 2.4 meters from the nozzle. The radiative flux profile computed for flame $318 \mathrm{~B}$ underestimates the measured profile by approximately 30 $\mathrm{KW} / \mathrm{m}^{2}$.

Gas temperatures calculated for each zone are compared with measured centerline temperatures in Figures 8.4 and 8.5 . The gas temperatures predicted along the flame are in good agreement with the measurements except for the end of the flame where the predicted temperatures are too low. In this case, sharp temperature gradients prevail across the last two sections of the chamber due to the bare metal water cooled walls. Temperatures measured close to the cooled surfaces were lower by $300^{\circ} \mathrm{C}$ than the centerline values.

\section{Natural Gas Flame}

A 2.25 Megawatt natural gas flame was studied. The furnace was comprised of 15 sections, four of which had bare metal walls for an increased heat extraction (58\% of thermal input). The oxygen concentration on a dry baeis was 1.85 at the furnace exit. 


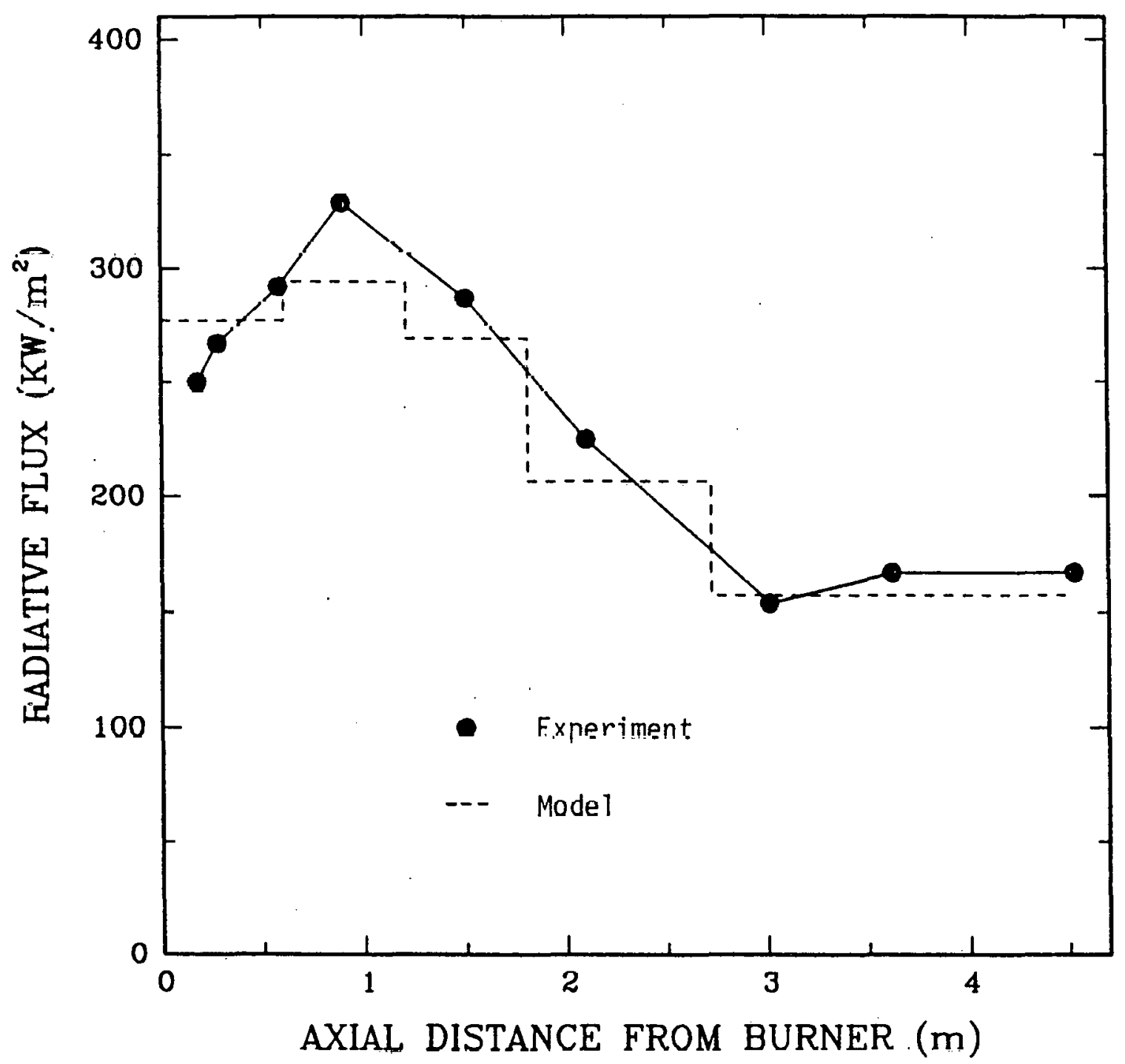

Figure 8.2 Radiative Flux Frofiles iñ Rün 318A (UILrafine-yrind CWF) 


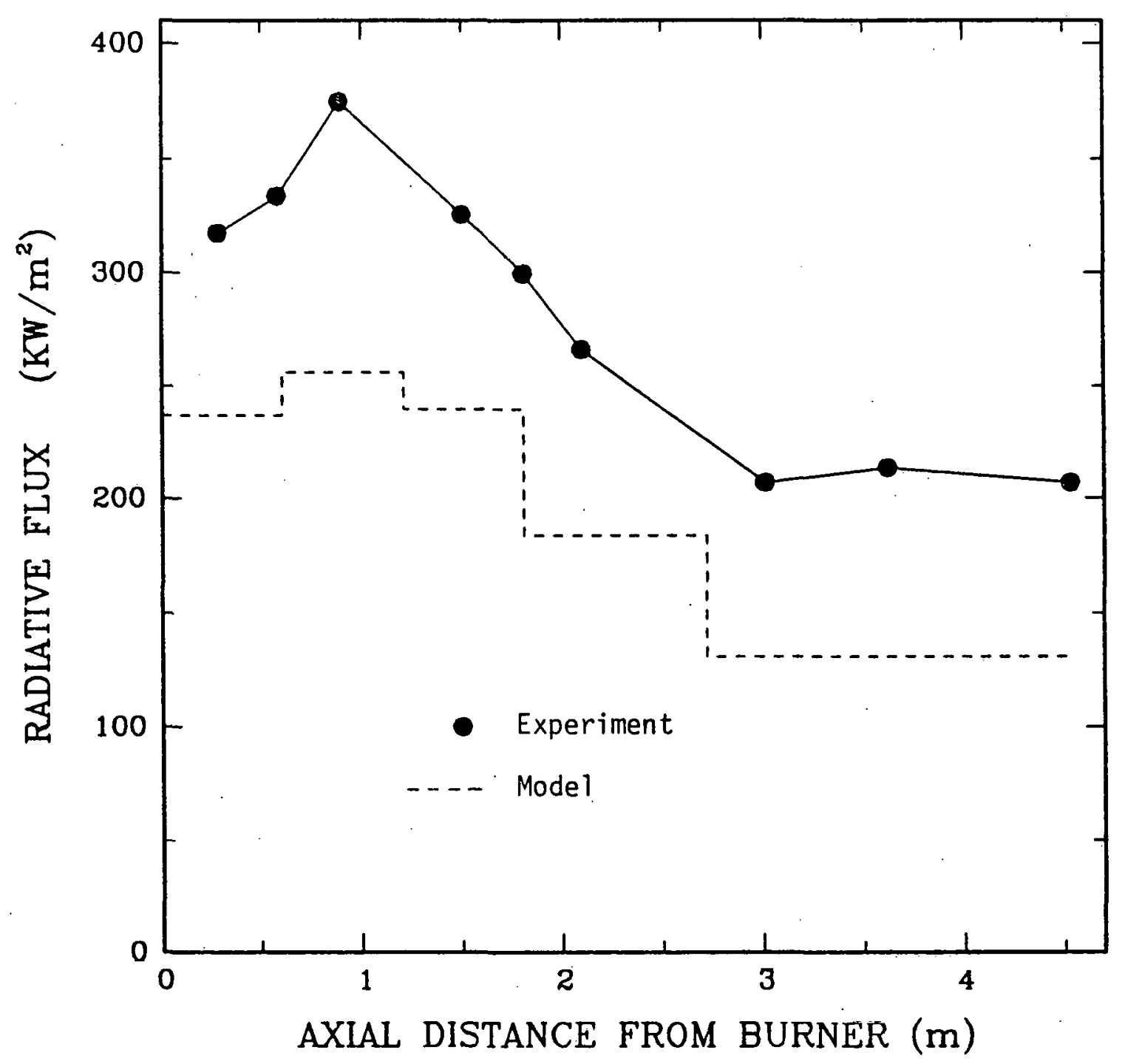

Fịgure 8.3 Radịative Flux Profiles in Run 318B (Fine grind CWF) 


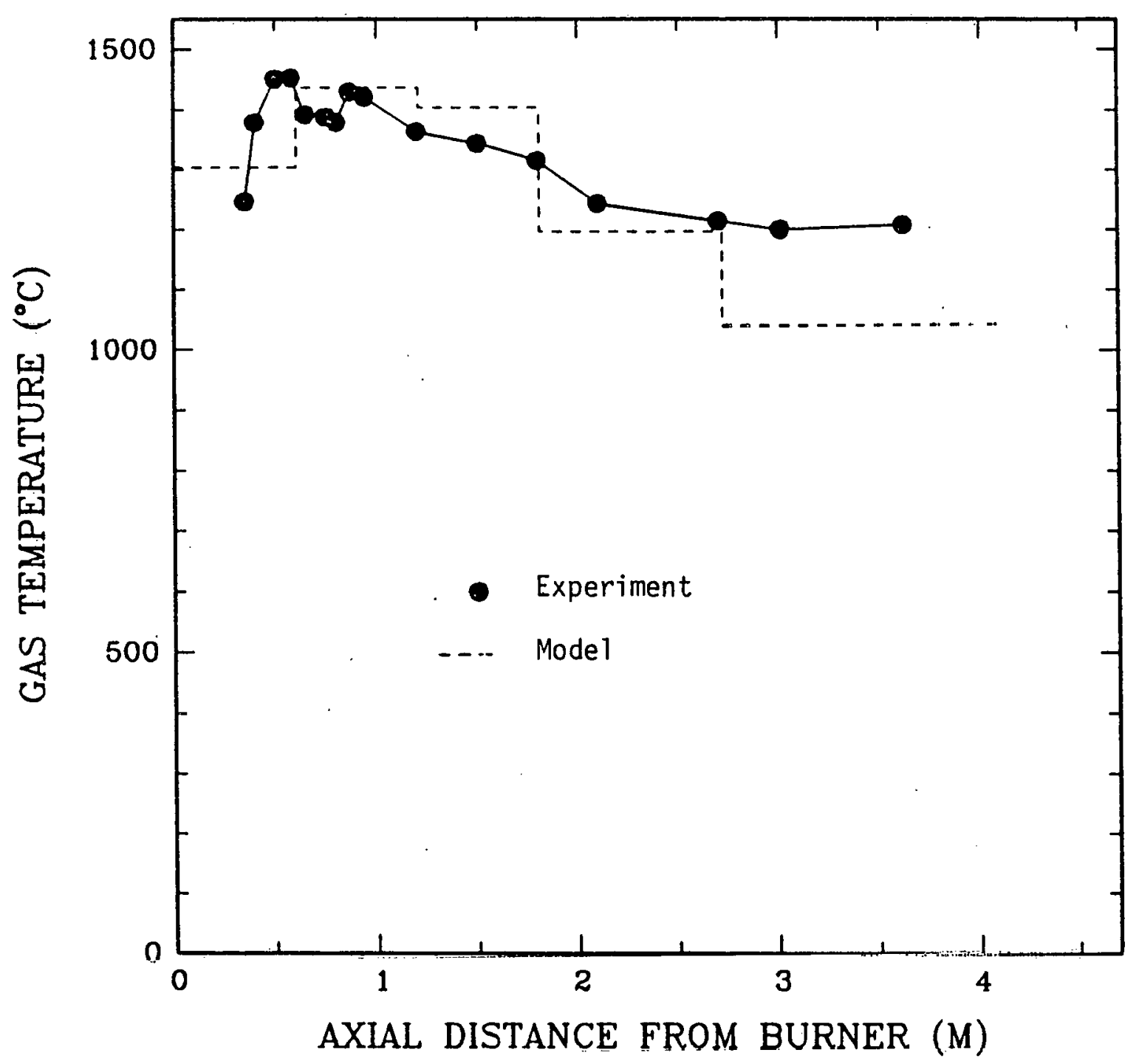

Figure 8.4 Axial Temperature Profiles in Run 318A (U1trafine grind CWF) 


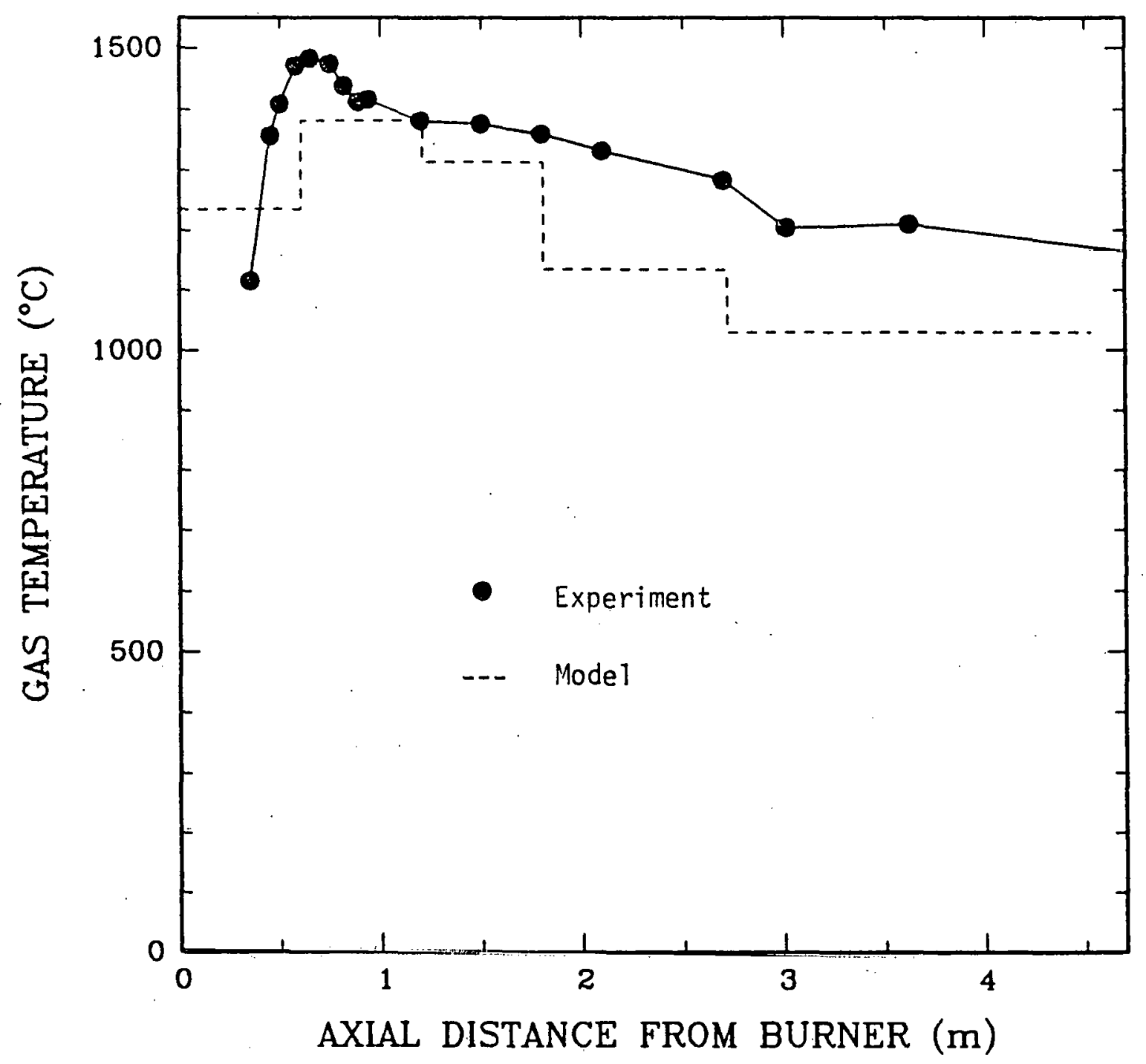

Figure 8.5 Axial Temperature Profiles in Run 3188 (U1trafine grind CWF) 


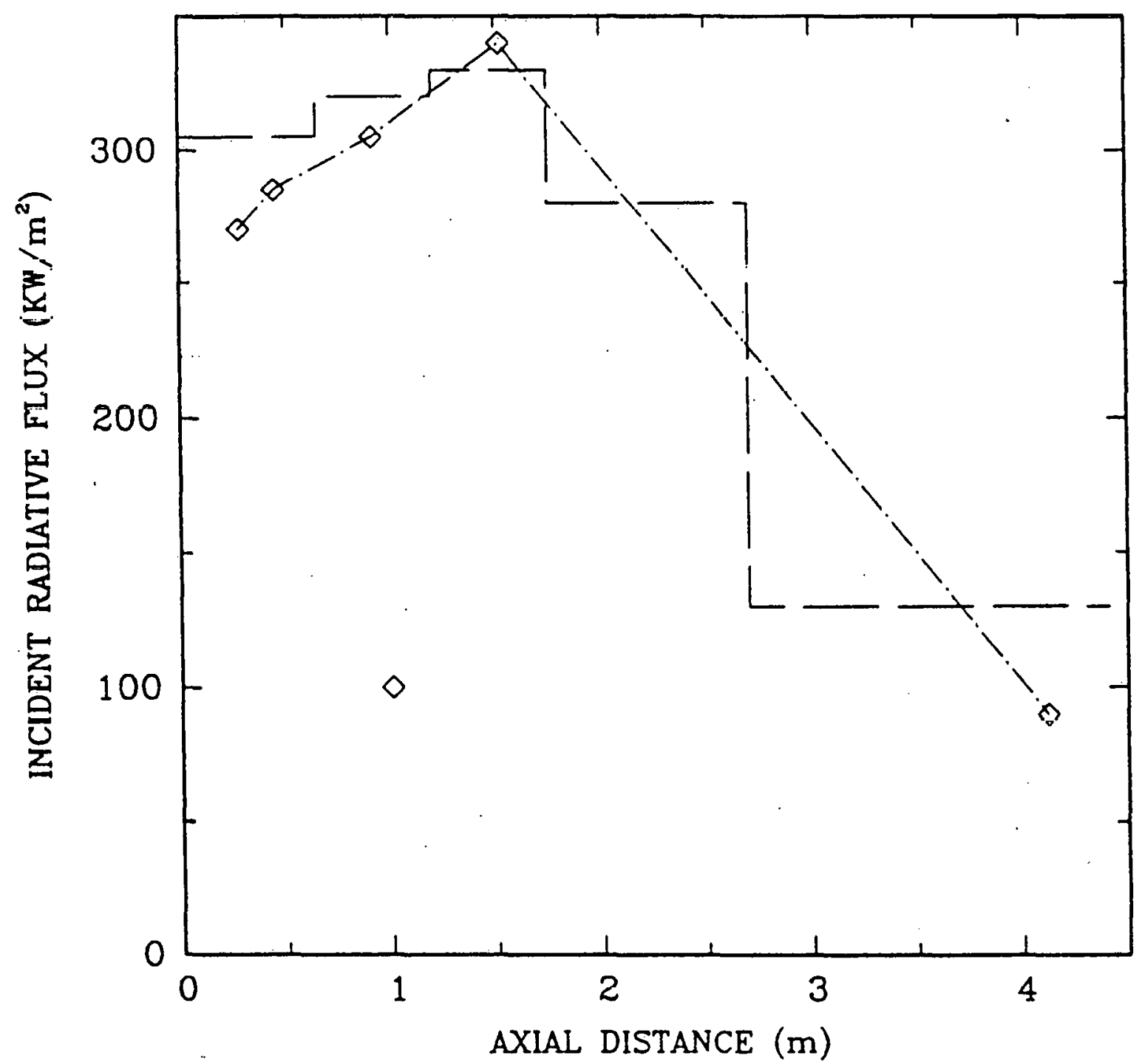

Figure 8.6 Comparison of predicted incident radiative flux using the zone methnd with the measured radiative flux from a natural gas flame 
Radiative flux measurements for this run are compared to the modeling results in Figure 8.6 . The maximum radiation flux was measured at about $1.5 \mathrm{~m}$ from the nozzle. The flux then falls off due to the cooling of gases by the presence of cold sections. Modeling results are in excellent agreement both in shape and value with the measured radiation flux.

\section{Sensitivity Analysis}

The use of the zone method of analysis combined with the Monte Carlo technique to model the heat exchange taking place in a furnace requires extensive input data. Most of this information can be either obtained from geometrical and physical characteristics of the system in question, or are desired parameters of operation. However some other values are obtained from experimentation under similar but not exact conditions and there may be uncertainty on their validity. This might be the case of vartables such as species concentrations or absorption coefficients.

Duong $^{20}$ performed a sensitivity analysis on the model, testing the effect of changes in: soot concentration, flame shape and length, flame spread angle, rerirculation flow rate, gas emissivity, and the effect of equivalent cylindrical shape for the furnace enclosure.

For the effect of soot concentration two different furnace configurations were studied by Duong, one of them being similar to the one used in this work (model 6 in Duong) ${ }^{20}$. The soot concentration of the first flame zone was reduced to 408 of its original value producing no significant effect on the heat transfer. In other configurations studied, 1 changes in heat transfer remained below 48 .

Duong also showed that changes in flame shape and length, flame spread angle, recirculation flow rate and gas emissivity have very little effect on heat transter, both to cold surfaces and in the overall values. 
In this program a sensitivity analysis was carried out to determine the effect of parameters thought to have a major influence on the radiation characteristics of CWF diffusion flames both at atmospheric and elevated pressures.

Parameters affecting radiation characteristics of coal water fuel flames

The input conditions for the base case were first chosen. Several computer runs were made by changing the value of a single parameter or a set of parameters and determining the effect upon CWF flame radiation and heat extractionly radiation from the flame.

The parameters were:

(1) Soot concentration

(2) Soot absorption coefficients

(3) Fuel heating value

(4) Excess air

(5) Surface emissivity

(6) Temperature of water cooled surfaces

(7) Flame spread angle

(8) Partial pressures of carbon dioxide and water vapor

(9) Distribution of heat release by combustion

Two fuels were considered in the computer modeling calculations. The first was a solvent refined coal (SRC-II) used in earlier experimental studies at the Combustion Research Facility, and the second was an Atlantic Research fine grind coal water fuel. The input conditions chosen to carry out the numerical computations are listed in Table 8.1 .

All computations, except those carried out to characterize the effect of soot concentration on the radiative characteristics of flame, were made using coal water fuel. An SRC-II flame was investigated to characterize the 
Table 8.1

Input Conditions for the Numerical Computation

Fuel Type:

Fuel Flow Rate $(\mathrm{kg} / \mathrm{hr})$

Fuel Heating Value $(\mathrm{Cal} / \mathrm{g})$

Air Flow Rate

$(\mathrm{kg} / \mathrm{hr})$

Air Temperature

(K)

Total Thermal Input $(\mathrm{kW})$

Excess $\mathrm{O}_{2}$ Dry Basis (8)
Solvent Refined

Coal (II)

98

9069

1324

309

1048

$-2$
1720

Fine Grind Atlantic Research Coal Water Fuel

310

4196

2205

588

$-3$ 
effect of soot concentration on radiation and gas temperatures. The reason we chose the SRC-II fuel for this particular investigation was that an unambiguous relationship between the radiative properties of the flame and the soot concentration measured could be established.

Soot Concentration

The rate of soot formation is known to increase with increasing pressure. There are several studies reported in the literature (21-30) on the effect of pressure on soot concentrations in different types of flames. This will be the subject of further discusstinn in Chapter 9, where the use of the model for the simulation of heat exchange in gas turbine combustorc is analyzed.

In the present Investigation, soot concentration measured experimentally is varied in the model calculations to determine its Influence on the radiative characteristics of turbulent diffusion flames. In the model, different soot concentrations are used tin estimate the absorption coefflcients using Hottel's method ${ }^{21}$ of the weighted sum of the three gray gaceo cxtended to sout vearing flames by Johnson and Beér ${ }^{31}$. Figure 8.7 shows the effect of soot concentration on the total heat extraction in the combustion tunnel. It is noteworthy tn nhserve that the presence of soot is particularly effective in increasing radiation when its concentration is initially low, but the effect of increasing soot concentration upon the radiative heat transfer from the flame is slight when the soot concentration was already high. The significance of these results for gas turbine conditions is that the increased rate of soot formation as a result of elevated pressure would increase the flame emissivity in a natural gas flame, but little relative increase of flame emissivity can be expected 


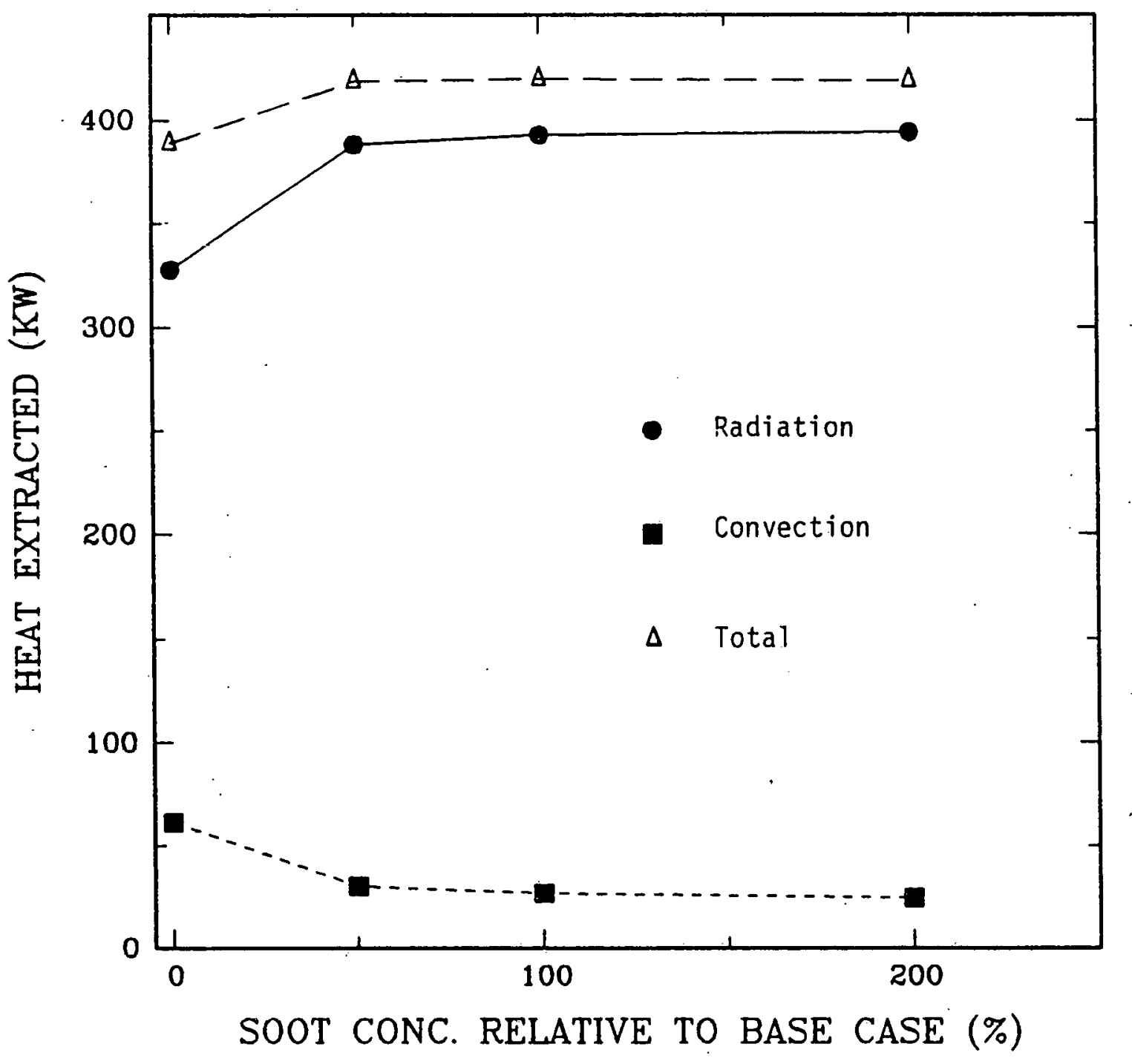

Figure 8.7 Effect of Soot Concentration on Heat Extraction 
for a coal water fuel flame which already is highly luminous at atmospheric pressure conditions.

The contribution of the convective heat exchange to the total heat extracted from the system decreases as the soot concentration increases from low initial values. This is in accordance with the observed decrease in temperature of the combustion products due to higher radiation exchange at higher levels of soot concentration.

\section{Soot Absorption Coefficient}

Associated with the provious case is the effect of changing the sont. absorption coefficients. This coefficient is multiplied with the soot concentration in estimating the absorption coefficients of the three gray gases. In the base case, a 1.7 Megawatt coal water fuel flame, these values are:

$$
\begin{aligned}
& \mathrm{K}_{\mathrm{S} 1}=2012 \mathrm{~m}^{2} /(\mathrm{kg}) \\
& \mathrm{K}_{\mathrm{S} 2}=2352 \mathrm{~m}^{2} /(\mathrm{kg}) \\
& \mathrm{K}_{\mathrm{S} 3}=3171 \mathrm{~m}^{2} /(\mathrm{kg})
\end{aligned}
$$

Twn rases were shosen for running the numerical calculations. In Llie first of these, a value of $1000 \mathrm{~m}^{2} /(\mathrm{kg})$ was chosen for the three coefficients. In the second, a value of $3000 \mathrm{~m}^{2} /(\mathrm{kg})$ was selected to replace the base case values. These values are considered to be within a phȳsically realistic range.

Figure 8.8 shows the effect of soot absorption coefficient on the heat removed by the walls through radiation. Additional 20 Kilowatts are removed when the absorption coefficients are increased from 1000 to $3000 \mathrm{~m}^{2} /(\mathrm{kg})$. The gas zone temperatures are reduced only by $20^{\circ} \mathrm{C}$. 


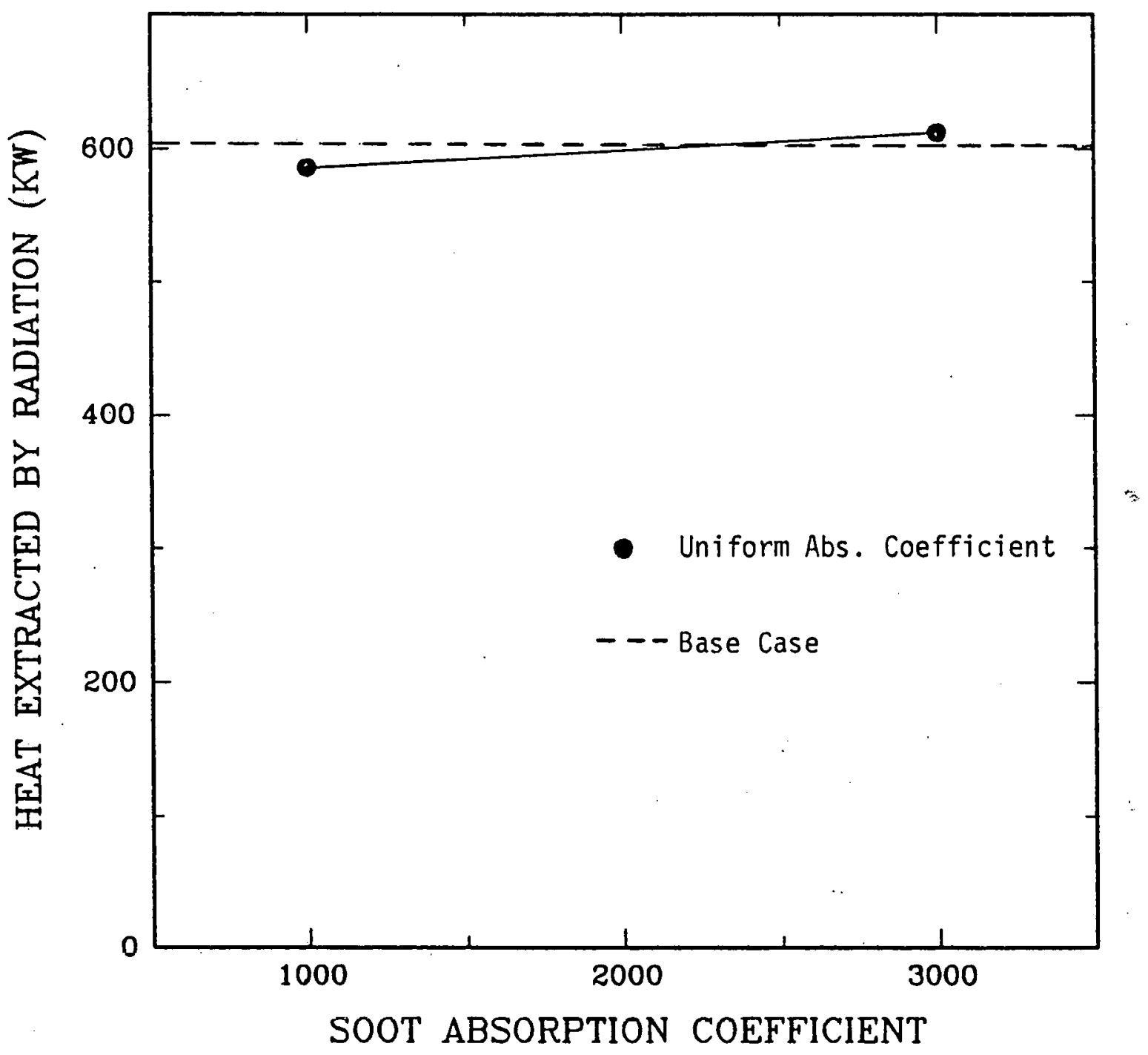

Figure 8.8 Effect of Soot Absorption Coefficient on Heat Extraction 


\section{Fuel Thermal Input}

An increase of the fuel thermal input by means of increasing the fuel heating value while maintaining a constant air flow rate, produces an increase in gas temperatures and, in turn, in the radiation to the walls due to the strong dependence of radiation on temperature (proportional to the fourth power of absolute temperature). However, refractory surface temperatures also increase, resulting in higher values of reradiation. The net result of increasing the fuel thermal input by 48 is an increase of 88 In the total energy extracted from the system (Figure 8.9), and the total heat extracted by the walls as a fraction of the total heat input changeo from 398 to 40.58 .

\section{Excess Air}

Decreasing the air flow rate for a given fuel input results in an increase of the gas temperatures which, in turn, causes an increase in the net radiative flux to the walls of the combustor. As in the case of increasing fuel input for constant air flow rate, increased radiation increases surface temperatures thus increasing reradiation. A reduction of the excess air from 158 to 58 produces an increase of 88 in the total energy extracted from the combustion tunnel as shown in Figure 8.10. At the same time the heat extracted by the walls increases from 398 to 438 .

\section{Surface Emissivity}

Fifteen furnace sections were used in the computer modeling calculations. Two of these sections had bare metal walls and an emissivity of 0.8 was assumed because of the oxide layer coverage on these metal walls. The rest of the sections are lined with refractory bricks, which accumulated a layer of slag during coal water fuel and pulverized coal experiments. 


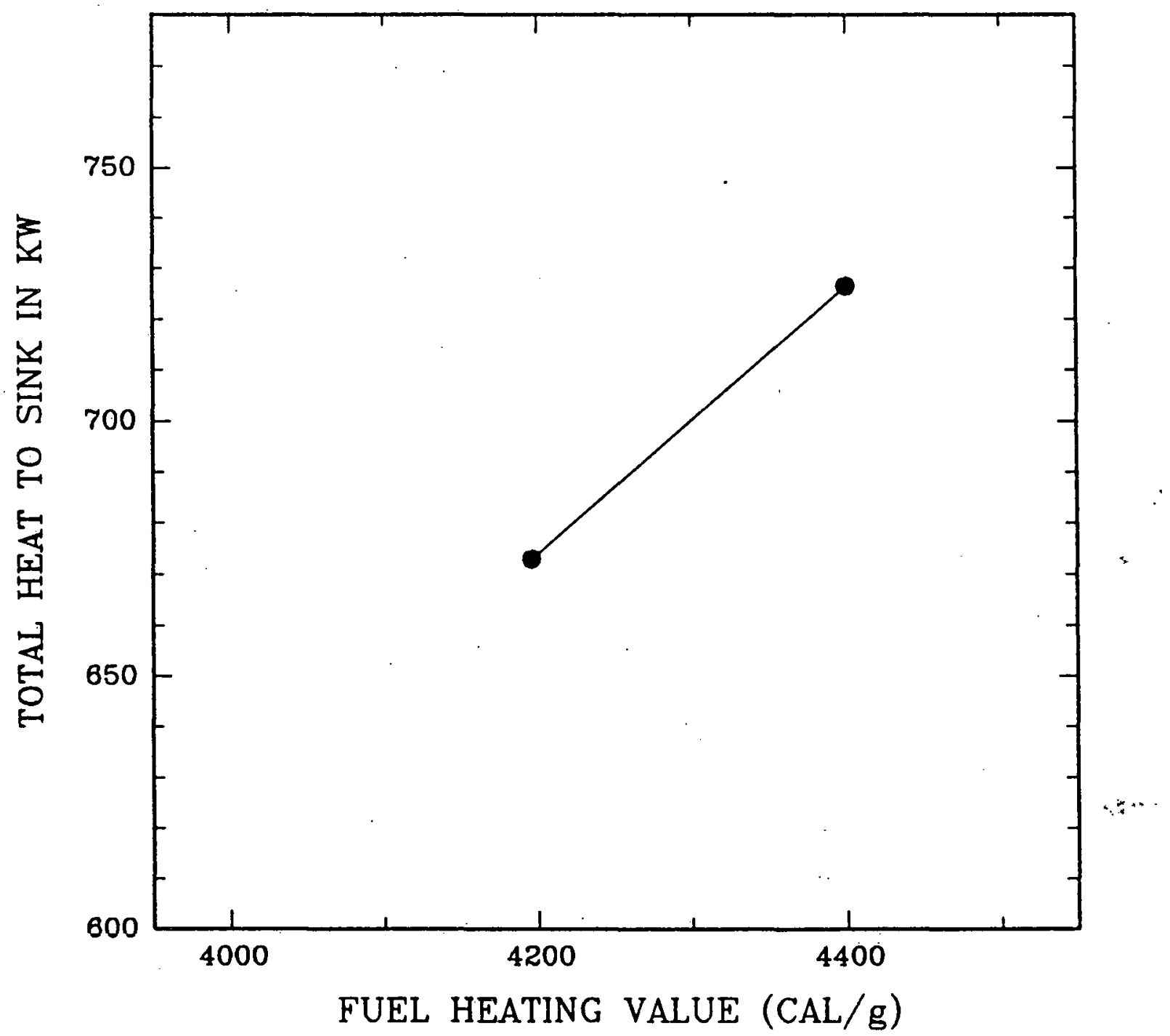

Figure 8.9 Effect of Fuel Thermal input on Heat Extraction 


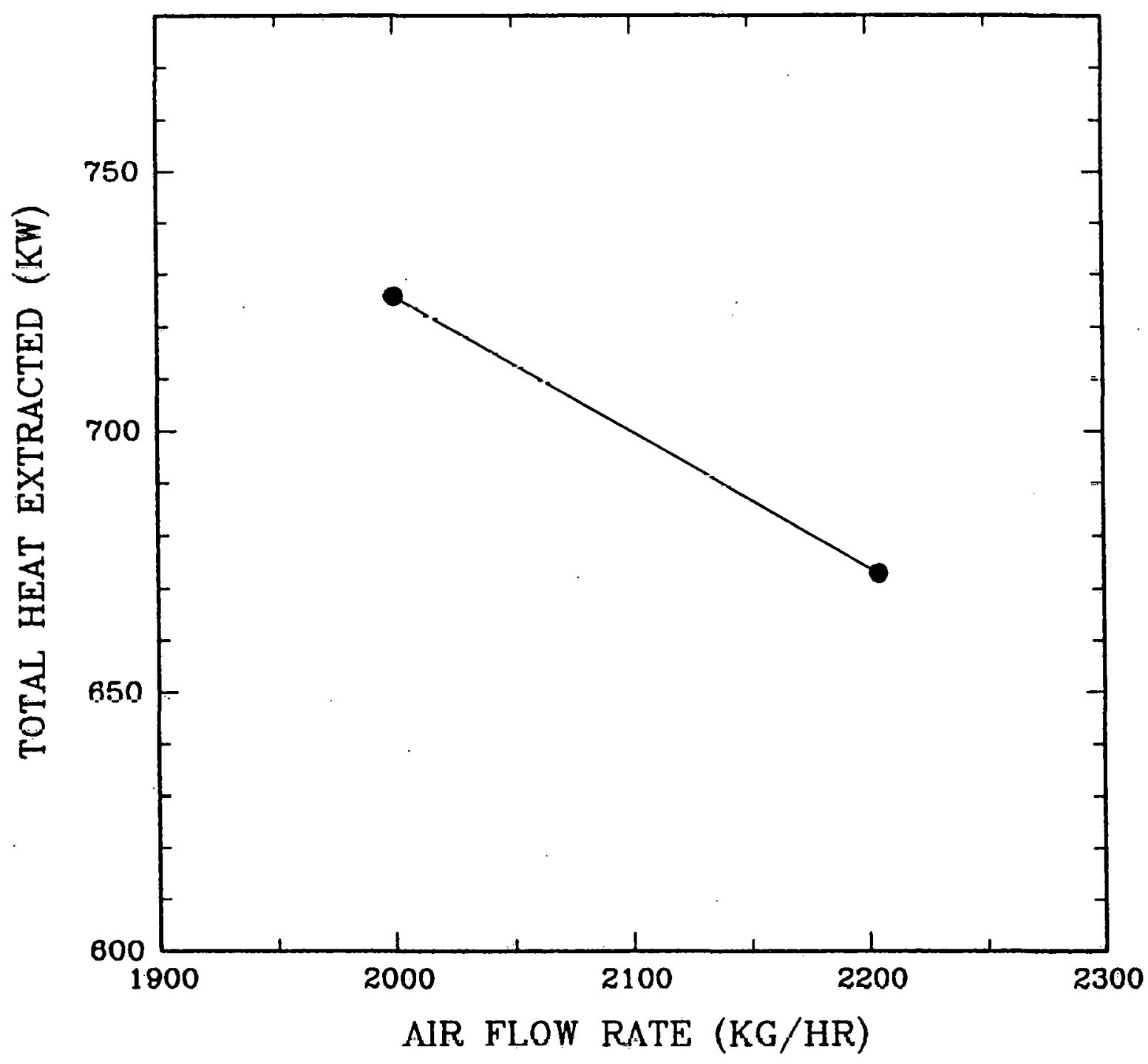

Figure R. 1n Effert. of Air Flow Rate on Heat Extraction 
Surface emissivity plays an important role in the heat transfer to the walls. Goetz, Nsakala and Borio ${ }^{32}$ found that emissivities for glassy deposits are temperature dependent, i.e., emissivity decreases with increasing temperature. Other authors $(33,34,35)$ observed similar behavior for ash bearing flames with non-gray gases present, although the wall emissivities reported were higher in some cases (0.7-0.8) (35) and lower in others $(0.4-0.6)(36)$. In the numerical calculations carried out the surface emissivities for the refractory surfaces were varied from 0.24 to 0.70 . Figure 8.11 shows that the emissivity of the refractory surface has very little effect on heat extraction. This is because over 608 of the heat is extracted through the cold sections (see Table 8.2), for which a constant emissivity of 0.8 was assumed.

Another test was carried out in which a refractory emissivity of 0.4 was assumed and then all of the values, including those for the cold sections, were multiplied by a factor $X$ which varied from 0.6 to 1.2. Figure 8.12 shows the effect of this variation on the total heat extraction from the combustion tunnel. The radiative heat flux and the total heat removed from the system increase linearly with increasing surface emissivity due to the linear relationship of heat extractions through radiation and surface emissivity. This effect is most significant for the cold surface since in this case reradiation is negligible.Consequently, using higher surface emissivities for bare metal sections results in larger heat extraction by the furnace walls through radiation and in turn higher total heat extraction is achieved. Similar results are reported in the literature $(35,36)$. 


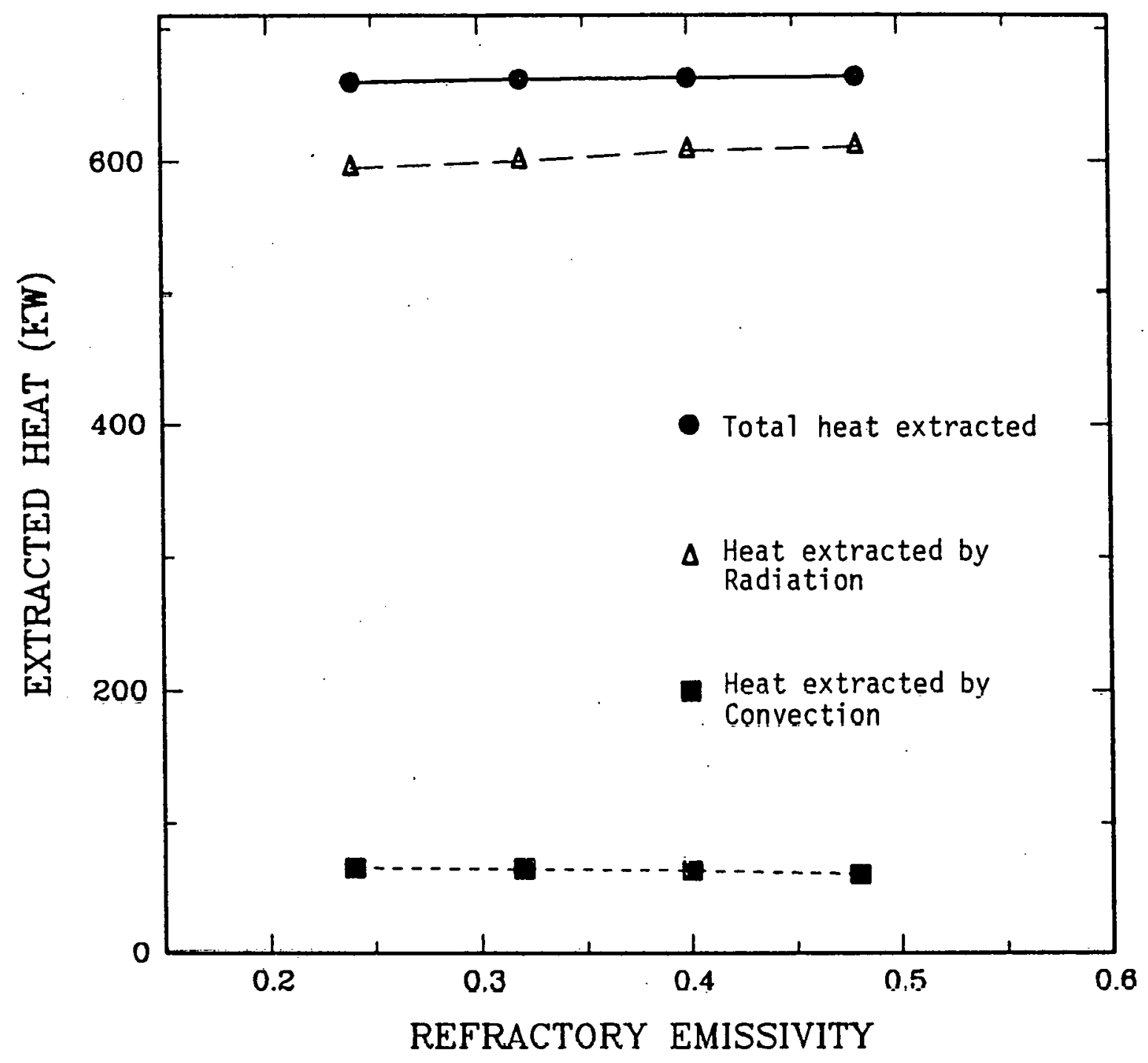

Figure 8.11 Effect of Refractory Emissivity on Heat Extraction 


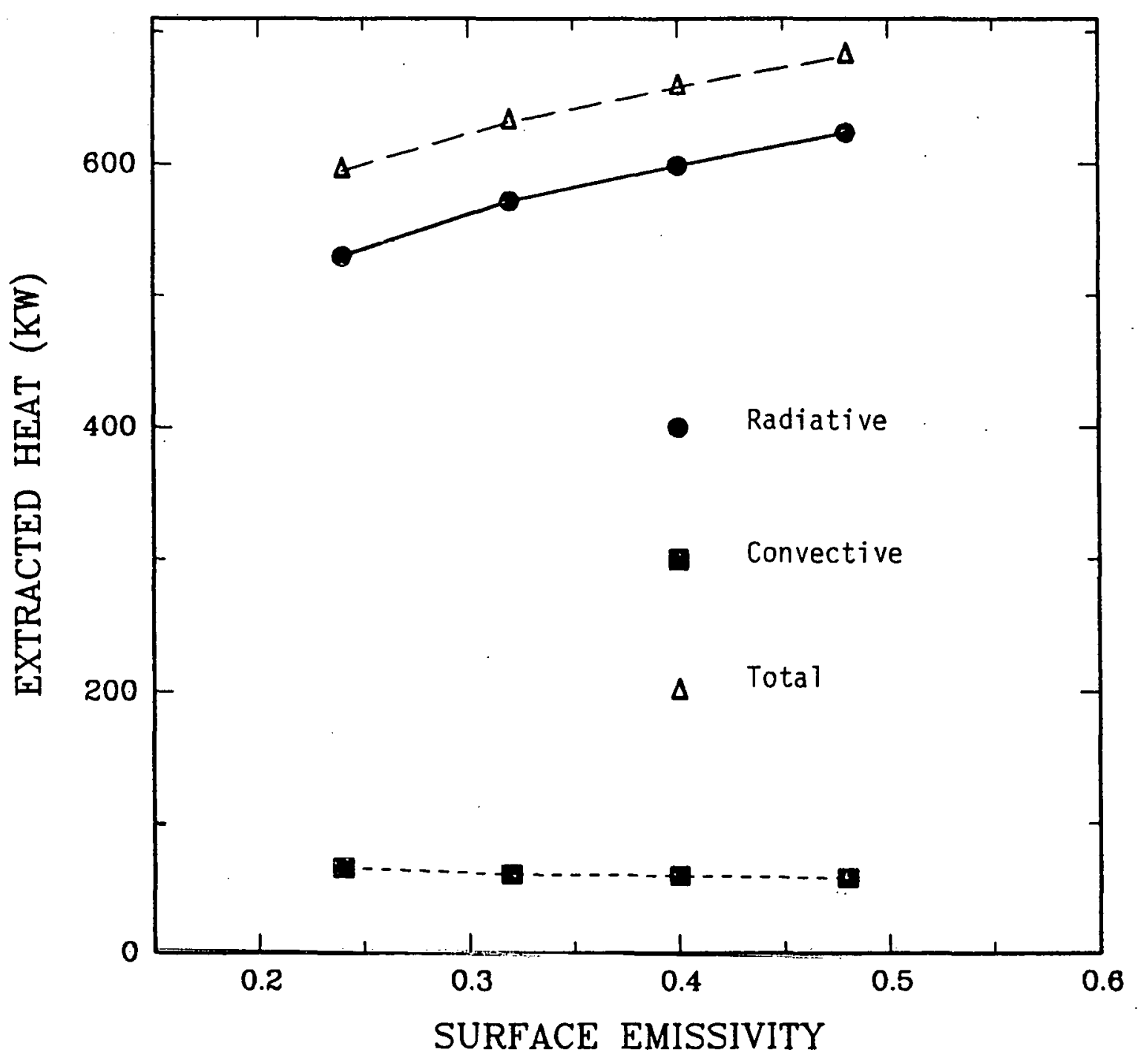

Figure 8.12 Effect of Cold Surface Emissivity on Heat Extraction 
Table 8.2

Heat Extracted as a Function of Refractory Emissivity

\begin{tabular}{|c|c|c|c|c|c|}
\hline $\begin{array}{l}\text { Refractory } \\
\text { Emissivity }\end{array}$ & $\begin{array}{c}\text { Total } \\
\mathrm{kW}\end{array}$ & $\begin{array}{c}\text { Radiative } \\
\mathrm{kW}\end{array}$ & $\begin{array}{c}\text { Convective } \\
\mathrm{kW}\end{array}$ & $\begin{array}{l}\text { Coal } \\
\mathrm{kW}\end{array}$ & $\begin{array}{r}\text { Surface } \\
8\end{array}$ \\
\hline 0.24 & 660.60 & 595.30 & 65.30 & 416.90 & 63.11 \\
\hline 0.32 & 661.80 & 600.20 & 61.70 & 414.30 & 62.60 \\
\hline 0.40 & 663.40 & 604.10 & 59.40 & 413.10 & 62.27 \\
\hline 0.48 & 664.00 & 606.30 & 57.70 & 411.80 & 67. .2 \\
\hline 0.60 & 665.40 & 609.50 & 56.00 & 410.80 & 61.74 \\
\hline 0.70 & 666.10 & 611.20 & 54.90 & 409.50 & 61.48 \\
\hline
\end{tabular}




\section{Temperature of Water Cooled Surfaces}

The model uses different boundary conditions for the energy equation if bare metal surfaces are used instead of refractory lined surfaces. For the refractory lined surfaces the heat flux removed is transferred to the air surrounding the furnace by convection. As for the bare metal sections, the surface temperatures are fed into the model as boundary conditions. The value of this temperature is seldom known with precision. It is then important to see the influence of changing this surface temperature on the calculation of the total heat extracted throughout the walls, in particular in those cases where several sections of the furnace are water cooled.

The net heat transfer to the cold surfaces by radiation is proportional to the difference between the fourth power of the cold surface absolute temperature and the fourth power of the absolute temperature of other exchanging zones, hot gases and refractory surfaces.

$$
Q \propto\left(T_{i}^{4}-T_{s}^{4}\right)
$$

Where:

$\mathrm{T}_{1}=$ Gas or refractory absolute temperature

$\mathrm{T}_{\mathbf{S}}=$ Cold surface absulute teiuperature

The results of the model indicate that when $T_{1}$ is increased from $300^{\circ} \mathrm{C}$ to $500^{\circ} \mathrm{C}$, the heat extraction is slightly reduced, therefore gas and refractory temperatures increase by about $20^{\circ} \mathrm{C}$. The overall difference $\left(T_{i}{ }^{4}-T_{s}{ }^{4}\right)$ remains roughly unchanged, and so does the radiative heat exchange (Figure 8.13).

\section{Elame Spread Angle}

The flame spread angle used in earlier studies was $17^{\circ}$. A case in which the angle was reduced to $5.7^{\circ}$ was investigated. The results show that 


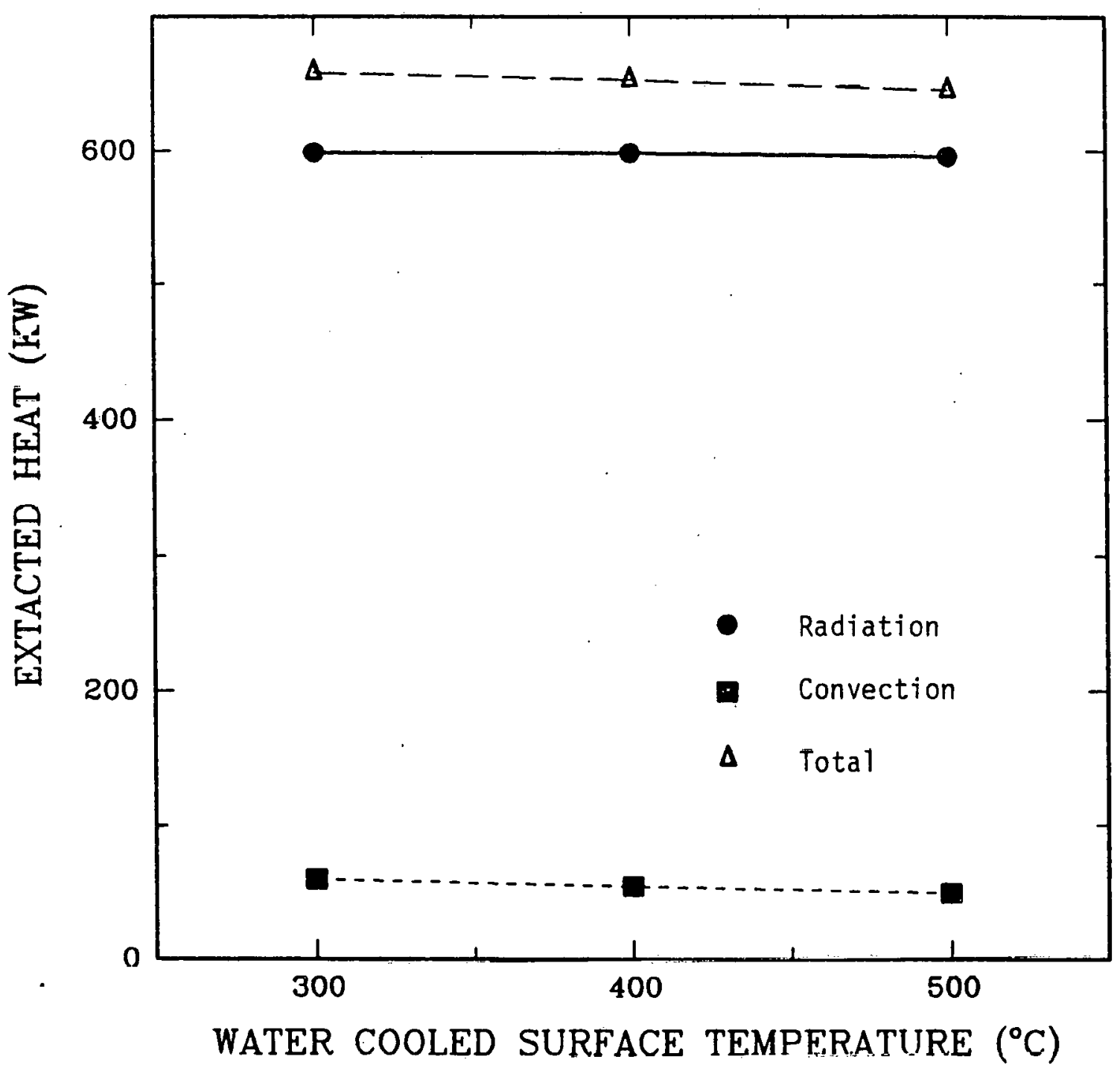

Figure 8.13 Effect of Water Cooled Surface Temperațre on Heat Extract.ion 
the heat extracted by the walls was redistributed. A reduction of the heat removed by the surface zones near the nozzle and an increase in the heat removed from the surfaces downstream were obtained. The total change of the overall heat extracted due to the spread angle was below 18 .

Partial Pressures of Carbon Dioxide and Water Vapor

Gas emissivity is a function of the partial pressures of carbon dioxide and water vapor as well as soot concentration. However, the relative contribution of soot concentration to the total gas emissivity is much greater than that of the partial pressures of these gases. As a result of that a tenfold increase in these partial pressures (yielding physically unrealistic values) produced less than 18 increase in total heat exchange. Degree of Fuel Oxidation

The oxidation of the fuel in the combustion tunnel in the experiments carried out was measured to have $65 \%$ of the fuel burned in the first flame zone and $35 \%$ in the second zone. In the modelling calculations two other cases were investigated:

(i) 508-50\%. This case might represent coals of low volatile matter content. The complete combustion of the solid carbon or char generated from these coals would take relatively long residence times ( $-2 \mathrm{sec})$. In this case, the degree of oxidation was distributed equally among the first two flame zones. The net result is an elongation of the flame, slightly reducing the temperatures of the first gas zones and increasing the temperatures toward the end of the furnace. The overall change in the heat extracted is negligible.

(ii) 1008-08. This case represents combustion conditions that may exist in a lean natural gas flame where complete combustion is 
achieved at relatively short distances from the fuel nozzle. In this case all the fuel is considered to be burning in the first flame zone. The effect is opposite to the previous case: the temperatures is higher near the nozzle and lower towards the furnace end. The total change in the heat removed was below 18 . 


\section{Section 9}

\section{HEAT EXCHANGE IN GAS TURBINE COMBUSTORS}

\section{Introduction}

A comparison of the experimental results from the Combustion Research Facility with the theoretical predictions using the radiation model, shows that realistic estimates of the radiative characteristics of coal water fuel flames can be obtained at atmospheric pressure. Further application of the data and the model to gas turbine combustors might be achieved by scaling of the flame shape, volume and structure with combustor pressure. Literature data on the effect of pressure upon the variation of radiative properties can be used in combination with such flame scaling to obtain an approximate estimate of radiative heat transfer in gas turbine combustors. Having the above constraints in mind the variables which were considered in this investigation were:

(1) pressure (1-10 atm)

(2) combustor dimensions

(3) excess air $(188-408)$

(4) thermal input (0.25-1.0 MW)

The input conditions chosen for performing the calculations were based on the data available from the METC gas turbine combustor ${ }^{39}$ and the data obtained from the CRF. The values of pressure, thermal input and combustor size chosen for the modeling study were similar to those reported by Farag et a1 ${ }^{37}$ using the METC combustor. The scaling of the flame from the CRF to the gas turbine combustor was done by maintaining geometric similarity. This meant that corresponding flame zones chosen for the purpose of radiative heat flux calculations had identical molar species concentrations but their size was reduced by a factor of four. In the 
calculations of the radiative properties of the combustion products $\mathrm{CO}_{2}, \mathrm{H}_{2} \mathrm{O}$ and soot the total pressure was taken into account.

In the following section results from this study are reported. The input conditions used in these calculations are listed in Table 9.1.

\section{$\underline{\text { Pressure }}$}

The pressure range considered was between 1 and 10 atmospheres. The values of partial pressures of carbon dioxide and water vapor at atmospheric pressure were increased linearly with increasing pressure.

The effect of pressure on soot production was investigated by several authors. Flower and Bowman 25,26 found that the sont yield (mass of soot/mass of fuel) is proportional to the pressure raised to a power of 0.7 \pm 0.3 . This implies that:

$$
C_{s} \propto p^{(n+1)}
$$

where:

C: Soot concentrations $\left(\mathrm{g} / \mathrm{m}^{3}\right)$.

p: Pressure

n: Soot yield exponent.

Kadota, Hiroyasu and Farazandehmehr ${ }^{27}$ found a similar exponent as the one found by Bowman and Flower. On the other hand, MacFarlane, Holderness and Whitcher 28 and Homann ${ }^{29}$ found that the soot yield was proportional to the pressure raised to a power between 2.5 and 3 . Similar work performed by M1lberg ${ }^{30}$ at pressures below atmospheric had shown a linear relationship between soot yield and pressure.

In our work, when the soot concentration was varied between 1 ts value at atmospheric pressure and a value proportional to the square of the pressure no significant differences in the gas temperature or radiant heat transfer were observed. 
Table 9.1

Input Conditions of Gas Turbine Combustor Numerical Simulation

Run

312

A

B

c

D

$\mathbf{E}$

$\mathbf{F}$

$\mathbf{G}$

H

Input:

configuration

CRF

GIC

GTC:

GTC

GIC

GIC

GIC

GTC

GIC

Exponent for Soot

vol. Conc.

1.00

1.00

1.0

1.00

0.00

1.00

1.50

0.00

1.00

Pressure (ATM)

2.00

$7 . \leq 0$

10.00

7.40

7.40

7.40

4.50

4.50

Fuel Flow Rate

181.48

181.48

181.48

181.40 , 40.80

40.80

40.80

46.50

46.50

Air Flow Kate $(\mathrm{kg} / \mathrm{h})$

Excess Air

(\%)

1350.00

1720.00

1720.00

1720.00

360.00

360.00

360.00

330.00

330.00

10.90

39.20

39.20

39.20

39.20

39.20

39.20

18.20

18.20

output:

Total Heal Input (kW)

lleat to Gases

$$
\begin{array}{r}
(\mathrm{kW}) \\
(\%)
\end{array}
$$

67.72

1165.40

96.65

1162.90

96.44

1162.70

96.43

235.40

87.41

234.40

87.04

234.30

87.00

237.90

83.62

236.90

Total Heat Extraction

$$
\text { ( } k \text { H) }
$$

(s)

363.50

30.78

37.40

3.10

38.00

38.10

32.70

32.50

12.07

32.20

11.96

45.60

16.03

45.00

Heat Extraction

by Rad.

354.50

35.90

37.40

37.40

31.50

31.90

31.60

44.70

44.40 
In the computer Runs $E, F$ and $G$, the soot yield was varied while keeping the other parameters constant. From Table 9.1 and Figures 9.1 and 9.2 that it can be seen the soot yield did not have any effect on either the radiative flux or the gas temperature. This is shown in Section 8 to be the result of the fact that the flame emissivity reaches an asymptotic value with increasing soot concentrations.

Moreover, the higher partial pressures of $\mathrm{CO}_{2}$ and $\mathrm{H}_{2} \mathrm{O}$ at higher pressure did not affect the heat extracted significantly in the range sturiat.

Figure 9.3 shows the effect of pressure on the incident radiation to the walls. Radiative fluxes for Runs B, C and E corresponding to pressures of $1,7.4$ and 10 atmospheres respectively, are plotted versus axial distance. A small increase in the radiative flux is observed when the pressure is increased from 1 to 7.4 atmospheres; the flux remains constant beyond that. No significant change in the gas temperature with increasing pressure was observed as shown in Figure 9.4 .

\section{Combustor Dimensions}

As mentioned in the foregoing discussion on the scaling of the flame data, the dimensions of the combustion chamber were reduced by a factor of 4. The resulting gas turbine combustor dimensions which were considered in this study were 0.3 meters in diameter and 1.15 meters in length, similar to the dimensions of the U.S. DOE Morgantown Energy Technology Center bench scale combustor ${ }^{37}$.

Using these gas turbine dimensions, the total heat extraction through the combustor walls was reduced from 308 in the CRF flame to about 38, for the same fuel flow rate (Runs $A$ and $B$ in Table 9.1). This is due to the reduction in the wall surface area by more than one order of magnitude. 


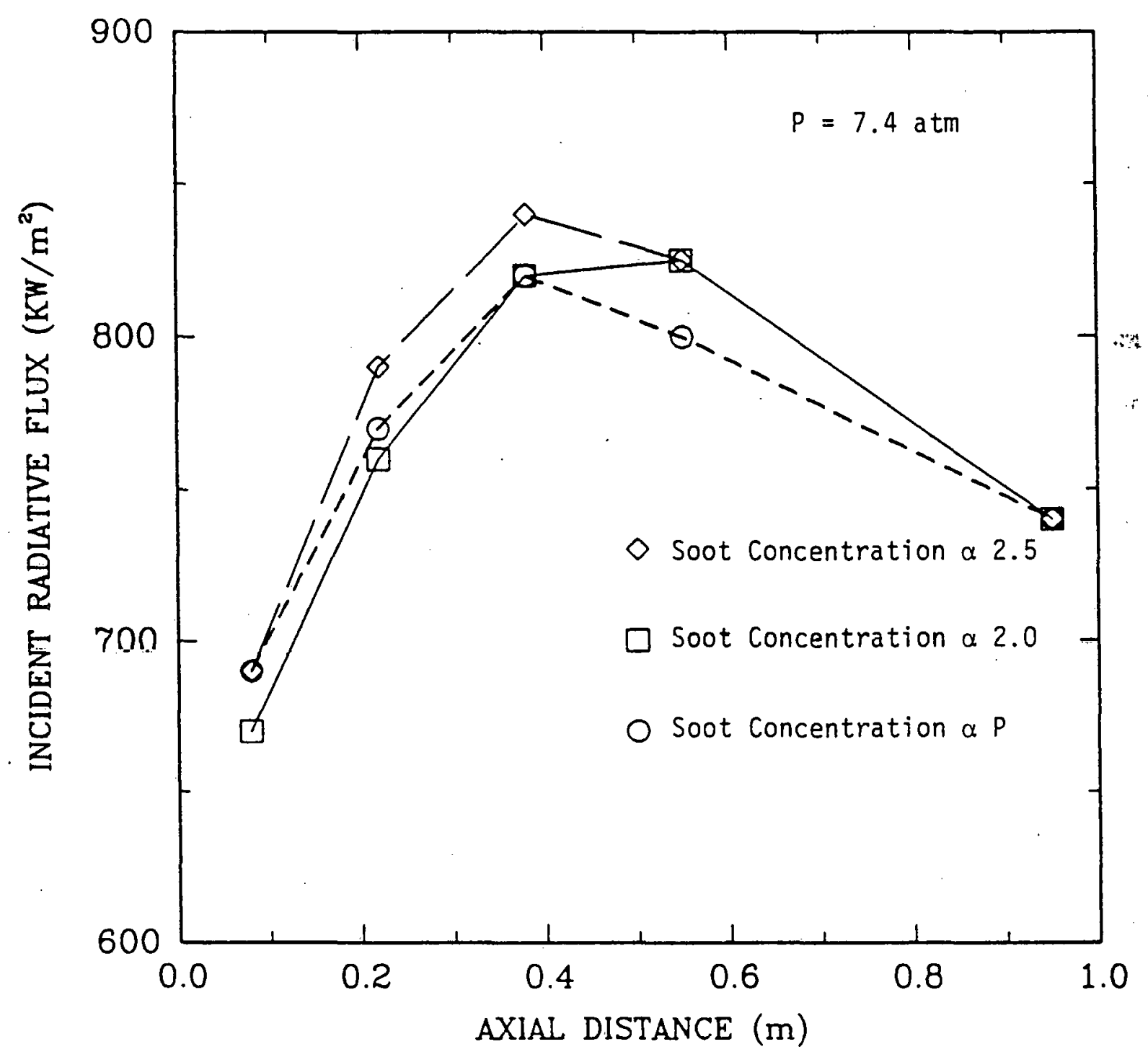

Figure 9.1 The Effect of the Functional Variation of Soot Concentration with Pressure upon the Incident Radiative Heat Fiux in a Gas Turbine Combustor 


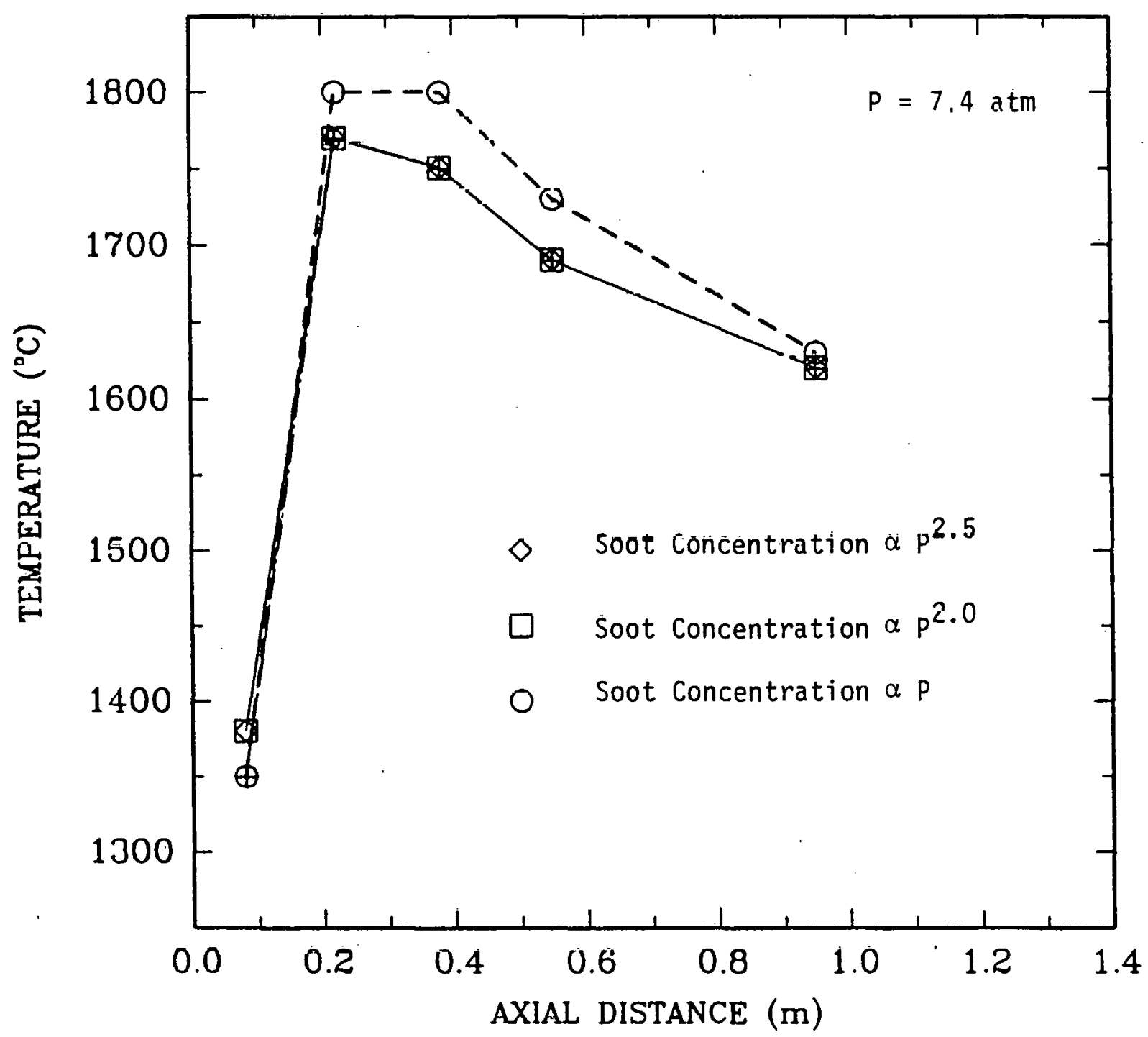

Figure 9.2 The Effect of the Functional Variation of Soot with Pressure upon Gas Temperature in a Gas Turbine Combustor 


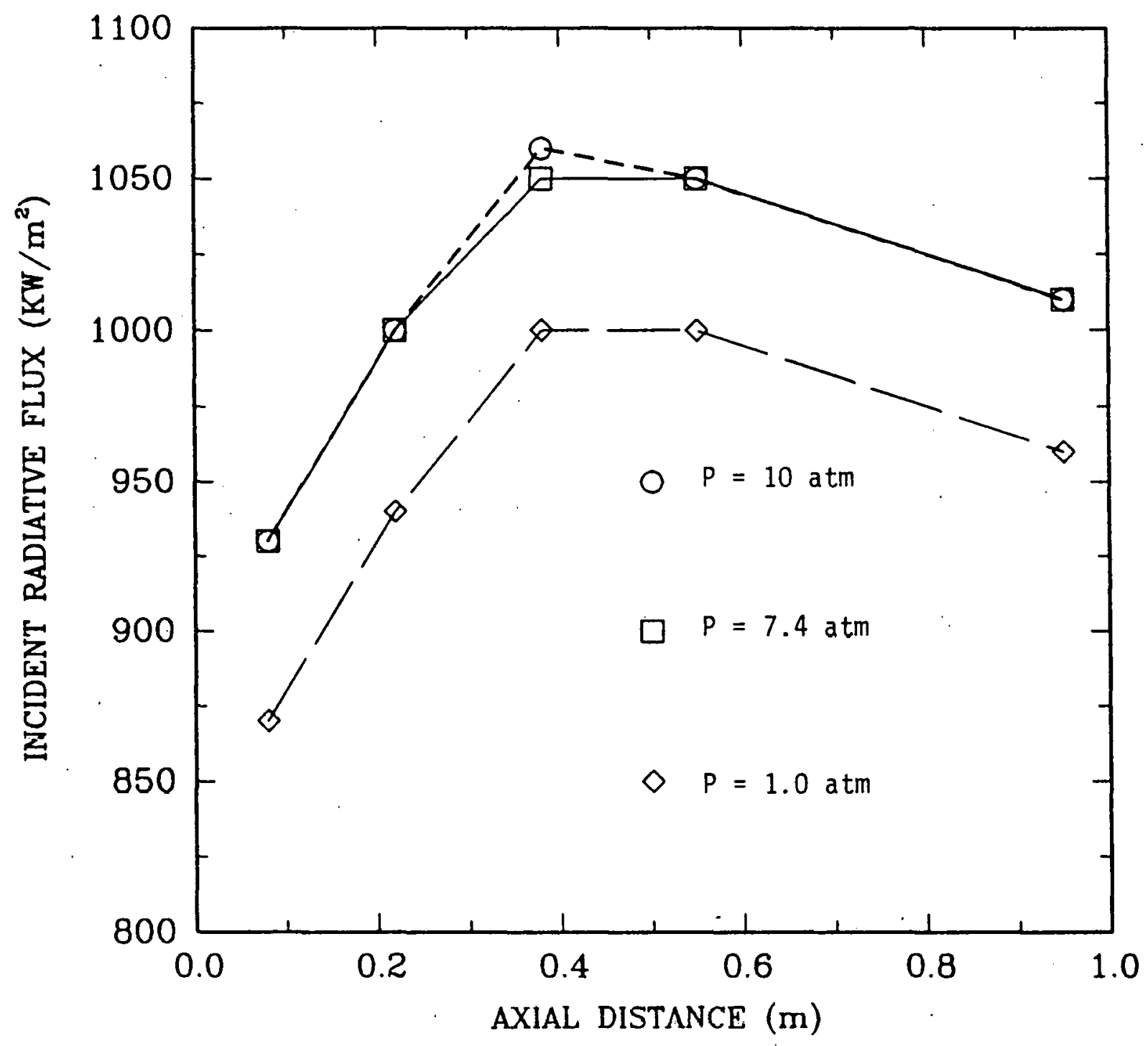

Figure 9.3 Effect of Pressure on Radiative Flux 


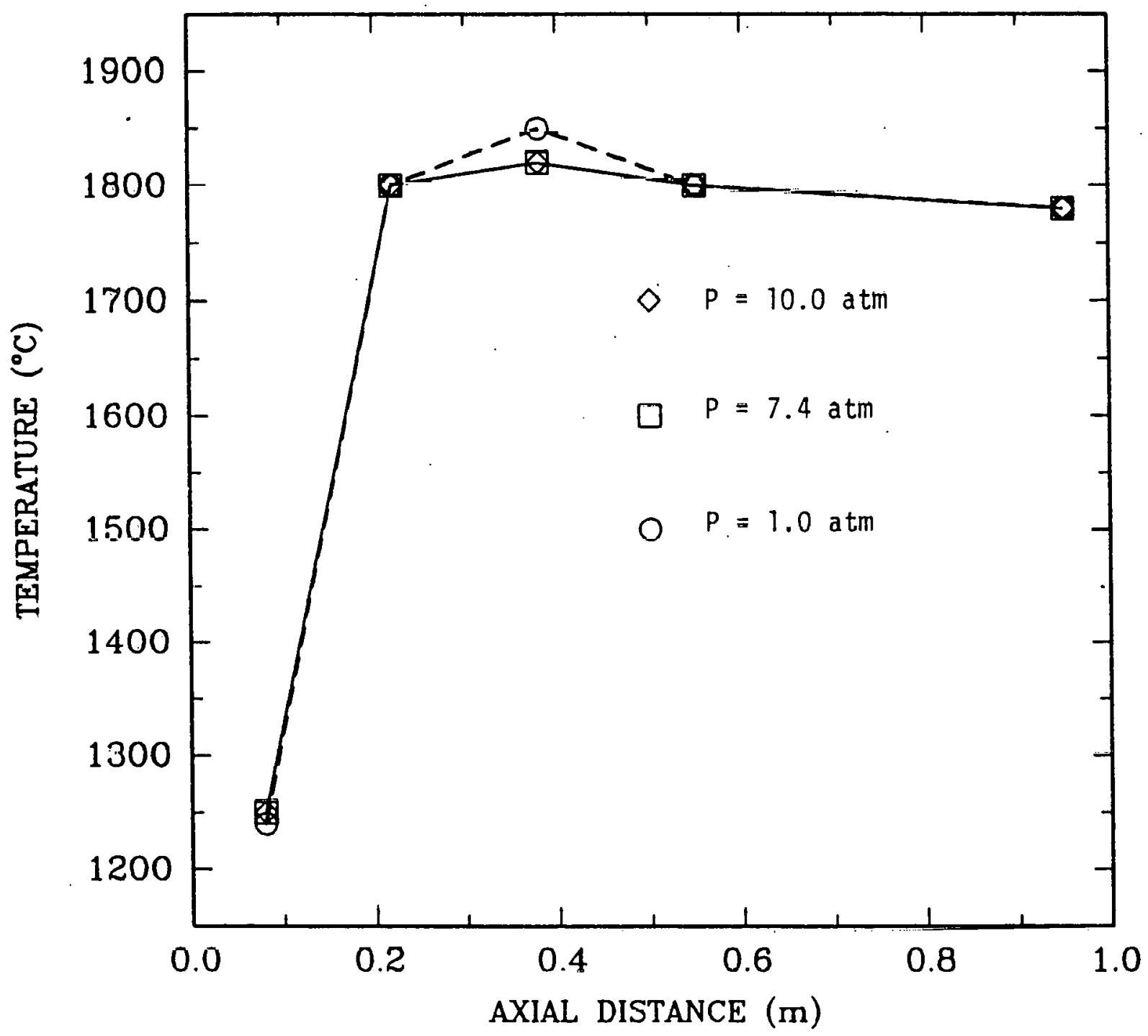

Figure 9,4 Effect of Pressure on Gas Temperature 
Because of this reduction in heat extraction it was necessary to increase the excess air in order to keep the temperature of the exiting gases below $1000 \mathrm{~K}$ as measured in the METC experiments ${ }^{37}$. Accordingly, the excess air level was increased to 39.208 in Runs $A, C$ and G.

The effect of the reduction in combustor size on the incident radiative flux to the walls and the gas temperatures can be seen in Figures 9.5 and 9.6. In these Figures the radiative flux to the wall and the gas temperature in the CRF are compared with those in the gas turbine combustor, without accounting for the pressure effects on the flame emissivities (Runs $A$ and $B$ in Table 9.1). Both the incident fluxes of radiation and the gas temperatures are higher in the case of the gas turbine flame. However because of the higher wall temperature of the refractory lined gas turbine combustor wall the net radiation absorbed is only about one tenth of that for the CRF flames.

\section{Excess Air}

Excess air can vary within a wide range in gas turbine combustor operation since it is the mechanism by which exit gas temperature is controlled. Gases leaving the combustor to the turbine must be below an allowable temperature limit and must have uniform temperature distribution across the combustor exit.

In the cases studied the excess atr levels used were 39.28 and 18.28 respectively. The radiative flux and gas temperature profiles calculated for pressures of 7.4 and 4.5 atmospheres respectively are shown in Figures 9.7 and 9.8. They show that for the same thermal input higher temperatures and thus higher radiation fluxes are obtained for the lower excess air combustion (excess air level 18z). 


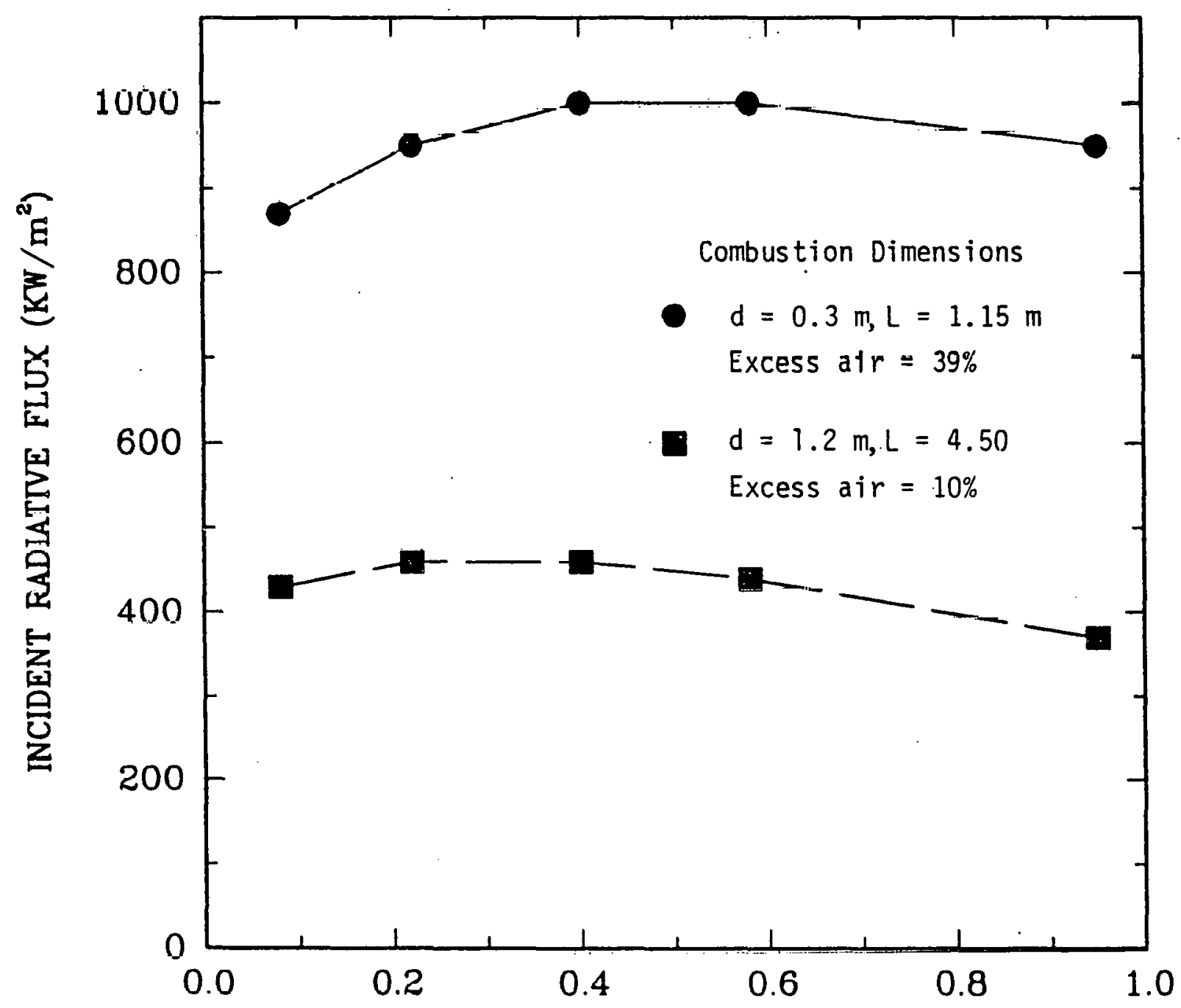

AXIAL DISTANCE AS A FRACTION OF CUMBUSTOR LENGTH

Figure 9.5 Effert of Combustor Dimensions on Radiative Flux 


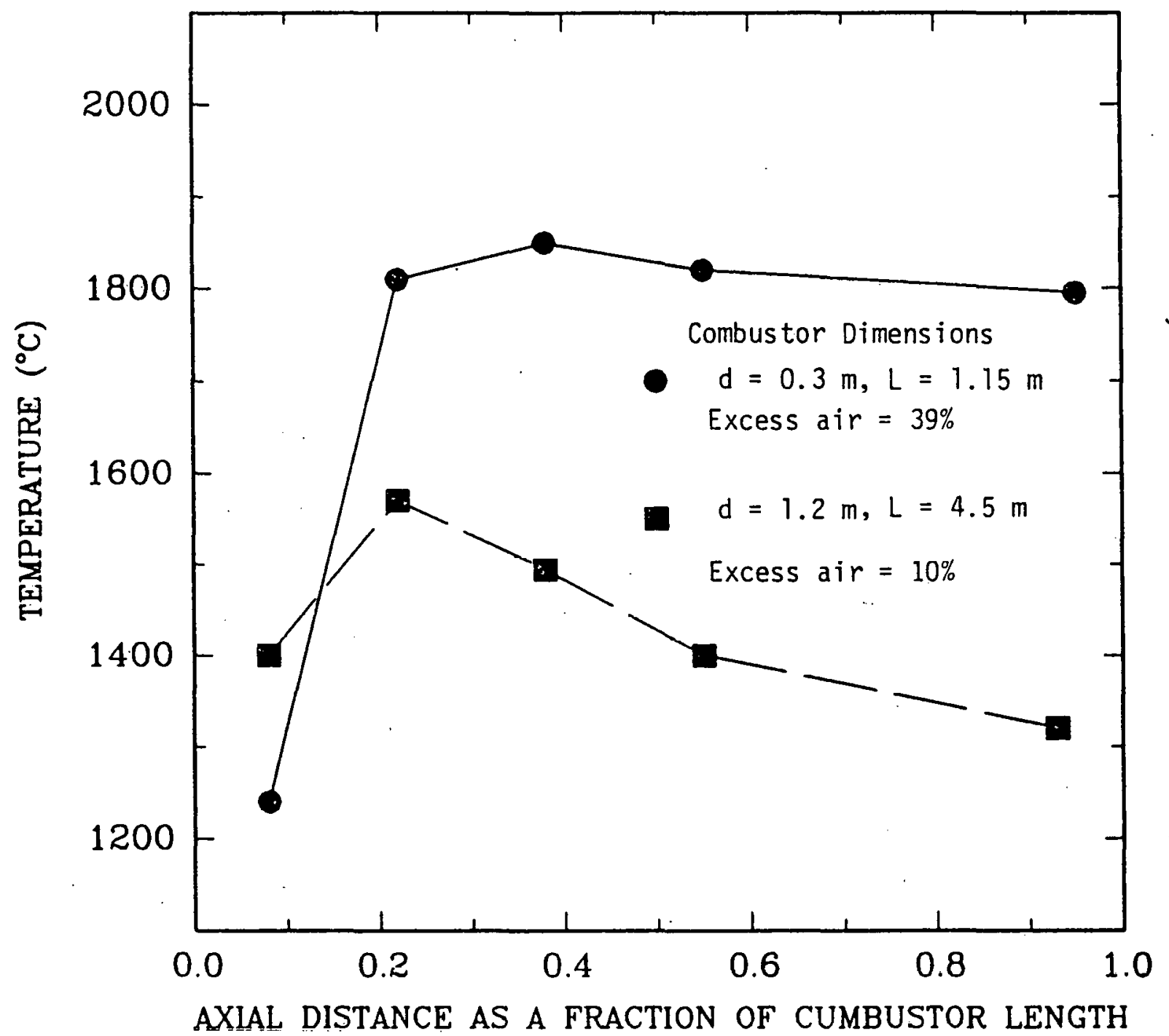

Figure 9.6 Effect of Combustor Dimenstons on Gas Temperature 


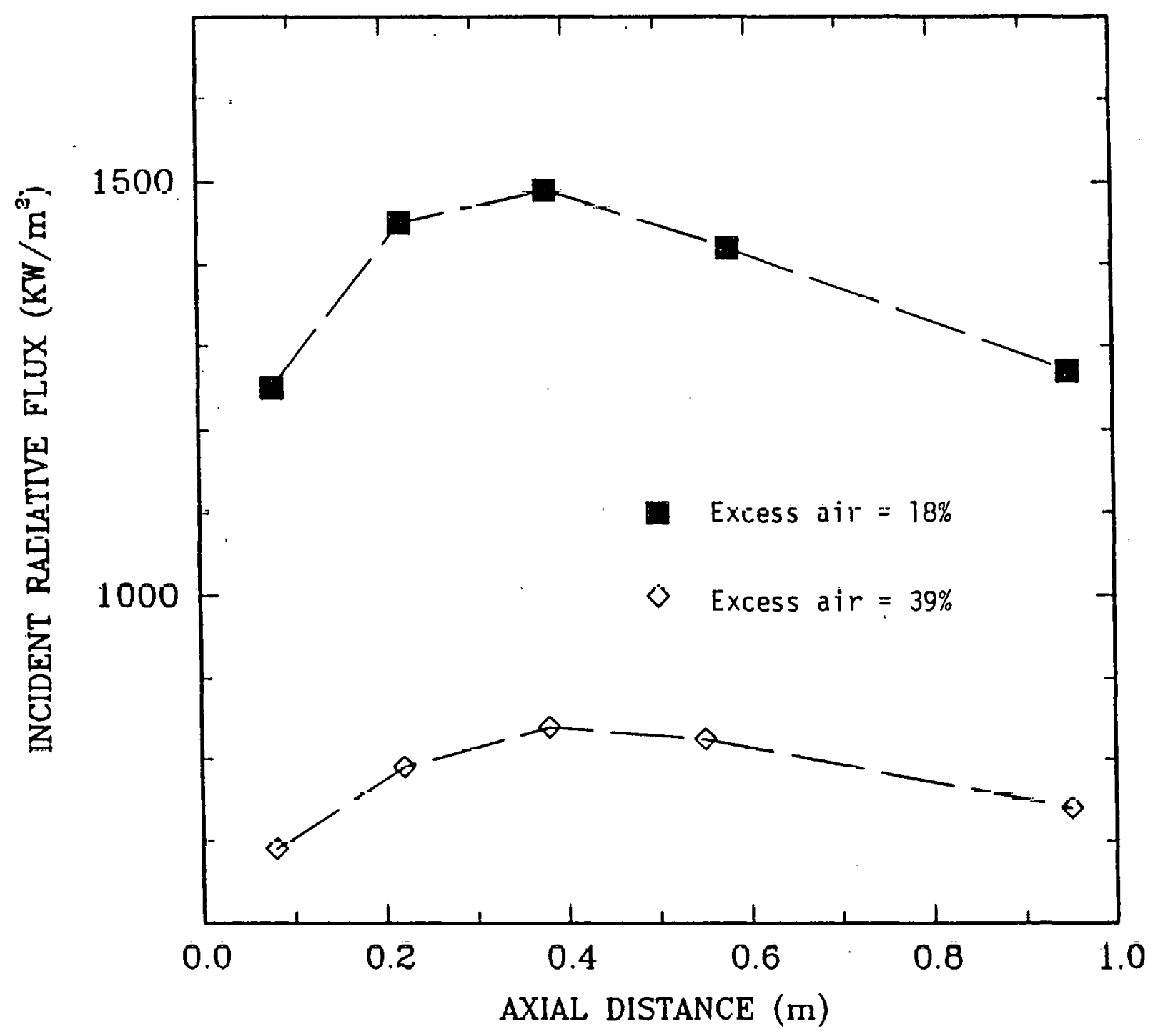

Figure 9.7 Effect of Excess Air Upon Incident Radiative Flux in a Gas Turbine Combustor 


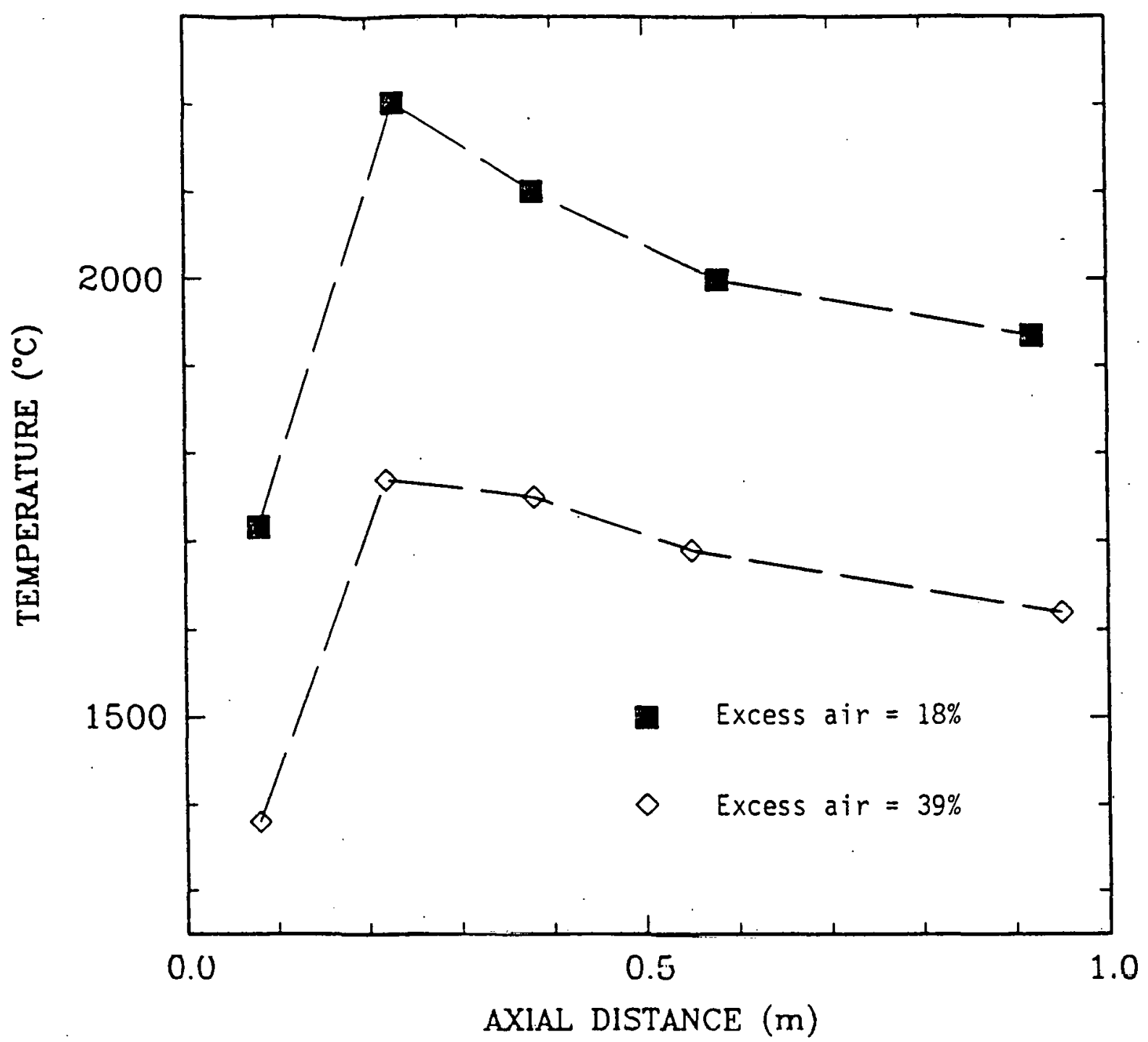

Figure 9.8 Effect of Excess air on Gas Temperature in a Gas Turbine Combustor 
Thermal Input

Three fuel flow rates were considered. The first flow rate used was similar to the one chosen in the atmospheric pressure runs $(181.48 \mathrm{~kg} / \mathrm{hr})$. The other two were $40.80 \mathrm{~kg} / \mathrm{h}$ and $46.50 \mathrm{~kg} / \mathrm{h}$ at pressures of 7.4 and 4.5 atmospheres respectively, corresponding to the flow rates used at the Morgantown gas turbine combustor.

By comparing Runs $C$ and $F$ we can see that while reducing the thermal input by a factor of 4 (Table 9.1) results in a small reduction in the total heat extracted (from $38 \mathrm{~kW}$ to $32.5 \mathrm{~kW}$ ), the pexcentage of the thermal input removed through the furnace walls incrcases fourfold, from 3.28 to 12,18 . This is tantamount to saying that the net radiative flux to the wall is little affected by the heat input to the combustor and hence, its fraction of the total heat input is approximately inversely proportional to thermal input to the combustor. 


\section{Section 10}

\section{Conclusions}

\section{Effect of Burner Input Parameters on Fuel/air Rate of Mixing}

- The mixing of the "fuel jet" with the burner airflow and the flow field in the region near the burner was studied in cold flow experiments. The "fuel jet" was represented by the atomizing airflow without or with the addition of water. The decay of the "fuel jet" velocity and of the concentration of a chemical tracer (CO) introduced into the atomizing airflow was determined along the jet axis for the effects of the degree of swirl in the combustion air, the atomizing air flow rate, the addition of water to the atomizing air and total flow rates corresponding to 0.7 and $1.0 \mathrm{MW}$ heat inputs respectively.

- Fuel/air mixing is faster for swirling burner airflows than for non swirling annular jets. However, swirl degree beyond that which is needed for the establishment of an internal recirculation zone (S 0.75) does not bring proportional benefits in terms of mixing as illustrated by the axial decay of the concentration of a chemical tracer (CO) introduced into the "fuel" jet.

- Flame stability requires both the fast mixing of the fuel spray with hot recirculated gas and also the establishment of regions of the flow field near the burner where the gas velocity is sufficiently low to provide for anchorage of the flame front.

- When the atomizing airflow is increased for a glven atomizing nozzle, the gas velocity rises along the jet axis with the result that the stagnation region established by the swirling airflow is displaced further downstream from the burner. 
- The same effect is observed when the mass flow rate of the atomizing airflow is increased by the addition of water (representing the fuel spray).

- The implications of results of the near field mixing and flow patterns for burner-atomizer design are:

a) Hollow cone, wide angle spray $\left(>50^{\circ}\right)$, combined with low swirl degree burner airflow is favorable for flame stabilization but there will bc a limit to the splay angle in a gas turbine combustor because of lie rlsk of fuel impingement on the combustor wall.

b) Solid cone, narrow angle sprays $\left(<50^{\circ}\right)$ ought to be combined with higher degree of swirl in the burner airflow to ensure good flame stability. This arrangement is free from the risk of particle impingement on the combustor wall but it requires fine atomization to ensure that the largest char particles on the flame axis whileh lave residence Eimes signiticantly shorter than the mean residence time in the combustor, would not leave the combustor before they are completely burned.

\section{CWF Flames Investigation}

- The prime variable that determines carbon hurn-out in the flame is the drop-size distribution of the CWF spray. Since the fine grind CWF spray (Run 318G) was finer than the ultra-fine GWF (Run 318A), the carbon burnout in the first case was better.

- Dilution of fine grind CWF with water can be used to reduce the effective fuel viscosity and hence to improve the aconization quality without significant penalty in terms of cycle efficiency. 
- In the fly ash, the large particle fraction $(>38 \mu \mathrm{m})$ consists mainly of incompletely burned carbonaceous solids.

- The ultrafine CWF showed the potential of producing a fly ash of very fine particle sizes $(<5 \mu \mathrm{m})$ in case complete burnout of the char particles can be achieved.

- In low ash content coal the probability of releasing small ash centers from the burning char particle is increased whereas these small ash centers may more likely coagulate and form larger molten ash particles when the ash content of the coal is high.

- The theoretically predicted carbon burnout efficiency using a mechanistic model of droplet dry-out, coal devolatilization and char burn-out is in good agreement with experimentally measured values:

\section{NO $x$ Emission}

- Results of experimental studies on fine grind CWF flames show that $\mathrm{NO}_{\mathrm{x}}$ emission can be effectively controlled by staged air injection into the flame. The $\mathrm{NO}_{\mathrm{x}}$ emission was reduced from about $900 \mathrm{ppm}$ in single stage flames to $270 \mathrm{ppm}\left(38 \mathrm{O}_{2}\right)$ in a rich-lean combustion system.

n. The fuel-rich stage residence time necessary for the conversion of FBN to $\mathrm{N}_{2}$ is determined by the nitrogen evolution time during coal pyrolysis.

- Fine atomization is a necessary prerequisite not only for complete combustion in a restricted combustion space but also for high rate of volatile nitrogen evolution necessary in the fuel-rich stage.

o When the atomization quality is high because of effective atomization, the flame solids particle size distribution follows the constituent coal size distribution. In the ease of staged 
combustion process modification, full advantage can be taken of fine coal particle sizes in the CWF for increasing the volumetric heat release rate in the flame without increased $\mathrm{NO}_{\mathbf{x}}$ emission.

Radiative Heat Flux Distribution

Experimental data on atmospheric pressure coal water fuel flames obtained in the MIT Combustion Research Facility, and a zone model of radiative heat flux distribution were used to make approximately calculations of radiative heat transfer in a gas turbine combustor.

For purposes of the ralrulation tho mcasured flame slouclure ispatial distributions of chemical species concentrations) was scaled by a faclur of four, preserving geometric similarity from the CRF flame to the METC experimental gas turbine flame size. Pressure effects upon the contribution of $\mathrm{CO}_{2}, \mathrm{H}_{2} \mathrm{O}$ and soot to flame emissivities were taken into account.,

The results showed that:

- The incident flux of radiation increases with total prcssure; the increase is significant between atmospheric pressure and 7.0 atm but levels off above this pressure level.

o The net radiative heat flux to the combustor wall is insensitive to the variation of the thermal input to the combustor and hence the fractional radlative heat transfer to the wall varies inversely proportionally with the heat input.

o The radiative heat flux incident on a wall element is generally enhanced by increasing soot concentration. The enhancement is significant at low soot concentrations but reaches saturation conditions for soot concentrations in excess of $100 \mathrm{mg} / \mathrm{m}^{3}$.

o It is noteworthy that the above calculations were made for a refractory lined combustor (as in the case of the METC experiments). 
The conclusions concerning the net radiative flux to the wall would be significantly affected by the reduction in the wall temperature e.g. for bare metal gas turbine combustor walls. 


\section{REFERENCES}

1. Karthauser, F.B., "Pulverized Fuel Firing for the Stationary Gas Turbines". Inst. of Fuel Conference on Pulverized Fuel, Harrogate, England, 1947, pp. 724-746.

2. Yellot, J.L. and C.F. Kottkampf, "The Pulverized Coal Gas Turbine Locomotive," Inst. of Fuel Conference on Pulverized Fuel. Harrogate, England, 1947, pp. 830-863.

3. Morde11, D.L. "An Experimental Coal Burning Gas Turbine". Proc. Inst. Mech. Eng. 169 (1955) pp. 163-180; Engineer 203 (1957) No. 5272, pp. $210-213$.

4. Keller, C. "Operating Experience and Design Features of Closed Cycle Gas Turbine Power Plants," Trans. ASME 79 (1957), Pp, 627-643.

5. Gumz, W., Proceedings of Fifth World Energy Conference, 10, pp. 3465-67 (Discussions), Wien, Austria, 1956.

6. Chedaille, J., and Y. Braud, Measurements in Flames, Volume 1 of Industrial Flames, Edited by J.M. Beér and M.W. Thring, International Flame Research Foundation, Crane, Russak \& Company, Inc., N.Y., 1972.

7. Thermal Power Engineering Research Institute (Xian) and Northeast Electric Technology Improvement Bureau (Shenyang) (eds.) "Methods of Combustion Adjustment for Coal-Fired Boilers," pp. 248-249, Water Conservation and Electric Power Press, Beijing, 1976 (in Chinese).

8. Walsh, P.M., M. Zhang, W.F. Farmayan and J.M. Beér, "Ignition and Combustion of Coal-Water Slurry in a Confined Turbulent Diffusion Flame," MIT Energy Laboratory, Cambridge, MA, 1984.

9. Poh1, J.H., and A.F. Sarofim, Sixteenth Symposium (Int'1) on Combustion, The Combustion Institute, Pittsburgh, PA, pp. 491-501, 1976.

10. Srinivasachar, S., Experimental study and Modeling of Coal-Water Fuel Combustion in a Pilot Scale Furnace", Sc.D. Thesis, Dept. of Chemical Engineering, MIT, 1986.

11. Bird, R.B., W.E. Stewart, and E.N. Lightfoot: Transport Phenemena, Jnhn Wiley and Sons, New York (1960).

12. Varela, F.A., "Radiative Heat Trasfer Characteristics of Coal Water Fuel Flames", M.S. thesis, Department of Mechanical Engineering, Massachusetts Institute of Technology, 1986.

13. Kolb, T., W.F. Farmayan, P.M. Walsh and J.M. Beér, "The Combustion of Radiation to Ignition of a Confined Turbulent Coal Water Slurry Diffusion flame", Combustion Science and Technology, to be published.

14. Kobayashi, H., Howard, J.B., and A.F., Sarofim: Sixteenth Symposium (International) on Combustion, p. 411, The Combustion Institute, 1976. 
15. Ubhayakar, S.K., D.B. Stickler, C.W. Von Rosenberg, and R.E Gannon: Sixteenth Symposium (International) on Combustion, p. 427, The Combustion Institule, 1976.

16. Field, M.A.: Combustion and Flame 13, 237 (1969).

17. Murdoch, P.L., M. Pourkashanian and A. Williams: Twentieth Symposium (International) on Combustion, The Combustion Institute, 1984.

18. Yuen, M.C. and L.W. Chen: Combustion Science and Technology 14, 147 (1976)

19. Monroe, L.S., "High Speed Cine Films of CWS Flames, MIT Energy Laboratory Combustion Research Facility, 1984.

20. Duong, H.T., "The Monte CArlo Method and Radlative Transfer from Luminous Flames in Simple Zone Furnace Models", Ph.D. thesis, Department of Chemical Engineering, University of Newcastle, 1977.

21. Hotte1, H.C., Melchett Lecture: "Radiative Transfer in Combustion Chambers", Institute of Fuel Journal 34, 1961.

22. Gabriel, C.T., "Radiative Heat Transfer from Synthetic Fuel and CoalSlurry Flames", M.S. thesis, Department of Chemical Engineering, Massachusetts Institute of Technology, 1982

23. Hadvig, S., "Gas Emissivity and Absorptivity: A Thermodynamic STudy", Institute of Fuel Journal 43, pp. 129-135, 1970.

24. McArragher, J.S. and K.J. Tan, "Soot Formation at High Pressures - A Literature Review", Combustion Science and Technology, Vol. 5 No. 5, July 1972

25. Flower, W.L., and C.T. Bowman, "Measurements of the Structure of Sooting Laminar Diffusion Flames at Variable Pressure", Presented at the 1983 Fall Meeting of the Western States Section of the Combustion Institute, University of California, Los Angeles, CA, October 17-18, 1983, Paper WSS/CI 83-56.

26. Flower, W.L., and C.T. Bowman, "Measurements of the Structure of Sooting Laminar Diffusion Flames at Elevated Pressures", Presented at the 20th Symposium (International) on Combustion, Ann Arbor, MI, 13-14 August, 1984

27. Kadota, T., H. Hiroyasu, and A. Farazandehmehr, "Soot Formation by Combustion of a Fuel Droplet in High Pressure Gaseous Enviruntents", Combustion and Flame 29, 1977.

28. MacFarlane, J.J., F.H. Holderness, and F.S.E. Whitcher, "Soot Formation Rates in Premixed C5 and C6 Hydrocarbon-Combustion and Flame 8, 1964.

29. Homann, K.H., "Gaxbon Formation in Premixed Flames", Combustion and Flame 11, 1967. 
30. Milberg, M.E., "Carbon Formation in an Acetylene-Alr Diffusion Flame", Journal of Physical Chemistry, Vol. 63, 1959.

31. Johnson, T.R. and J.M. Beér, "Radiative Heat Transfer in Furnaces Further Development of the Zone Method of Analysis", Fourteenth Symposium (Int'1) on Combustion, The Combustion Institute, Pittsburgh, PA, pp. 639-648, August 1972 .

32. Goetz, G.J., N.Y. Nsakala, and R.W. Borio, "Development of Method for Determining Emissivities and Absorptivities of Coal Ash Deposits", ASME Paper 78-WA/Fu-6, American Society of Mechanical Engineers, 1978.

33. Combustion - Fossil Power Systems, Appendix C; Singer, J.G. Fditor, Combustion Englneering Inc., Windsor, CT, 1981.

34. Dolezal, R., Large Boiler Furnaces - Thenry, Construotion and Cüuliul, Elsevier Publishing Company, Amsterdam, 1967.

35. Mulcahy, M.F.R., J. Boow, and P.R.C. Goard, "Fireside Deposits and their Effect on Heat Transfer in a Pulverized Fuel-fired Boiler", Institute of Fuel Journal 39, 1966.

36. Tucker, R.J., Symposium Report: "The Emissivity of Furnace Materials and its effect on Plant Performance", Energy World, No. 130, Institute of Energy, November 1985.

37. Farag, I.H. and J.L. Vaillancourt (1985), "Simulation of the Heat Transfer in a Gas Turbine Combustor Fueled with Coal-Water S1urry. rart II: Model Prediction and Experimental Data", 3nth Annuzl ASME Internarional Gas Turbine Conference, March 18-21, Houston, Texas 
Appendix A

Results of Cold Flow Study 


\section{Table A.1}

Axtal Velocities in $(\mathrm{m} / \mathrm{sec})$

$$
\text { Run } 1 \text { (a) }
$$

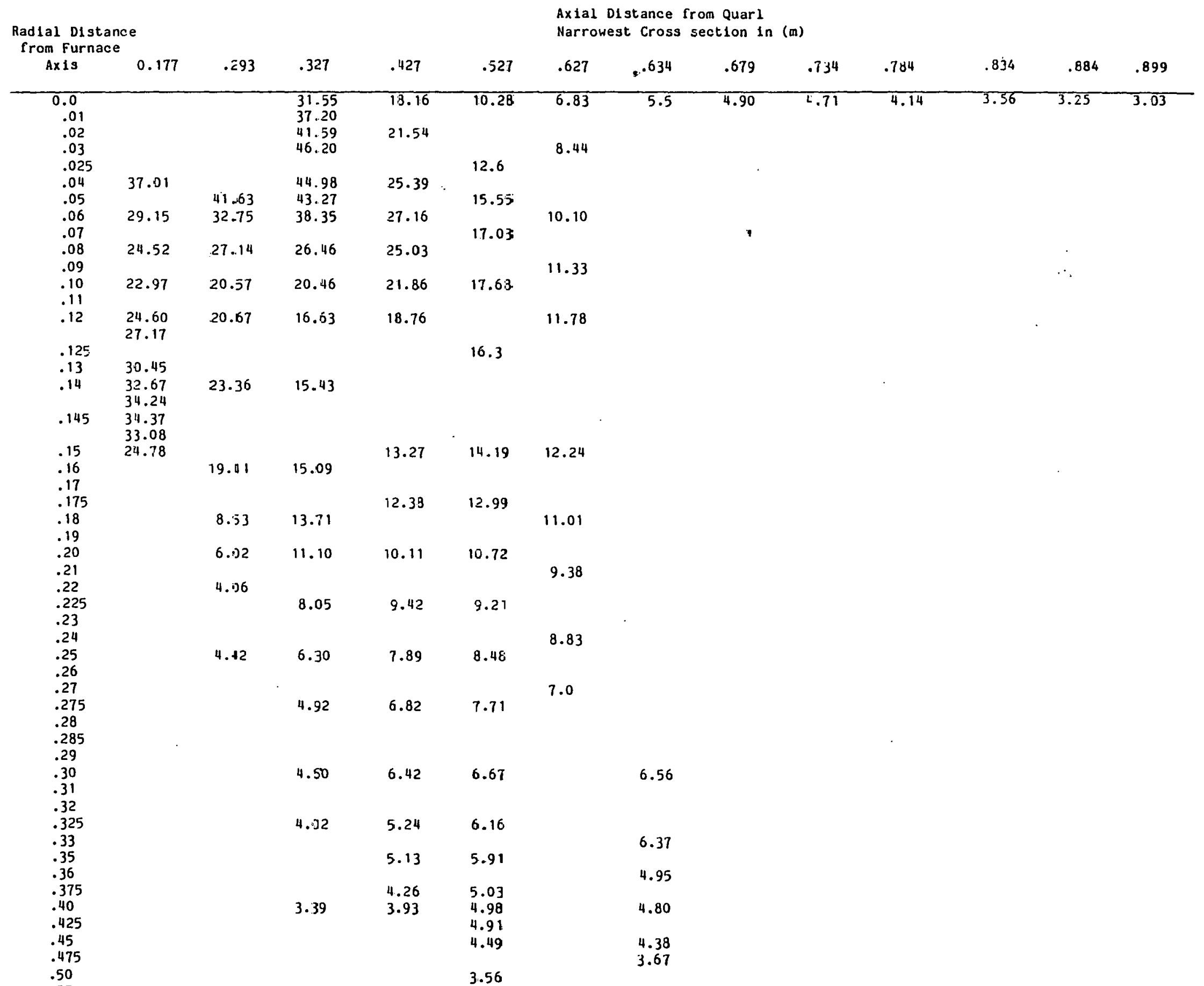


Table A.2

$$
\begin{gathered}
\text { Concentration of } \mathrm{CO} \text { in ppm } \\
\text { Run } 1(\mathrm{a})
\end{gathered}
$$

Axial Distance From Quarl Narrowest Cross-section (m)
.293
.343
0.543
0.443
0.643
0.743
6.15

Radial Distance

from Furnace

\begin{tabular}{|c|c|c|}
\hline 0.0 & & 1029 \\
\hline .01 & & 1096 \\
\hline .02 & & 1012 \\
\hline .03 & & 839 \\
\hline .04 & & 651 \\
\hline .05 & & 328 \\
\hline .06 & & 317 \\
\hline .07 & $\Rightarrow$ & 211 \\
\hline .08 & & 156 \\
\hline .09 & & 125 \\
\hline .10 & & 98 \\
\hline .11 & & 89 \\
\hline .12 & & 80 \\
\hline .13 & & 75 \\
\hline .14 & & 75 \\
\hline .15 & & 80 \\
\hline .16 & & 93 \\
\hline .17 & & 111 \\
\hline .18 & & 133 \\
\hline .19. & & 147 \\
\hline .20 & & 147 \\
\hline .21 & & 156 \\
\hline .22 & & 156 \\
\hline .23 & & \\
\hline .24 & & \\
\hline .25 & & \\
\hline .26 & & \\
\hline .27 & & \\
\hline .28 & & \\
\hline .29 & & \\
\hline .30 & & \\
\hline .40 & & \\
\hline .50 & & \\
\hline
\end{tabular}

Axis in ( $m$ )

481

541

566

561

536

496

451

393

355

308

252

224

197

174

156

151

1.42

138

138

147

147

$15 !$

151

151

151

156

165

165

161

161

165

336

364

379

412

412

412

408

388

374

350

334

308

280

252

238

229

206

192

179

170

161

298

322

326

252

266

266

$341 \quad 275$

$341 \quad 280$

$341 \quad 275$

$345 \quad 275$

$355 \quad 280$

$345 \quad 284$

$336 \quad 284$

$326 \quad 284$

$322 \quad 289$

$308 \quad 280$

$298 \quad 275$

$289 \quad 270$

$275 \quad 256$

$261 \quad 247$

$243 \quad 252$

$238 \quad 247$

$233 \quad 243$

$211 \quad 238$

$201 \quad 233$

$201 \quad 224$

$183 \quad 220$

$179 \quad 211$

$179 \quad 211$

165

165

170

192

165
147

183

171 
Table A. 3

Axial Velocities on Furnace Axis

$$
\text { in }(\mathrm{m} / \mathrm{sec}) \text { (Run } 1(\mathrm{~b})
$$

Axial distance
from quarl,
narrowest cross
section (in m)

0.253
0.293
0.313
0.343
0.393
0.1113
0.493
0.543
0.593
0.643
0.693
0.743
0.793
0.843
0.893
0.943

Air introduced through

the atomizer (along)
28.2

15.47

10.01

7.63

6.37

5.88

4.83

4.34

4.13

3.92

3.85

3.43

3.57

3.36

3.22
27.16

25.27

16. 63

9.00

4.9

$-4.2$

$-4.09$

$-2.98$

2.4

4.41

3.22

3.43

3.29 
Table $\mathrm{A.4}$

Axial Velocities in $(\mathrm{m} / \mathrm{sec})$

Run 2 (a)

Radial

distance

from

furnace

axis in

(m)

Axial distance from quarl narrowest cross-section

(m)

\begin{tabular}{|c|c|c|c|c|c|c|c|c|c|}
\hline & 0.261 & 0.316 & 0.366 & 0.466 & 0.521 & 0.536 & 0.556 & 0.566 & 0.666 \\
\hline $\begin{array}{l}0.0 \\
0.005\end{array}$ & & 48.93 & 24.84 & 8.96 & 6.27 & 6.27 & 5.54 & -4.02 & -4.28 \\
\hline $\begin{array}{l}0.01 \\
0.02 .\end{array}$ & 35.06 & $\begin{array}{l}39.60 \\
23.71\end{array}$ & $\begin{array}{l}20.96 \\
16.14\end{array}$ & 8.63 & & & & & -4.06 \\
\hline $\begin{array}{l}0.025 \\
0.03 \\
0.04\end{array}$ & $\begin{array}{l}23.48 \\
15.53 \\
12.64\end{array}$ & $\begin{array}{l}17.10 \\
13.35\end{array}$ & $\begin{array}{l}13.12 \\
11.25\end{array}$ & $\begin{array}{l}7.82 \\
7.18\end{array}$ & $\begin{array}{r}5.64 \\
-4.11\end{array}$ & & & & -4.49 \\
\hline $\begin{array}{l}0.05 \\
0.06\end{array}$ & $\begin{array}{l}12.60 \\
12.26\end{array}$ & $\begin{array}{l}11.72 \\
11.38\end{array}$ & 10.69 & 7.02 & 5.57 & & & $-4 \cdot 16$ & \\
\hline $\begin{array}{l}0.07 \\
0.08\end{array}$ & $\begin{array}{l}11.83 \\
11.39\end{array}$ & $\begin{array}{l}10.91 \\
10.32\end{array}$ & 9.15. & 6.73 & 5.36 & & & & -4.17 \\
\hline $\begin{array}{l}0.09 \\
0.10\end{array}$ & $\begin{array}{l}10.56 \\
10.15\end{array}$ & $\begin{array}{l}9.41 \\
8.98\end{array}$ & 8.15 & 6.10 & 5.40 & & & 3.78 & -4.17 \\
\hline $\begin{array}{l}0.11 \\
0.12\end{array}$ & $\begin{array}{l}10.57 \\
13.57\end{array}$ & $\begin{array}{r}9.90 \\
11.50\end{array}$ & $\begin{array}{r}9.54 \\
11.60\end{array}$ & 6.44 & & & & 3.85 & -4.100 .1 \\
\hline $\begin{array}{l}3 \\
0.14 \\
0.145\end{array}$ & $\begin{array}{l}18.80 \\
22.68 \\
23.24\end{array}$ & $\begin{array}{l}14.36 \\
16.63\end{array}$ & $\begin{array}{l}13.23 \\
14.11\end{array}$ & 7.88 & & & & 4.03 & 4.32 \\
\hline $\begin{array}{l}0.15 \\
0.155\end{array}$ & $\begin{array}{r}21.34 \\
7.38\end{array}$ & 17.01 & 14.81 & 9.91 & 7.30 & & & & 4.22 \\
\hline $\begin{array}{l}0.16 \\
0.17\end{array}$ & $\begin{array}{l}1.45 \\
4.36\end{array}$ & $\begin{array}{l}14.52 \\
10.12\end{array}$ & 11.69 & 10.01 & & & & 4.85 & \\
\hline $\begin{array}{l}0.18 \\
0.19\end{array}$ & $\begin{array}{l}3.08 \\
2.36\end{array}$ & $\begin{array}{l}5.65 \\
4.22\end{array}$ & $\begin{array}{l}9.05 \\
6.54\end{array}$ & 9.43 & & & & 5.09 & \\
\hline $\begin{array}{l}0.20 \\
0.21\end{array}$ & & 3.16 & $\begin{array}{l}4.76 \\
4.63\end{array}$ & 7.21 & & & & 5.50 & 5.47 \\
\hline $\begin{array}{l}0.22 \\
0.23\end{array}$ & & 2.51 & 3.75 & & & & & 5.19 & \\
\hline 0.24 & & 2.63 & & 5.41 & & & & 5.23 & \\
\hline $\begin{array}{l}0.25 \\
0.26 \\
0.27\end{array}$ & & & 3.0 & $\begin{array}{l}4.20 \\
3.75\end{array}$ & & & & 4.46 & 5.61 \\
\hline $\begin{array}{l}0.28 \\
0.29\end{array}$ & & & & 3.92 & & & & 4.22 & \\
\hline $\begin{array}{l}0.30 \\
0.32 \\
0.34\end{array}$ & & & & 3.66 & & & & $\begin{array}{l}4.77 \\
4.22 \\
4.25\end{array}$ & 5.53 \\
\hline 0.35 & & & & & & & & & 4.60 \\
\hline $\begin{array}{l}0.36 \\
0.38\end{array}$ & & & & & & & & $\begin{array}{l}3.91 \\
3.66\end{array}$ & \\
\hline 0.40 & & & & & & & & 3.62 & 4.10 \\
\hline $\begin{array}{l}0.42 \\
0.44\end{array}$ & & & & & & & & 3.24 & \\
\hline $\begin{array}{l}0.45 \\
0.46\end{array}$ & & & & & . & & & & $-3 \cdot 30$ \\
\hline $\begin{array}{l}0.48 \\
0.50\end{array}$ & & & & & & & & & -2.62 \\
\hline
\end{tabular}


Table A.5

Concentration of $\mathrm{CO}$ in pprn

Run 2(a)

Radial distance

from furnace axis

Axial distance from quar 1

narrowest aross-seation

$$
\text { in }(m)
$$

\begin{tabular}{|c|}
\hline $\begin{array}{l}0.0 \\
0.01\end{array}$ \\
\hline $\begin{array}{l}0.02 \\
0.03\end{array}$ \\
\hline $\begin{array}{l}0.04 \\
0.05\end{array}$ \\
\hline $\begin{array}{l}0.06 \\
0.07\end{array}$ \\
\hline 0.08 \\
\hline 0.09 \\
\hline 0.10 \\
\hline 0.11 \\
\hline 0.12 \\
\hline 0.13 \\
\hline 0.14 \\
\hline 0.15 \\
\hline 0.16 \\
\hline 0.17 \\
\hline 0.18 \\
\hline $\begin{array}{l}0.19 \\
0.20\end{array}$ \\
\hline $\begin{array}{l}0.20 \\
0.22\end{array}$ \\
\hline 0.25 \\
\hline 0.30 \\
\hline 0.35 \\
\hline 0.40 \\
\hline
\end{tabular}

$\begin{array}{llllllll}.286 & 0.301 & .316 & .341 & .366 & .391 & .416 & .441 \\ 1295 & 0.34 & & .34 & \end{array}$

$\begin{array}{llll}1295 & 854 & 756 & 72 \\ 1275 & & & 696\end{array}$

723
696 $\quad 4.31 \quad 42$

985

654
364
252

174

1.1

98

84

71

67

67

98

120

38

138

33

138

592

521

412
364

364
303

303
261

211

165

142

120

111

102

100
98

98
107

116
125

125

129

133

147

0.40

147

$\begin{array}{ll}393 & 270 \\ 364 & 26 \\ 326 & 252 \\ 261 & 247 \\ 197 & \\ 188 & 229 \\ 174 & \\ 151 & \\ 147 & \\ 133 & \\ 129 & \\ 129 & 188 \\ 129 & \\ 129 & \\ 133 & \\ 151 & \\ 142 & \\ 133 & \\ 125 & \end{array}$

$.518 \quad .56$

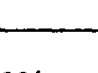

.616

276

224

$215 \quad 247$

261

252

247

229

188

i

161 
Table A.6

Axial Velocities in $(\mathrm{m} / \mathrm{sec})$

Run 2

(C)

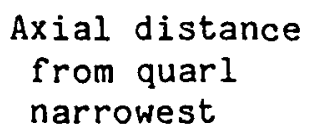

(m)

0.261

0.316

0.336

0.346

0.356

0.366

0.416

0.466

0.526

0.566

0.616

0.666

0.686

0.781

0.866

0.916

0.966

1.02

26.04

9.1

4.76

1.33

-3.46 .

$-3.89$

\author{
Air introduced \\ through the \\ fuel nozzle
}

Radial distance from furnace axis (in)
0.0
0.0
0.01
0.02
0.03
$0.04^{\circ}$
0.05

$\begin{array}{llllll}25.0 & 21.8 & 13.02 & 7.07 & 4.13 & 4.76\end{array}$

15.4

9.52

5.67

$-2.78$

$-4.11$

$-3.99$

$-3.46$

$-1.05$

1.89

1.47

1.05

0.98

0.91 


\section{Table A.7 \\ Concentration of $\mathrm{CO}$ in ppm \\ Run 2}

(C)

Axial distance from quarl, narrowest cross-section (m)

\author{
Air Introduced \\ through the \\ fuel line
}

(B)
Air and Water Introduced through the
fuel nozzle

$\begin{array}{ll}0.261 & 1940 \\ 0.316 & 1221 \\ U .366 & 165 \\ 0.391 & 571 \\ 0.416 & 336 \\ 0.456 & 183 \\ 0.506 & 179 \\ 0.516 & \\ 0.566 & \\ 0.616 & 179 \\ 6.15 & 179\end{array}$

1149

824

718

511

461

364

336

179 
Table A.8

Concentration of $\mathrm{CO}$ on Furnace Axis for Different Swirl Numbers (ppm)

\begin{tabular}{|c|c|c|c|c|c|}
\hline \multirow{2}{*}{$\begin{array}{l}\text { from Quarl } \\
\text { Narrowest } \\
\text { Cross Section } \\
\text { in (m) }\end{array}$} & \multicolumn{5}{|c|}{ Swirl Number } \\
\hline & 0.0 & 0.37 & 0.75 & 1.45 & 2.24 \\
\hline 0.261 & 1475 & 1454 & 1393 & 1149 & 1275 \\
\hline 0.286 & 1166 & 1149 & 1012 & 722 & 854 \\
\hline 0.301 & 1046 & 1012 & 854 & 675 & 756 \\
\hline 0.316 & 932 & 885 & 739 & 592 & 723 \\
\hline 0.341 & 780 & 794 & 582 & 471 & 481 \\
\hline 0.366 & 745 & 696 & 511 & 393 & 422 \\
\hline 0.391 & 654 & 592 & 412 & 336 & 336 \\
\hline 0.416 & 576 & 521 & 355 & 298 & 303 \\
\hline 0.441 & 516 & 481 & 317 & 270 & 275 \\
\hline 0.466 & 461 & 412 & 280 & 243 & 270 \\
\hline 0.491 & 422 & 384 & 252 & 229 & 247 \\
\hline 0.506 & 403 & 374 & 243 & 224 & \\
\hline 0.518 & & & & & 224 \\
\hline 0.541 & 345 & 326 & 211 & 206 & \\
\hline 0.566 & 326 & 308 & & 197 & 224 \\
\hline 0.616 & 308 & 270 & & 188 & 215 \\
\hline 0.686 & & 247 & 183 & 188 & \\
\hline $\begin{array}{l}0.766 \\
0.866\end{array}$ & & 215 & & & 170 \\
\hline 6.15 & & 170 & 170 & & \\
\hline
\end{tabular}


Table A.9

Concentration of $\mathrm{CO}$ in $\mathrm{ppm}$

Run 2(d)

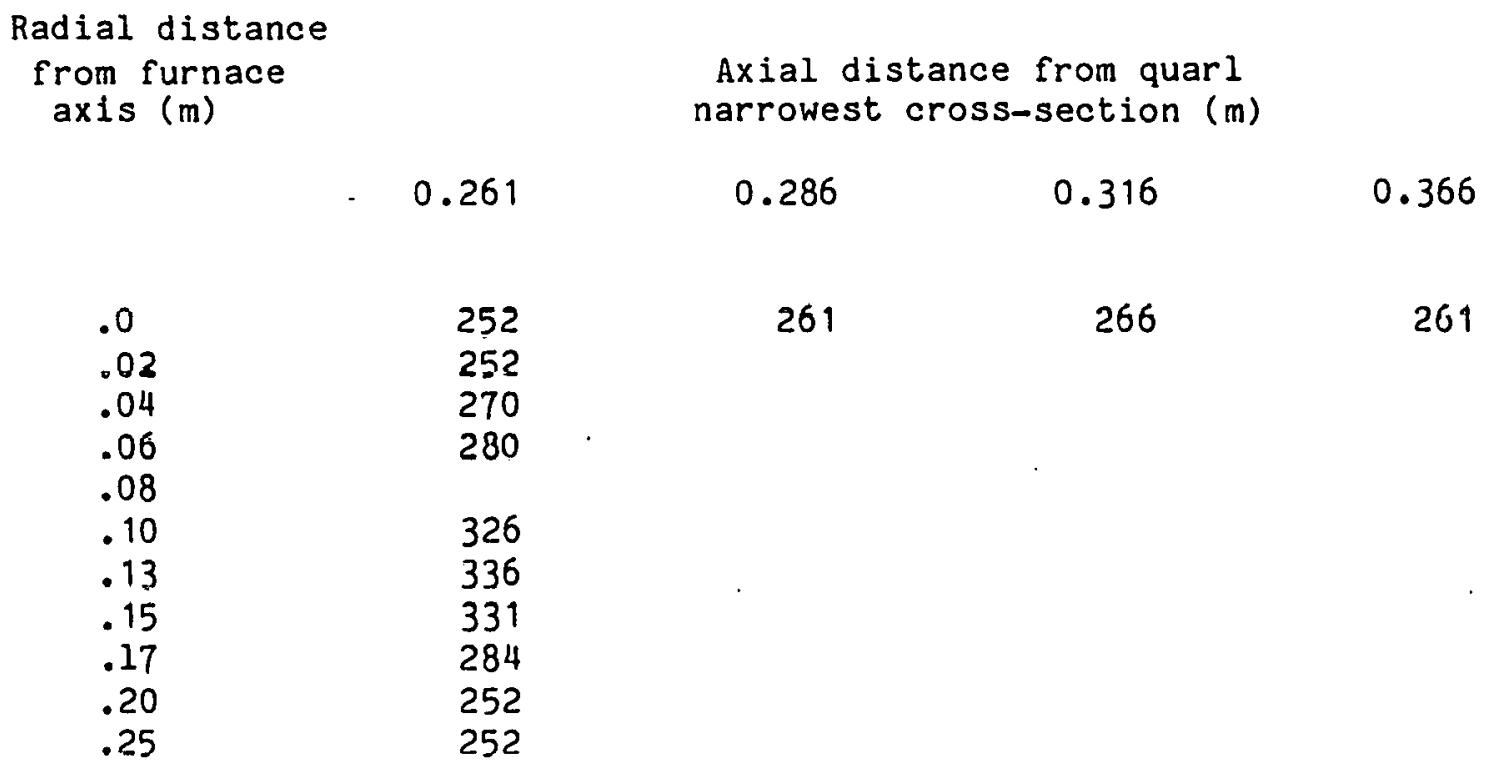


Appendix B

Results of Flame Study 
Table B. 1

Centerline Values of Temperature, Gas Composition, Solfas Conzentrat:on and Axial Velocity in flame $318 \mathrm{~A}$ (Ultrafline AMEX CHF)

Gas Compositions (by voluine)

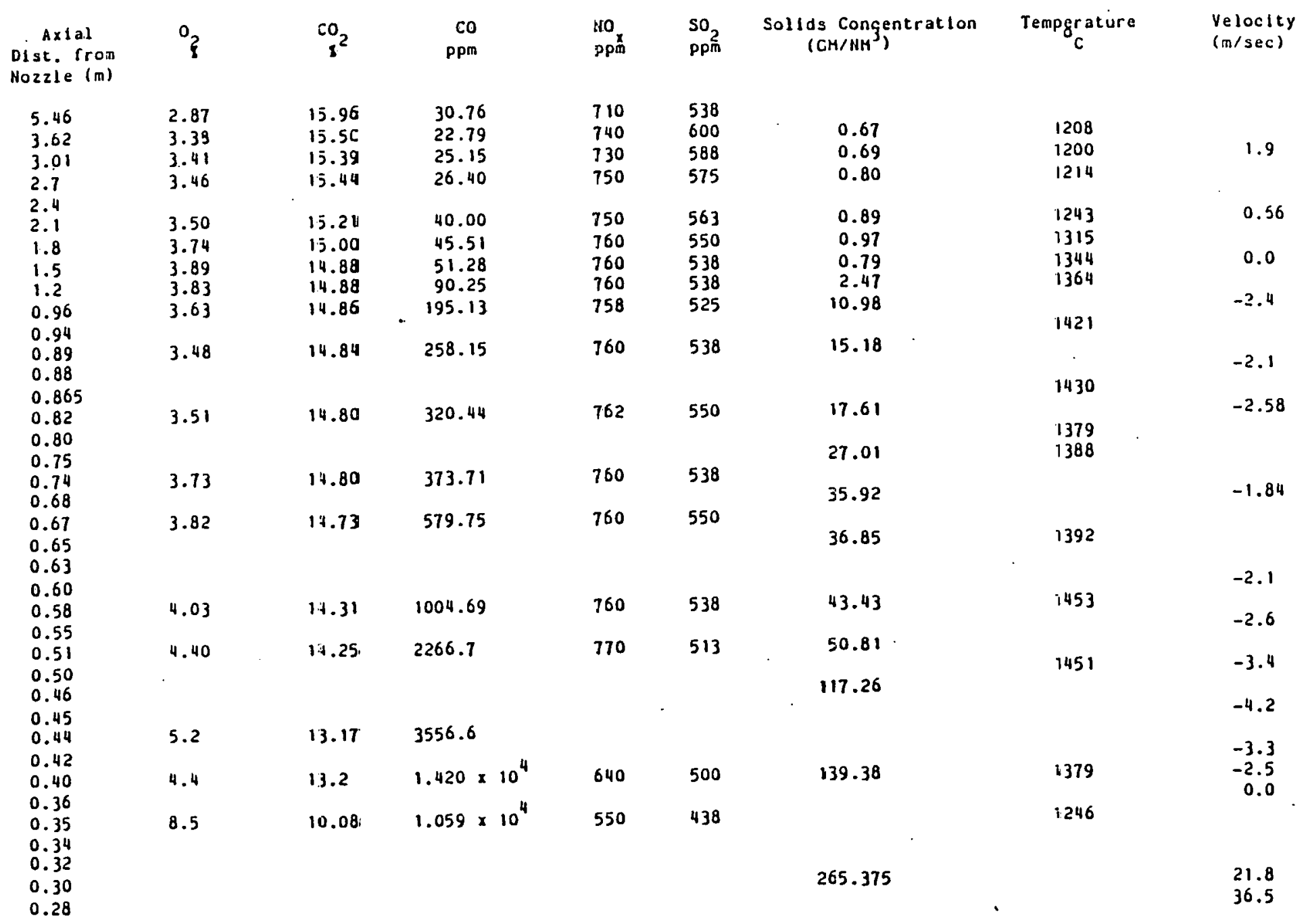


Radlal Values of Temperatures and Specles Concentration

$\left(\mathrm{O}_{2}, \mathrm{CO}_{2}, \mathrm{CO}, \mathrm{HO}_{x}, \mathrm{SO}_{2}\right.$, SOllds) in Flame $318 \mathrm{~A}$ (Ultraline AMAX CHF)

\begin{tabular}{|c|c|c|c|c|c|c|c|c|}
\hline $\begin{array}{c}\text { Axtal } \\
\text { Dist. from } \\
\text { Hozzle (m) }\end{array}$ & $\begin{array}{c}\text { Radlal } \\
\text { Dist. from } \\
\text { Centerilne (m) }\end{array}$ & $8^{2}$ & $\mathrm{CO}_{2}$ & $\begin{array}{l}\text { Co } \\
\text { ppm }\end{array}$ & $\begin{array}{l}\text { No } \\
\text { ppman }\end{array}$ & $\begin{array}{l}\mathrm{SO}_{2} \\
\text { ppmi }\end{array}$ & $\begin{array}{l}\text { Solids Concegntration } \\
\text { (GM/MM })\end{array}$ & Tempegrature \\
\hline \multirow[t]{10}{*}{0.35} & 0.0 & 8.5 & 10.08 & $1.059 \times 10^{4}$ & 550 & 438 & & 1246 \\
\hline & 0.05 & 6.28 & 11.29 & $2.248 \times 10^{4}$ & 540 & 650 & 374.56 & 1265 \\
\hline & 0.10 & 6.57 & 11.54 & $1.465 \times 10^{4}$ & 560 & 500 & 81.201 & 1083 \\
\hline & 0.15 & 12.5 & 7.49 & $1.059 \times 10^{4}$ & 370 & 475 & & \\
\hline & 0.20 & 11.0 & 8.39 & $1.239 \times 10^{4}$ & 360 & 438 & 22.225 & 1020 \\
\hline & 0.25 & 7.32 & 11.55 & 6130 & 540 & 463 & & \\
\hline & 0.30 & 5.29 & 13.30 & 917. & 640 & 500 & 19.363 & 1250 \\
\hline & 0.35 & 4.0 & 14.80 & 601.71 & 650 & 538 & & \\
\hline & 0.40 & 4.74 & 14.01 & 102.2 & 700 & 475 & & 1250 \\
\hline & 0.50 & & & & & & 0.623 & \\
\hline \multirow[t]{8}{*}{1.2} & 0.0 & 3.83 & 14.85 & 90.25 & 760 & 538 & 2.47 & \\
\hline & 0.05 & 3.63 & 15.01 & 57.7 & 770 & 538 & & \\
\hline & c. 10 & 3.60 & 1.5 .05 & 59.71 & 770 & 538 & . & \\
\hline & 0.15 & & & & & & 1.27 & 1350 \\
\hline & 0.20 & 3.61 & 14.89 & 64.88 & 770 & 538 & & 1357 \\
\hline & 0.30 & 3.72 & 14.78 & 80.58 & 770 & 538 & 2.38 & 1365 \\
\hline & 0.42 & 3.96 & 14.54 & 75.53 & 7600 & 438 & 1.934 & 1371 \\
\hline & 0.42 & 3.63 & 14.85 & 195.13 & 758 & 525 & 10.98 & \\
\hline
\end{tabular}


Table B.3

Centerline Values of Temperature, Gas Composition and Velocity Data in Flane 319B (FIne Grlad ARC CHF)

Cas Compositions (by volume)

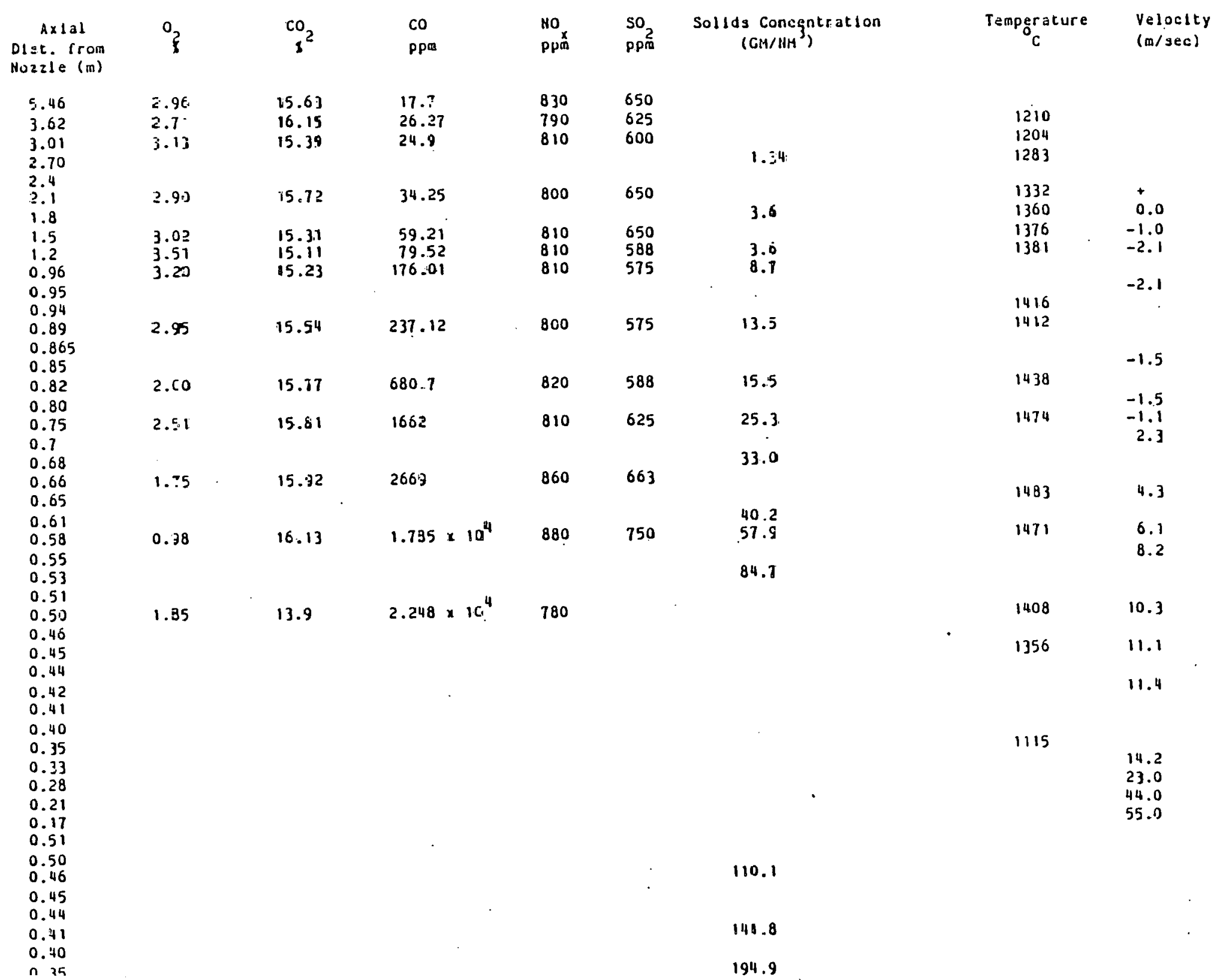


Raclal Values of Temperature and Specles Concentration

$\left(\mathrm{O}_{2}, \mathrm{CO}_{2}, \mathrm{CO}, \mathrm{NO}_{x}, \mathrm{SO}_{2}\right.$, Solldg) in flame $318 \mathrm{~B}$ (FIne Grind ARC (WF)

\begin{tabular}{|c|c|c|c|c|c|c|c|c|c|}
\hline $\begin{array}{c}\text { Axial } \\
\text { Dist. from } \\
\text { Nozzie (m) }\end{array}$ & $\begin{array}{c}\text { Radial } \\
\text { Dlst. from } \\
\text { Centerilne (m) }\end{array}$ & $i^{2}$ & $\mathrm{CO}^{2}$ & $\begin{array}{l}\text { co } \\
\text { ppro }\end{array}$ & $\begin{array}{l}\text { NO } \\
\text { ppor }\end{array}$ & $\begin{array}{l}\mathrm{SO}_{2} \\
\text { ppm }\end{array}$ & $\begin{array}{l}\text { Sollda Concgntration } \\
\text { (CM/HM) }\end{array}$ & Teinpegrature & $\begin{array}{l}\text { Velocity } \\
(\mathrm{m} / \mathrm{sec})\end{array}$ \\
\hline \multirow[t]{8}{*}{0.35} & 0.0 & & & & & & 194.9 & & \\
\hline & 0.05 & & & & & & 87.2 & & \\
\hline & 0.1 & 9.5 & 9.07 & $1.059 \times 10^{4}$ & 600 & 325 & & . & \\
\hline & 0.15 & & & . & & & 33.9 & 1115 & \\
\hline & 0.20 & 9.0 & 10.21 & $1.239 \times 10^{4} x$ & 620 & 350 & 20.4 & 1269 & \\
\hline & 0.25 & & & & & & & 1334 & \\
\hline & 0.30 & 4.18 & 14.51 & 380 & 800 & 525 & 4.48 & 1334 & \\
\hline & 0.40 & 3.93 & 14.66 & 177 & 790 & 500 & & 1346 & \\
\hline \multirow[t]{7}{*}{1.2} & 0.0 & 3.51 & 15.11 & 79.57 & 810 & 588 & 3.6 & 1381 & -2.6 \\
\hline & 0.05 & & & & & & . & 1384 & . \\
\hline & 0.1 & 2.5 & 16.35 & 89.5 & 800 & 650 & & 1379 & \\
\hline & 0.15 & & & & & & . & & \\
\hline & 0.2 & 2.75 & 15.8 & 76.3 & 790 & 625 & 2.13 & 1375 & \\
\hline & 0.30 & 3.35 & 15.3 & 70.8 & 840 & 575 & 4.1 & 1379 & . \\
\hline & 0.38 & 3.67 & 14.78 & 69.7 & 820 & 550 & & 1385 & \\
\hline
\end{tabular}


Table B.5

Incident Radiation Flux in Runs $318 \mathrm{~A} \& \mathrm{~B}$

Axial Distance

(m)

0.18

0.28

0.58

0.89

1.50

1.81

2.10

3.01

3.62

4.53
Radiative ${ }_{(k \mathrm{Wlux}}$
$\left.\quad \mathrm{W} / \mathrm{m}^{2}\right)$

Run $318 \mathrm{~A}$

Ultrafine

250

267

292

329

287

225

154

167

167
317

334

375

325

299

266

207

214

Run 3188

Fine Grind

\section{7}

207 
Table B.6

Measured Gas Emissivity in Runs 318A \& B

\begin{tabular}{|c|c|c|c|}
\hline \multirow{2}{*}{$\begin{array}{l}\text { Axial Position } \\
\text { (m) }\end{array}$} & \multirow{2}{*}{$\begin{array}{l}\text { Radial Position } \\
\text { (m) }\end{array}$} & \multicolumn{2}{|c|}{$\begin{array}{c}\text { Gas Enissivity } \\
\xi\end{array}$} \\
\hline & & $\begin{array}{l}\text { Run } 318 \mathrm{~A} \\
\text { Ultrafine } \\
\text { AMAX CWF }\end{array}$ & $\begin{array}{l}\text { Run } 318 \mathrm{~B} \\
\text { Fine Grind } \\
\text { ARC CWF }\end{array}$ \\
\hline 0.28 & & & 0.61 \\
\hline & 10 & & 0.68 \\
\hline & 30 & & 0.81 \\
\hline & 40 & & 0.88 \\
\hline & 50 & & 0.86 \\
\hline & 60 & & 0.86 \\
\hline 0.89 & 0 & 0.17 & 0.35 \\
\hline & 10 & & 0.38 \\
\hline & 20 & 0.13 & 0.44 \\
\hline & 30 & & 0.46 \\
\hline & 40 & 0.27 & 0.48 \\
\hline . & 50 & & 0.48 \\
\hline & 60 & 0.36 & 0.49 \\
\hline 1.20 & 0 & 0.16 & 0.28 \\
\hline & 10 & & 0.29 \\
\hline & 20 & 0.20 & 0.30 \\
\hline & 30 & & 0.38 \\
\hline & 40 & 0.27 . & 0.43 \\
\hline & 50 & & 0.42 \\
\hline & 60 & 0.39 & 0.43 \\
\hline
\end{tabular}


